San Jose State University SJSU ScholarWorks

Summer 2018

\title{
Micrometeorological Observations of Fire- Atmosphere Interactions and Fire Behavior on a Simple Slope
}

Jonathan Marc Contezac

San Jose State University

Follow this and additional works at: https://scholarworks.sjsu.edu/etd_theses

\section{Recommended Citation}

Contezac, Jonathan Marc, "Micrometeorological Observations of Fire-Atmosphere Interactions and Fire Behavior on a Simple Slope" (2018). Master's Theses. 4934.

DOI: https://doi.org/10.31979/etd.d7nc-77e4

https://scholarworks.sjsu.edu/etd theses/4934

This Thesis is brought to you for free and open access by the Master's Theses and Graduate Research at SJSU ScholarWorks. It has been accepted for inclusion in Master's Theses by an authorized administrator of SJSU ScholarWorks. For more information, please contact scholarworks@sjsu.edu. 
MICROMETEOROLOGICAL OBSERVATIONS OF FIRE-ATMOSPHERE INTERACTIONS AND FIRE BEHAVIOR ON A SIMPLE SLOPE

\author{
A Thesis \\ Presented to \\ San José State University \\ In Partial Fulfillment \\ of the Requirements for the Degree \\ Master of Science
}

The Faculty of the Department of Meteorology and Climate Science

by

Jonathan M. Contezac

August 2018 
(c) 2018

Jonathan M. Contezac

ALL RIGHTS RESERVED 
The Designated Thesis Committee Approves the Thesis Titled

MICROMETEOROLOGICAL OBSERVATIONS OF FIRE-ATMOSPHERE INTERACTIONS AND FIRE BEHAVIOR ON A SIMPLE SLOPE

\author{
by \\ Jonathan M. Contezac \\ APPROVED FOR THE DEPARTMENT OF METEOROLOGY AND \\ CLIMATE SCIENCE \\ SAN JOSÉ STATE UNIVERSITY
}

August 2018

Dr. Craig B. Clements Department of Meteorology and Climate Science

Dr. Sen Chiao Department of Meteorology and Climate Science

Dr. Neil Lareau Department of Meteorology and Climate Science 


\section{ABSTRACT \\ by Jonathan M. Contezac}

An experiment was designed to capture micrometeorological observations during a fire spread on a simple slope. Three towers equipped with a variety of instrumentation, an array of fire-sensing packages, and a Doppler lidar was deployed to measure various aspects of the fire. Pressure and temperature perturbations were analyzed for each of the grid packages to determine if the fire intensity could be observed in the covariance of the two variables. While two of the packages measured a covariance less than $-15^{\circ} \mathrm{C} \mathrm{hPa}$, there was no clear trend across the grid. The fire front passage at each of the three towers on the slope yielded extreme swings in observed turbulent kinetic energy and sensible heat flux. Vertical velocity turbulence spectra showed that the high-intensity fire front passage at the bottom tower was 2 to 3 orders of magnitude larger than the low-intensity fire front passages at the top two towers. Opposing wind regimes on the slope caused a unique L-shaped pattern to form in the fire front. A vorticity estimation from the sonic anemometers showed that vorticity reached a maximum just as a fire whirl formed in the bend of the L-shaped fire front, leading to a rapid increase in fire spread. 


\section{ACKNOWLEDGEMENTS}

I would like to thank Dr. Craig Clements for all the opportunities he provided me during my time at San Jose State University. The skills I learned while tinkering and building in the Fire Lab have aided me greater than any class has. And I wouldn't be where I am without his knowledge, wisdom, and patience.

l'd also like to thank Drs. Sen Chiao and Neil Lareau for serving on my thesis committee at the eleventh hour. This would not be possible without their support.

Thanks also must go to Dianne Hall and Braniff Davis for providing a few of the GIS maps.

Additionally, the Fort Hunter Liggett Fire Department is thanked for their help in logistics, executing, and managing all fire operations for our project.

Lastly, I wanted to thank all the faculty, staff, and students in the meteorology department, as well as my family and friends. It was a lot of hard work and effort to get through the program and I probably would not have succeeded without everyone's support.

Funding of this research was provided by the National Institute of Standards Fire Research Grants Program Award \#60NANB11D189. 


\section{TABLE OF CONTENTS}

List of Tables....................................................... vii

List of Figures................................................... viii

Chapter 1: Introduction..........................................

Chapter 2: Experimental Design .................................... 9

2.1 Site Selection and Characteristics............................. 9

2.2 Field Experimental Design................................... 12

2.3 Micrometeorological Measurements........................... 13

2.4 Ambient Meteorological Measurements....................... $\quad 18$

2.5 Synoptic Overview......................................... 21

Chapter 3: Temperature Pressure Perturbations....................... 22

3.1 Introduction.................................................. 22

3.2 Methods and Data Processing .............................. 24

3.3 Results and Discussion................................... $\quad 27$

3.4 Conclusion .............................................. $\quad 35$

Chapter 4: Micrometeorology..................................... $\quad 36$

4.1 Introduction ................................................... 36

4.2 Data Processing.......................................... $\quad 38$

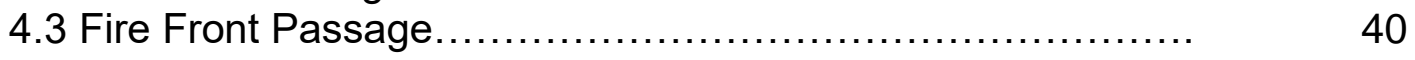

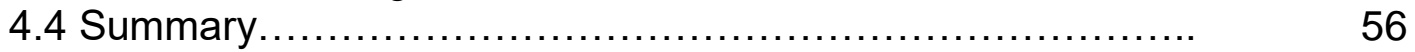

Chapter 5: Vorticity Estimation and Fire Whirls ..................... 57

5.1 Introduction.............................................. $\quad 57$

5.2 Data Processing ............................................ 58

5.3 Description of Event..................................... $\quad 59$

5.4 Results.................................................... 61

5.5 Summary and Conclusion.................................. 68

Chapter 6: Summary and Conclusion............................... 68

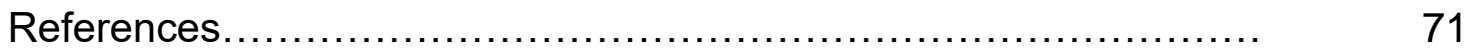




\section{LIST OF TABLES}

Table 1. Uniform sensors per tower.............................. 15

Table 2. FSP IDs and offsets made to each dataset................. 25 


\section{LIST OF FIGURES}

Figure 1. County map of California showing the names and areas of the 10 largest wildfires in California up to July 2013.

Figure 2. Percent of area burned for a given slope angle for each of California's largest wildfires.

Figure 3. Regional road map of west central California.............. 9

Figure 4. Map of experimentation site.

Figure 5. 3D satellite image of the burn plot generated from elevation data. Elevation contours are plotted across the slope

Figure 6. Detailed map of the burn area.

Figure 7. Photo of the burn area, pre-burn.

Figure 8. Aerial imagery of the (a) ignition line and fire front passage at the (b) bottom, (c) middle, and (d) top towers

Figure 9. Photo of Doppler SODAR (left) and CSU-MAPS tower (right).....

Figure 10. Photo of Doppler LIDAR .............................. 20

Figure 11. The $12 \mathrm{Z} 500 \mathrm{hPa}$ analysis from 20 June $2012 \ldots \ldots \ldots \ldots . . .21$

Figure 12. The $12 \mathrm{Z} 850 \mathrm{hPa}$ analysis from 20 June $2012 \ldots \ldots \ldots \ldots . . .22$

Figure 13. The $12 Z$ surface analysis from 20 June $2012 \ldots \ldots \ldots \ldots . . . .23$

Figure 14. Temperature time series from each of the FSPs in the grid.

Figure 15. Estimated rate of spread through sensor grid.

Figure 16. An aerial photo of the fire. 
Figure 17. Temperature and pressure time series with covariance plots for the duration of the fire front passage for each FSP $(a-v)$

Figure 18. Slope-valley wind coordinate system.....................

Figure 19. Time series of $u, v$, and $w$ velocities, as well as sonic temperature for the bottom tower (blue), middle tower (red), and top tower (magenta)

Figure 20. Five minute averaged two meter wind speed at RAWS located in the valley (red) and ridge (black)...............

Figure 21. Radiative heat flux measured at the bottom (blue) and middle (red) towers.

Figure 22. (a) shows the TKE and $\mathrm{H}_{\mathrm{s}}$ observed at the bottom tower during FFP. (b) shows the velocity variances at the bottom tower during the same time frame....

Figure 23. (a) is a $\mathrm{RHI}$ scan performed by the Doppler lidar during the FFP at the bottom tower. (b) is a corresponding aerial photograph

Figure 24. (a) shows the TKE and Hs observed at the middle tower during FFP. (b) shows the velocity variances at the middle tower during the same time frame.

Figure 25. (a) is a RHI scan from the Doppler lidar taken during FFP at the middle tower. (b) is a corresponding aerial photograph

Figure 26. (a) shows the TKE and Hs observed at the top tower during FFP. (b) shows the velocity variances at the top tower during the same time frame....

Figure 27. Four photos taken in 1-minute intervals depicting the downslope wind dispersing the smoke down the slope..

Figure 28. Perturbation time series of sonic temperature (a) and vertical velocity (b) from the top tower during a downslope wind. 
Figure 29. Momentum flux time series for (a) horizontal winds, (b) slope winds, and (c) cross-slope winds

Figure 30. Normalized power spectra during fire front passage at each tower for (a) u, (b) v, and (c) w wind velocities, as well as (d) sonic temperature. The bottom tower is in blue, middle in red, top in magenta.

Figure 31. 10-minute averaged sodar wind profile observed near the valley center

Figure 32. A series of photos depicting an L-shaped fireline, a fire whirl, and the resulting rapid increase in the rate of spread.

Figure 33. A map of 1-minute interval fireline locations georeferenced from aerial photography

Figure 34. Lidar RHI scan taken during the northeasterly wind......

Figure 35. Time series of estimated horizontal vorticity during the time of increased fire spread

Figure 36. A lidar PPI scan of alternating inbound and outbound winds over the valley

Figure 37. A series of lidar PPI scans depicting a velocity couplet forming near the ridge and propagating downslope and across the valley

Figure 38. A photo of a whirl lifting ash into the air in the wake of the fire 


\section{Chapter 1 - Introduction}

The interactions between wildland fires and the atmosphere are complex and dynamic (Jenkins et al., 2001; Potter 2014a; 2014b). On the large scale, longterm global oscillations have been shown to have a strong correlation with high fire activity (Kitzberger et al. 2007). Although, debate does remain as to the link between changing climate and increased fire activity (Westering et al. 2006). Fluctuations in fire activity have a direct impact on local ecosystems and economies, as management of wildfires still remains imperfect (Bowman et al. 2009). Despite this flaw, our knowledge of critical weather patterns leading to increased fire activity has greatly improved (Werth 2011).

Over the past century, research in the area of fire meteorology has identified synoptic scale patterns associated with increased fire activity. It was Beals (1914) who first identified the pressure, temperature, and wind patterns associated with large fires. Later, Schroeder et al. (1964) produced a complete analysis of fire weather patterns over the continental United States. It was shown that, for states bordering the Pacific Ocean, synoptic patterns producing offshore flow, or foehn winds, favored wildfire development (Werth 2011).

Schroeder et al. (1964) proposed that offshore flow in California is produced by an upper level northwest to southeast pressure gradient. Typically, this setup occurs when sea level pressure is elevated in the Great Basin region (Conil and Hall 2006; Raphael 2003). This area of high pressure forces the thermally 
induced low within the Central Valley offshore, creating a strong pressure gradient over California. This pressure gradient is the source of the föhn winds.

Several additional studies have indicated links between synoptic scale conditions and warm, dry, terrain driven winds (Durran 1990; Smith 1979, 1985; Klemp and Lilly 1975). Huang et al. (2009) performed an analysis of the synoptic and mesoscale conditions that favor Santa Ana wind development. He summarized the coupling between these scales into three stages. First, dry air is brought down from the mid-troposphere by subsidence from the ageostrophic circulation that exists within a jet exit region. The subsidence causes adiabatic warming of dry air and is strengthened as the jet curvature becomes more anticyclonic. Stationary atmospheric waves breaking over the mountain range become coupled with the subsidence upstream, bringing the warm dry air into the boundary layer and down to the surface.

Because terrain plays a key role in developing the atmospheric conditions leading to increased wildfire danger in California, it is often the case that major wildfires occur in areas of complex terrain. Fig. 1 shows a map of the ten largest wildfires by area in California, for which perimeter data exist. Fig. 1 was compiled before the 2013 Rim Fire. It can be seen that many of the largest wildfires in California tend to occur in roughly the same areas, with the exception of the McNally Fire. Still, when compared to topographic maps, it can be seen that all of these wildfires occurred in mountainous areas. 


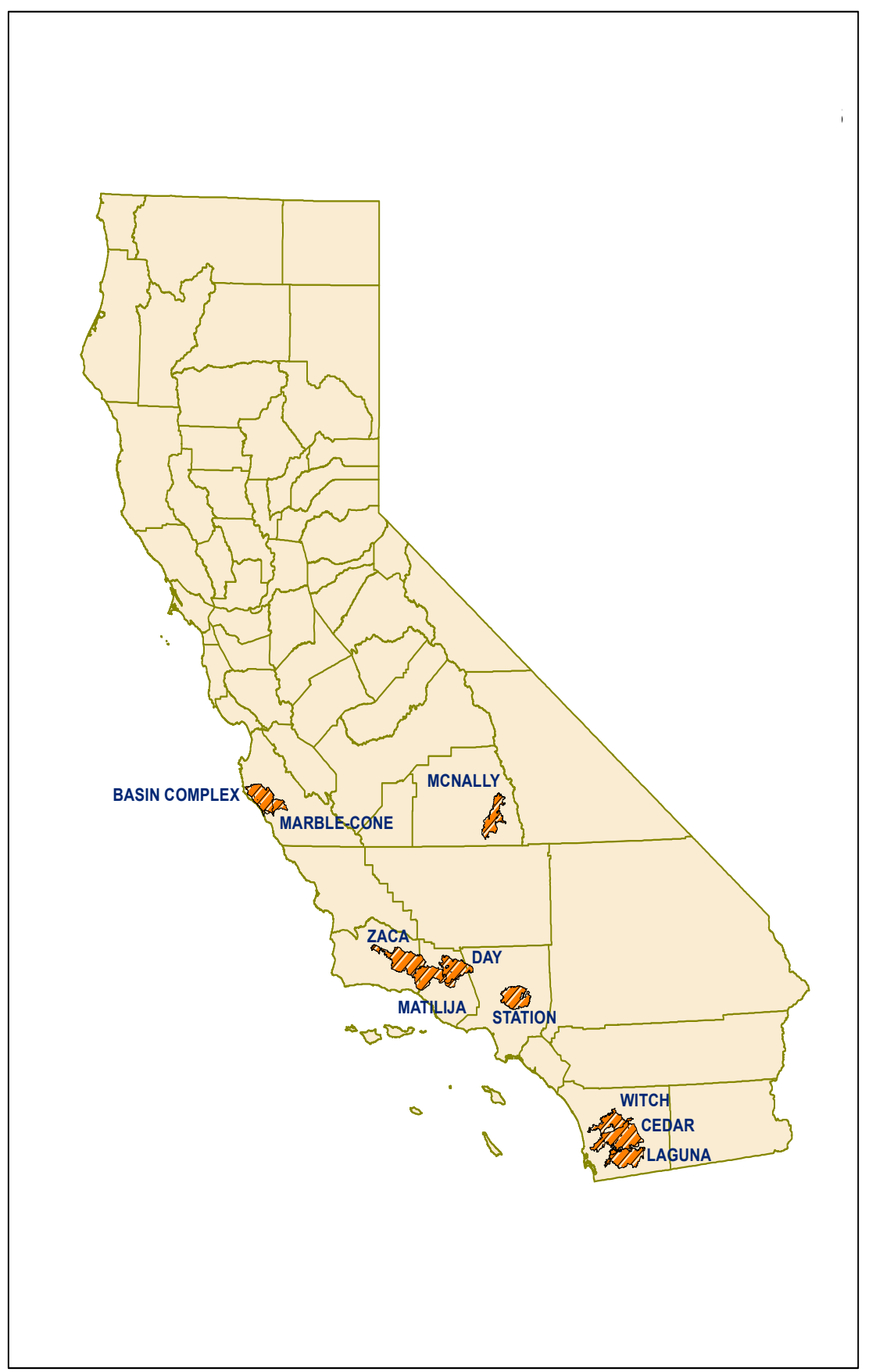

Fig. 1. County map of California showing the names and areas of the 10 largest wildfires in California up to July 2013. 
Using ESRI ArcMAP GIS software and elevation datasets, each of the burn areas can be separated into $10 \mathrm{~m}$ resolved slope angle in degrees. From these maps, the area of each burn to occur on slopes of varying angle was calculated. Fig. 2 shows the percentage of each wildfire area to occur on slopes of varying angle.

The seven leftmost columns in Fig. 2 represent fires that occurred in the Sierra Nevada, Southern Coastal Range, and Transverse Range. Over $80 \%$ of each of these fires occurred on terrain where the slope was greater than $10^{\circ}$. Disregarding the McNally Fire, over $60 \%$ of the fires occurred on terrain where the slope angle was greater than $20^{\circ}$.

On the right side of Fig. 2 are three columns representing fires that occurred east of San Diego in the Peninsular Range: Witch, Laguna, and Cedar. Compared to the others, these three fires occurred in much flatter terrain.

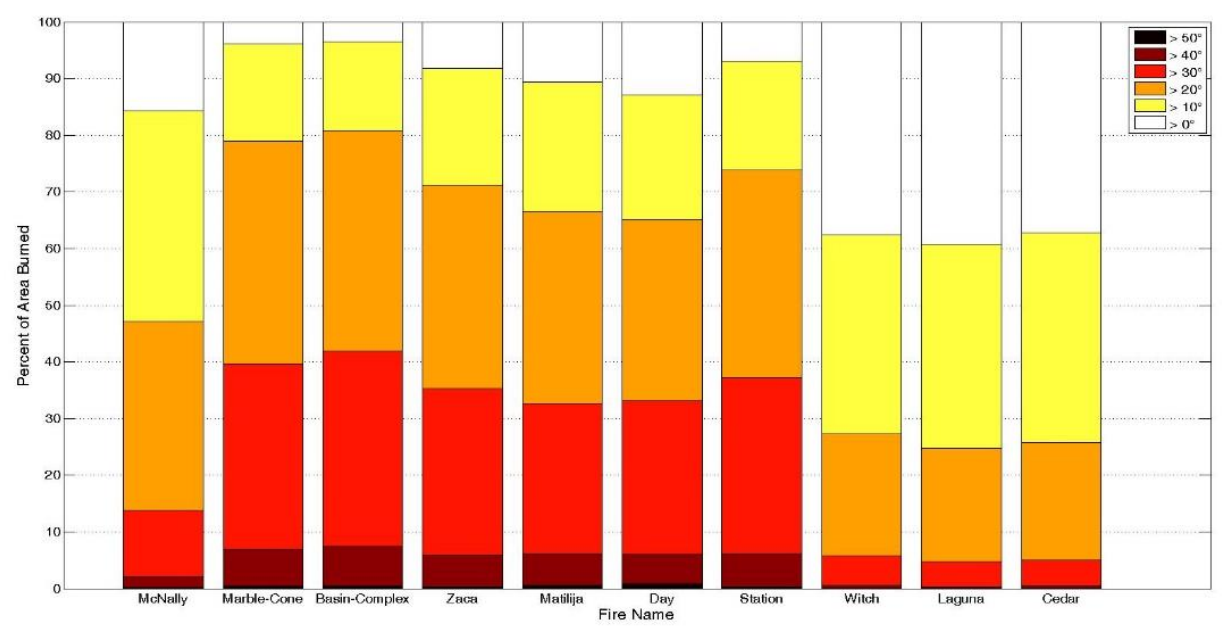

Fig. 2. Percent of area burned for a given slope angle for each of California's largest wildfires. 
Nevertheless, over $25 \%$ of these burns occurred on slopes greater than $20^{\circ}$. Therefore, in California, the largest wildfires are linked to complex terrain.

While it remains mostly unchanging, terrain has a considerable, and often unpredictable, effect on the atmosphere, the most variable and important parameter in fire behavior. Therefore it is critical that research be performed to understand how the atmosphere and terrain interact and how this interaction affects fire spread.

With the use of computer models and laboratory experiments, significant progress in fire science research has been made. Rothermel (1972) proposed and published a mathematical model for the spread of fire by wind and slope. His attempt was based on a simple empirical model with both wind and slope aligned in the same direction. Albini and Baughman (1979) used the Rothermel model to study the relationship between wind speeds and forest canopies. Their research concluded by listing several limitations of the model, including that there was no accounting for the interactions between the atmosphere and the fire. Later, a vector form of the model would allow for non-uniform winds and slopes to be used (Rothermel 1983). Many fire spread models today still rely on Rothermel's model, including BEHAVE (Andrews 1986) and FARSITE (Finney 1998). These models rely heavily on statistics for predicting fire behavior, but can still be a good tool for quickly predicting the movement of the fire under simple wind regimes. 
Current research in fire spread is focused on using models that couple the fire and atmosphere and collecting observations to help evaluate the models. Clements et al. (2007) collected the first high temporal, in situ, observational dataset of meteorological conditions during a grass fire in flat terrain. An array of instrumentation mounted on a $42 \mathrm{~m}$ tower captured 1 to $20 \mathrm{~Hz}$ data as a winddriven head fire moved through the tower. Among the variables measured were three-dimensional winds, fuel and plume temperatures, and net radiation.

Turbulence characteristics were calculated from the three-dimensional winds (Clements et al. 2008). The turbulence kinetic energy was found to have increased during the passage of the fire front to five times above ambient conditions. Also, increased spectral densities in the lower frequencies of the wcomponent of the wind were found. This indicated that fire induced horizontal eddies contributed a large amount to turbulence generation.

This dataset has been used to evaluate the output from many coupled fireatmosphere numerical models (Kochanski et al. 2013, Filippi et al. 2013). Clements et al. (2008) also showed that the observed surface winds in and around the fire front fit well with the numerical simulations of Cunningham and Linn (2007). Kochanski et al. (2013) also performed a comparative analysis using numerical output from the WRF-SFIRE model. After making small adjustments to the model, he concluded that there was overall agreement on spread rates, temperature profiles, and horizontal and vertical winds. Kochanski et al. stressed 
that care should be taken when comparing single point observations to gridded model data.

Several studies have focused on fire spreading on slopes using numerical models. Linn et al. (2007) used HIGRAD/FIRETEC to run ten simulated wildfires in various terrain types. It was found that fire behavior in varying complex terrain is strongly linked to the coupling between the atmosphere and the terrain. In a following paper, Linn et al. (2010) compared fire spread on flat terrain to sloped terrain in varying fuel types with ideal atmospheric conditions. From these simulations, several conclusions were reached. In addition to the faster spread rates, the shape of the head fire was more pointed on the sloped terrain. It was also noted that the effect of the slope is compounded as a head fire moves uphill. This was the result of an increasingly pointed fireline. As the point of the fireline increased on the slope, the angle between the slope and fire decreased, limiting air entrainment from upslope and increasing the entrainment from downslope. This caused a feedback in which the head of the fire tilted further, increasing entrainment from downslope, and allowing the head of the fire to spread faster. Additionally, fire spread rate on the sloped terrain varied greatly with changes in fuel type.

Laboratory experiments have shown that fire occurring on a slope can spread multidirectionally and can be adequately explained using wind and slope vectors (Viegas 2004). Viegas also noted that wind began to affect the spread of the fire more than the slope 40 seconds after ignition. This suggested that feedback from 
the fire-atmosphere interactions had begun to influence fire spread more than the terrain. Simpson et al. (2013) explored atypical fire spread on a leeward slope with varying fuels using WRF-Fire. He proposed that interactions between pyroconvection and terrain-modified winds produce updrafts and downdrafts, which propagate back and forth across the fire front. As they cross the fire front, vorticity driven circulations coupled with the updrafts and downdrafts, increasing lateral fire spread across the slope. These simulations were performed under idealized conditions.

To date, there have been essentially no comprehensive meteorological measurements made of fire-atmosphere over slopes with the exception of Clements and Seto (2015) which was a simple exploratory experiment with limited measurements. Further field measurements will support model improvements and aid in verifying theory in the area of wildfire micrometeorology.

This thesis presents new observations and the results of a field campaign in which fire behavior was observed in complex terrain during an experimental fire. In Chapter 2, the overall experimental design, site characteristics, and the meteorological instrumentation layouts are described. Chapter 3 presents measurements of temperature-pressure perturbations at the fire front. While in Chapter 4, the micrometeorological observations, including heat flux and turbulence, are analyzed. And Chapter 5 describes the generation of vorticity observed during the fire. Finally, the conclusions and summary are presented in Chapter 6. 


\section{Chapter 2 - Experimental Design}

\subsection{Site Selection and Characteristics}

The field experiment was conducted southwest of King City, CA, at the United States Army Garrison Fort Hunter Liggett (Fig. 3). This region of California is part of the Coastal Range, a mountain range extending for much of the Pacific coastline. A benefit of conducting an experiment at Fort Hunter Liggett was that it contains much mountainous terrain, thus providing many options for experimental sites. Several sites were surveyed at Fort Hunter Liggett and two were selected for experimentation.

The first selected site (Fig. 4) was on a southwestern facing slope within Stony Valley. This site had grass fuels that were the most uniform. Fig. 5 contains a three- dimensional satellite image of the burn plot generated from elevation data and displays the uniformity of the slope at the site. The plot had a

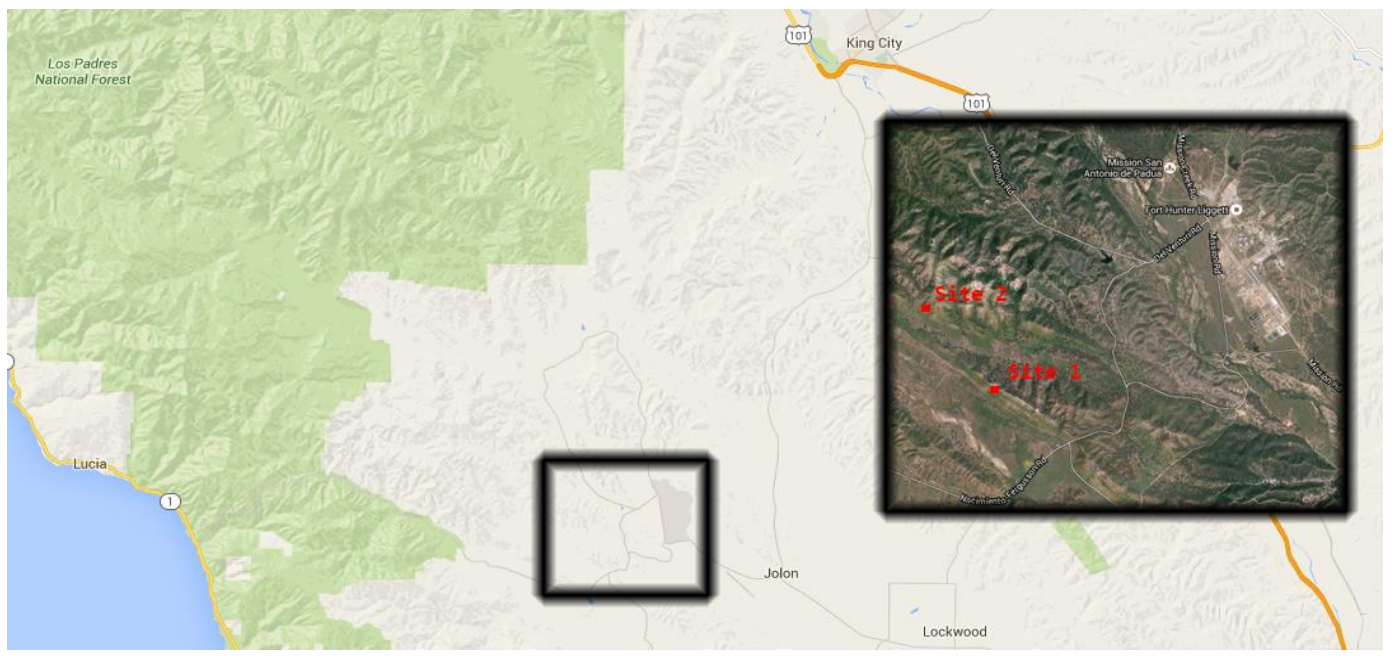

Fig. 3. Regional road map of west central California. Inset shows satellite view with road overlay of United States Army Garrison Fort Hunter Ligget (Google Maps, 2016). First and second sites marked and labeled in inset. 


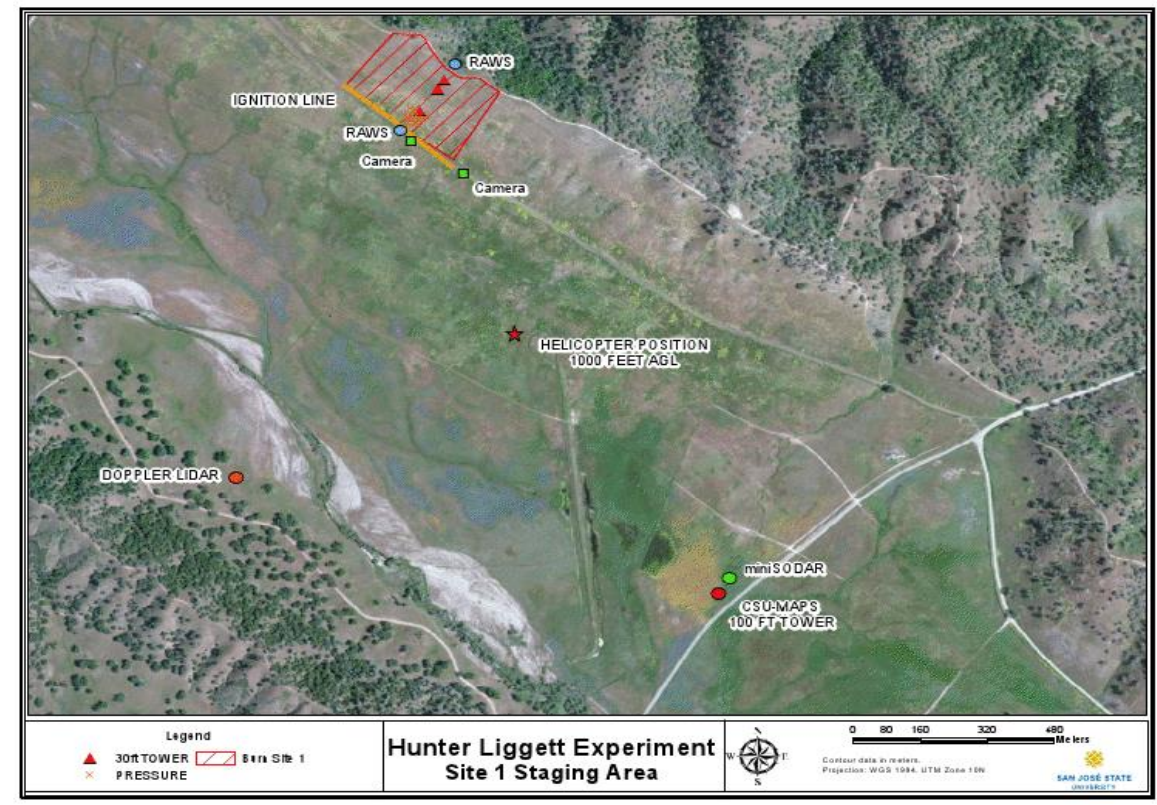

Fig. 4. Map of experimentation site. The orange circle marks the location of the Doppler lidar. The green and red circles mark the miniature sodar and CSU-MAPS tower respectively. The red star shows the general location of the helicopter. Figure produced by Braniff Davis and used with permission.

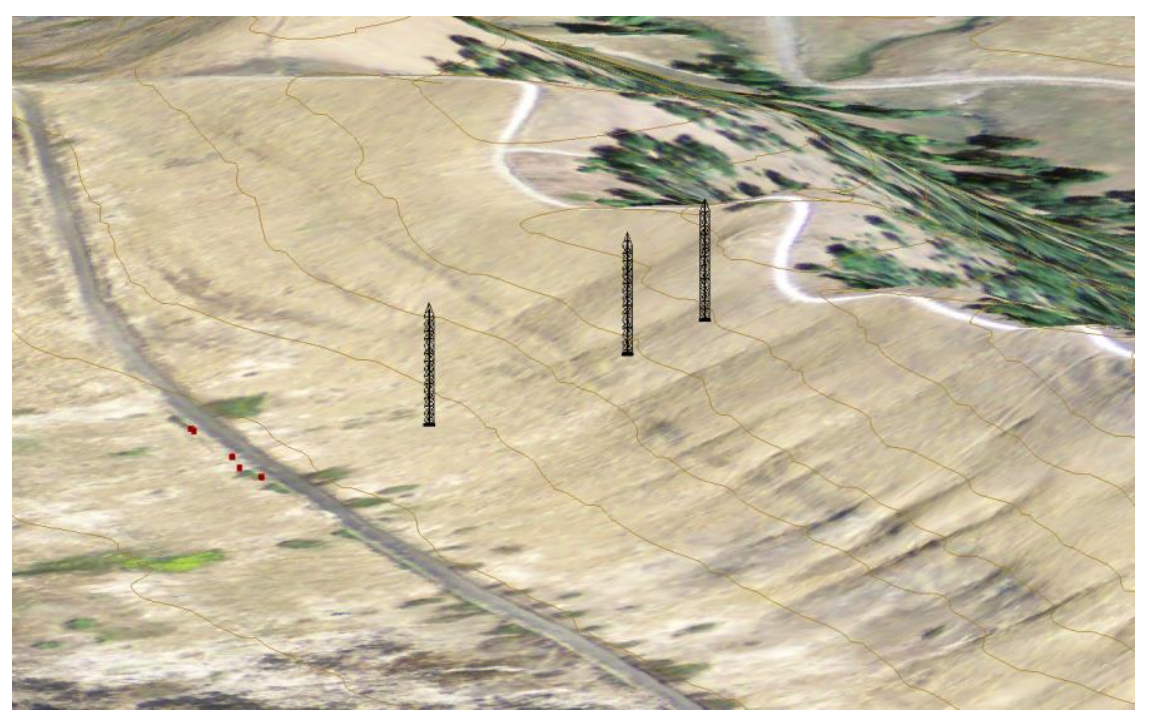

Fig. 5. 3D image of the burn plot generated from elevation data. Elevation contours are plotted across the slope. The location of the three towers on the slope is shown. Towers are not to scale. Camera locations are marked by red dots. Overlaid satellite image provided by Google Maps (2015). Figure produced by Braniff Davis and used with permission. 
slope angle of $20^{\circ}$ and an area of $6.0 \times 10^{4} \mathrm{~m}^{2}$. The burn plot, detailed in Fig. 6 , was located on an isolated low ridge and with shallow drainage channels.

A second experiment site was selected within Stony Valley. This site was on a taller mountain, with less uniform terrain and fuels. As a result, this site was not as heavily instrumented as the first site. This thesis will primarily focus on data and results from the first site.

The Stony Valley and surrounding lands of the garrison are an active bombing range, making the region highly prone to accidental munitions ignitions.

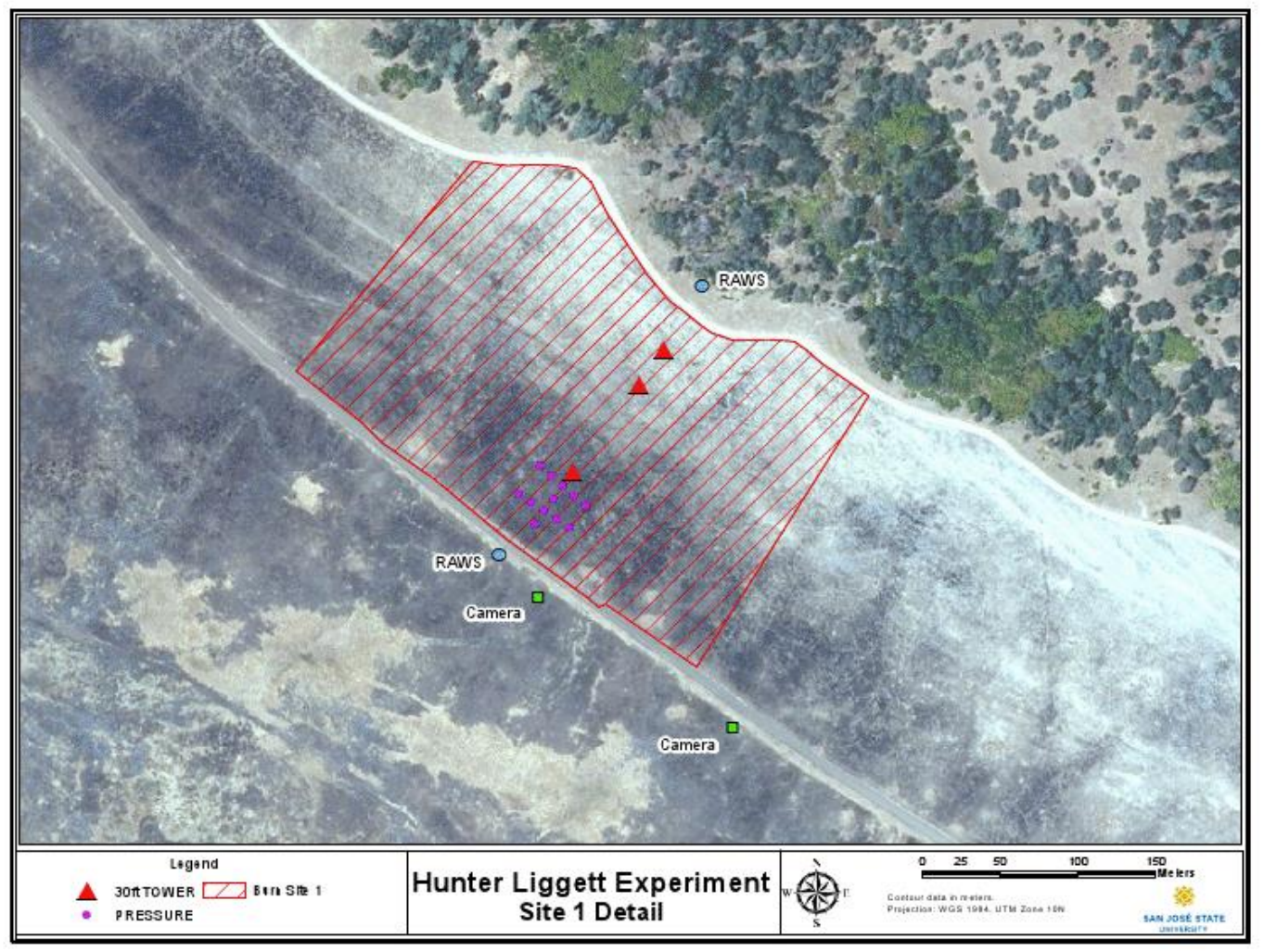

Fig. 6. Detailed map of the burn area. The burn plot area is shaded by diagonal red lines. The red triangles represent tower locations. Purple circles mark the location of each of the fire sensor packages. The blue circles are the location of the RAWS stations. And the green squares show the location of the cameras. Figure produced by Braniff Davis and used with permission. 
For this reason, the garrison is managed by prescribed fire, typically occurring during late spring to early summer.

\subsection{Field Experimental Design}

The field experiment was designed to capture phenomena pertaining to the interactions between the fire front and atmosphere on a simple and constant slope in uniform fuels. These conditions would be the most ideal for comparing numerical modeling with field observations. Fire-atmosphere interactions include, but are not limited to, fire induced heat fluxes, plume circulations, temperature and pressure perturbations due to the fire, vorticity generation, and fire-induced circulations (Potter 2012a, 2012b).

There are two forms of measurement, direct and remote sensing. Direct measurements of the propagating fire front were conducted by in situ instruments along the slope from steel tower platforms. These sensor are required to be capable of vertical and horizontal measurements and have a high temporal resolution in order to capture fine-scale meteorological phenomena. Additionally, they must be highly resistant to extreme heat.

Remote sensing measurements refer to instruments that are capable of measuring at a distance. Instruments capable of this form of measurement generally operate by measuring a portion of the electromagnetic spectrum. This type of instrumentation can conduct higher spatial and temporal resolution measurements in locations that cannot otherwise be reached. These measurements can target meteorological phenomena, the ambient atmospheric 
conditions, or any unique flow features associated with the local terrain and environment. In this experiment, remote sensing instrumentation made measurements of the smoke plume, the atmosphere surrounding the burn plot, and the ambient atmospheric conditions. Additionally, video and photographic observations were made from ground-based and aerial platforms to capture fire behavior properties and rates of spread.

2.3 Micrometeorological Measurements

Three $10 \mathrm{~m}$ guyed steel towers were constructed on the burn plot along the fall line of the slope (Fig. 5) to measure both meteorological and fire behavior properties during the fire front passage (FFP). Each tower is referred to by the position it had on the slope: bottom, middle, and top, which are referenced in Fig. 7. The bottom tower was placed on a flat section near the boundary where the terrain transitions from flat to a $20^{\circ}$ slope, approximately $40 \mathrm{~m}$ from the ignition line. The bottom tower had an elevation of $436.5 \mathrm{~m}$ above mean sea level (MSL). The middle tower was placed $71.2 \mathrm{~m}$ up the slope from the bottom tower and had an elevation of $458.8 \mathrm{~m} \mathrm{MSL}$, a difference in height of $22.3 \mathrm{~m}$ from the bottom tower. The top tower was placed $27.7 \mathrm{~m}$ upslope from the middle tower and had an elevation of $468.1 \mathrm{~m} \mathrm{MSL}$, a difference in elevation of $9.3 \mathrm{~m}$ from the middle tower.

Each of the three towers was equipped with an array of instrumentation designed to measure several aspects of fire-atmosphere interactions. Table 1 details the sensor model numbers used on each tower. The three-dimensional 


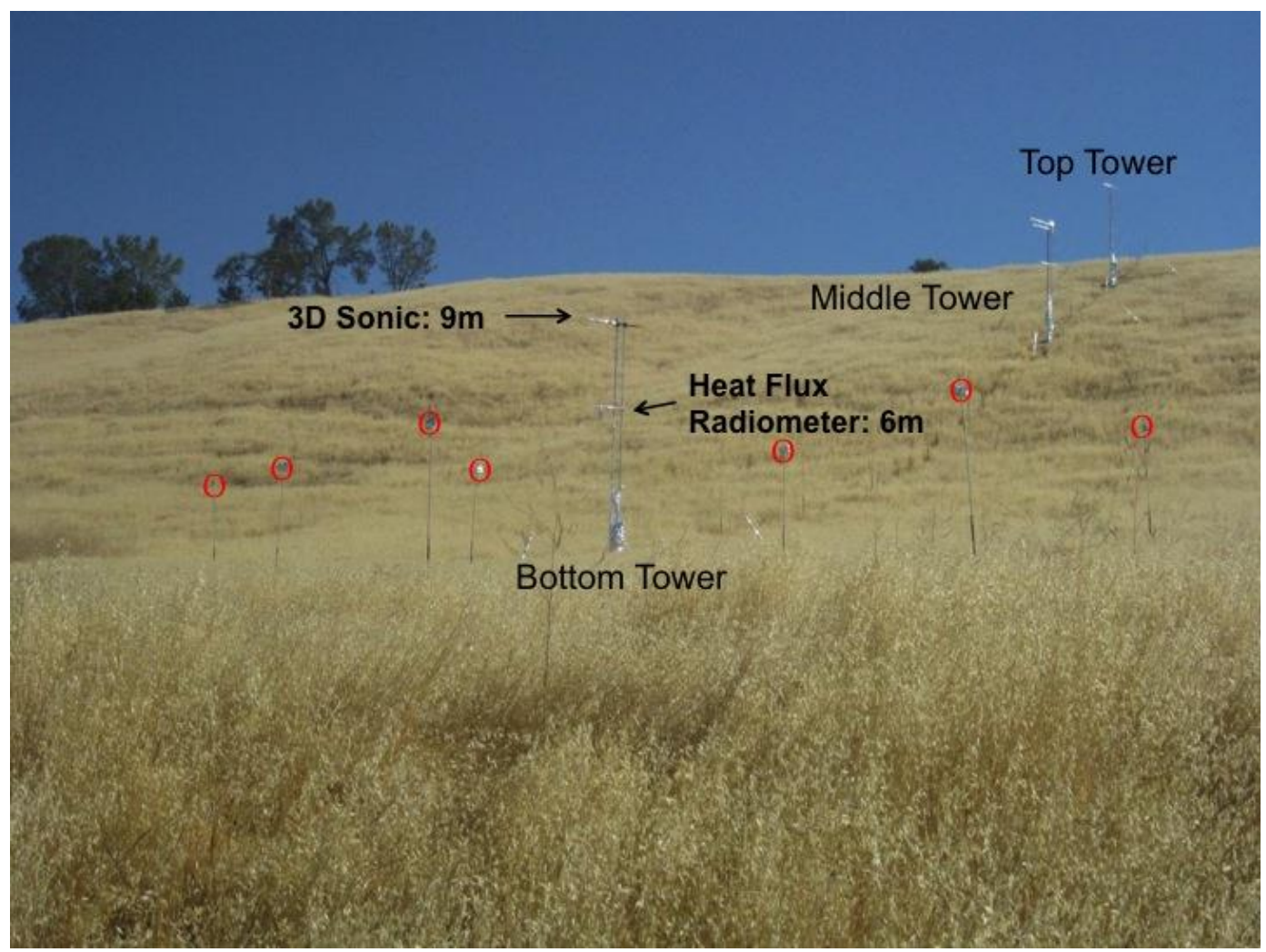

Fig. 7. Photo of the burn area, pre-burn. Towers and instrumentation labeled. Pressure-temperature sensor locations indicated by red circles. wind components were measured using 3D sonic anemometers (Applied Technologies, Inc., Sx-probe) (Fig 7). Radiative heat fluxes were measured with heat flux radiometers (Medtherm Corp, Model 64), also seen in Fig. 7. Nearsurface thermodynamic profiles were recorded utilizing an array of fine-wire thermocouples mounted in $1 \mathrm{~m}$ increments on each tower. Atmospheric surface pressure was measured at each tower using a barometer (R. M. Young, 61302) mounted at two heights ( 3 and $9 \mathrm{~m} \mathrm{AGL}$ ) on the bottom and middle towers and at one level, $3 \mathrm{~m}$ AGL, on the top tower.

Data were collected and stored on a Campbell Scientific Inc. (CSI) CR3000 datalogger. The clock on each datalogger was synchronized using a GPS sensor 
Table 1. Uniform sensors per tower

\begin{tabular}{|c|c|c|c|}
\hline$\frac{\text { Instrument, }}{\text { Model }}$ & Height(s) & $\begin{array}{l}\text { Variables } \\
\text { Measured }\end{array}$ & $\frac{\text { Sampling }}{\underline{\text { Rate }}}$ \\
\hline $\begin{array}{l}\text { 3D Sonic } \\
\text { Anemometer, } \\
\text { Sx-probe }\end{array}$ & $9 \mathrm{~m}$ & $\begin{array}{l}\mathrm{u}, \mathrm{v}, \mathrm{w} \text { wind } \\
\text { velocities } \\
\text { and Sonic } \\
\text { Temperature }\end{array}$ & $10 \mathrm{~Hz}$ \\
\hline $\begin{array}{l}\text { Heat Flux } \\
\text { Radiometer, } \\
\text { Model } 64\end{array}$ & $6 \mathrm{~m}$ & $\begin{array}{l}\text { Radiative Heat } \\
\text { Flux }\end{array}$ & $10 \mathrm{~Hz}$ \\
\hline $\begin{array}{c}\text { Type T } \\
\text { Thermocouples, } \\
\text { 5SC-TT-40 }\end{array}$ & $\begin{array}{c}1,2,3,4,5,6,7,8,9 \\
m\end{array}$ & Temperature & $1 \mathrm{~Hz}$ \\
\hline Barometer, 61302 & $3 \mathrm{~m}$ & Pressure & $1 \mathrm{~Hz}$ \\
\hline
\end{tabular}

(Garmin, GPS16X), which received timestamps from satellite for each record.

Power was supplied by a pair of $12 \mathrm{~V}$ deep cycle batteries wired in parallel. All of this equipment was mounted near the base of the tower and required protection from the fire. A fire resistant material, which resists emitted radiation, was wrapped around the base of each tower, including the datalogger and battery enclosures.

The 3D sonic anemometers were mounted on each tower to measure threedimensional wind and turbulence characteristics before, during, and after the FFP. Sonic anemometers utilize transducer pairs, which measure the time needed for sonic pulses to reach one another. The wind moving through the sensor affects the speed of the sonic pulse, allowing for the quantification of u-, v-, and w-components of the wind, as well as the virtual temperature of the air, called sonic temperature. Additionally, the sonic anemometers have a high temporal resolution and were sampled at a rate of $10 \mathrm{~Hz}$. This interval was 
needed in order to calculate turbulence statistics associated with the fire-induced winds. The sonic anemometers were mounted at a height of $9 \mathrm{~m}$ and extended 1-2 $\mathrm{m}$ outward from the tower to minimize any influence from the tower.

Heat flux radiometers were used to measure the upwelling radiative heat flux from the fire front and were mounted on the bottom two towers. These sensors were mounted at a height of $6.0 \mathrm{~m} \mathrm{AGL}$ and extended $\sim 1-2 \mathrm{~m}$ outward from the tower. Radiative heat flux (Medtherm Corp, Model 64) sensors measure only the radiative component of the heat flux by using a sapphire window over the sensor surface. The bottom tower was additionally equipped with a second type of radiometer, a total heat flux sensor (Hukseflux, SBG01). The total heat flux sensor measures both the convective and radiative components of heat flux. All of the radiometers faced downward in order to measure the heat being emitted vertically from the fire front. And like the sonic anemometers, the radiometers were sampled at a rate of $10 \mathrm{~Hz}$.

A $10 \mathrm{~m}$ thermodynamic profile was measured at each tower using a thermocouple array. The thermocouples are a fine-wire, type-T (Omega Inc., 5SC-TT-40). The thermocouples were arranged in $1 \mathrm{~m}$ increments beginning at 1 m AGL and rising to the top of the tower. Thermocouples were sampled at a rate of $5 \mathrm{~Hz}$.

Two remote automated weather stations, hereafter referred to as RAWS, were installed at locations on the ridge top and near the ignition line (Fig. 6). The ridge top RAWS was equipped with a 3D sonic anemometer, sampling winds at a 
rate of $10 \mathrm{~Hz}$, and a thermocouple array, sampling temperatures at $1 \mathrm{~Hz}$. The RAWS near the ignition line was equipped with a R.M. Young 03002 Wind Sentry cup anemometer and vane and a CSI CS215 temperature and relative humidity probe. The data collected at this station was sampled at $1 \mathrm{~Hz}$ and averaged over a 5 minute period.

An additional RAWS was situated on the ridge of site 2 and collected wind and temperature data in 5 minute intervals. The purpose of this RAWS was to collect data pertaining to the regional synoptic scale flow. This data was collected for three months prior to the experiment.

An array of 13 Fire Sensor Packages (FSP) was installed in a grid within the burn plot. The FSPs measured atmospheric pressure, external temperature, and internal temperature. Each FSP contained a type E thermocouple, an aneroid barometer, and a GPS. Each were sampled at $1 \mathrm{~Hz}$. The FSPs were mounted on steel T-posts at a height of $3 \mathrm{~m}$. The distance between each of these sensors was $10 \mathrm{~m}$. The sensors in this grid were arranged in two rows and a single column. The two rows were $20 \mathrm{~m}$ apart. The column ran down the center of the two rows. This arrangement is shown in Fig. 6.

Video footage was captured using high-definition camcorders, marked by green squares in Fig. 4. A ground-based unit was situated across the road from the ignition line. This camera's frame was fixed and encompassed all three towers. An airborne camera (Fig. 8) filmed the experiment from a helicopter, hovering approximately at $300 \mathrm{~m} \mathrm{AGL}$. Footage from the airborne camera was 


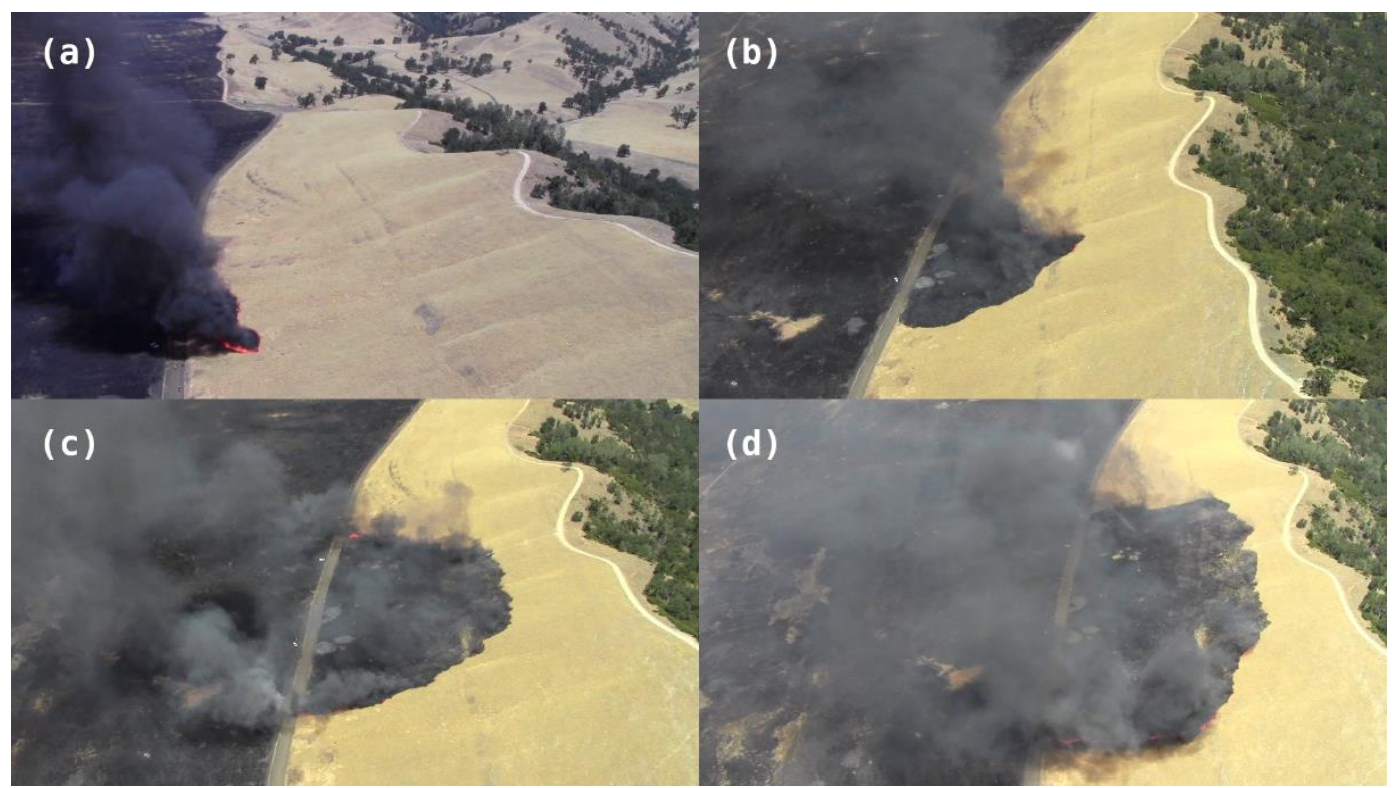

Fig. 8. Aerial imagery of the (a) ignition line and fire front passage at the (b) bottom, (c) middle, and (d) top towers.

not stationary due to movements made by the helicopter, but the framing of the picture was broad enough to capture the entire burn plot.

\subsection{Ambient Meteorological Measurements}

Ambient meteorological conditions were measured up wind from the burn plot and near the valley center by a Doppler miniSodar (Atmospheric Systems Corporation, 4000 Series) and a $32 \mathrm{~m}$ mobile meteorological tower (Figs. 4, 9). The sodar measured u-, v-, and w-components of the wind at heights between 20 and $200 \mathrm{~m} \mathrm{AGL}$ in increments of $5 \mathrm{~m}$. It also collected backscatter data from each of these heights. Data from the sodar was averaged over a 10 minute period and provided mean wind profiles of the surface layer and lower boundary layer. The $32 \mathrm{~m}$ mobile tower was equipped with a 2D sonic anemometer (Gill, Windsonic) and a temperature and relative humidity probe (Vaisala, HMP45C) at heights of 7, 12, 22, and $32 \mathrm{~m} \mathrm{AGL}$. Sensors were sampled at $1 \mathrm{~Hz}$ and data 


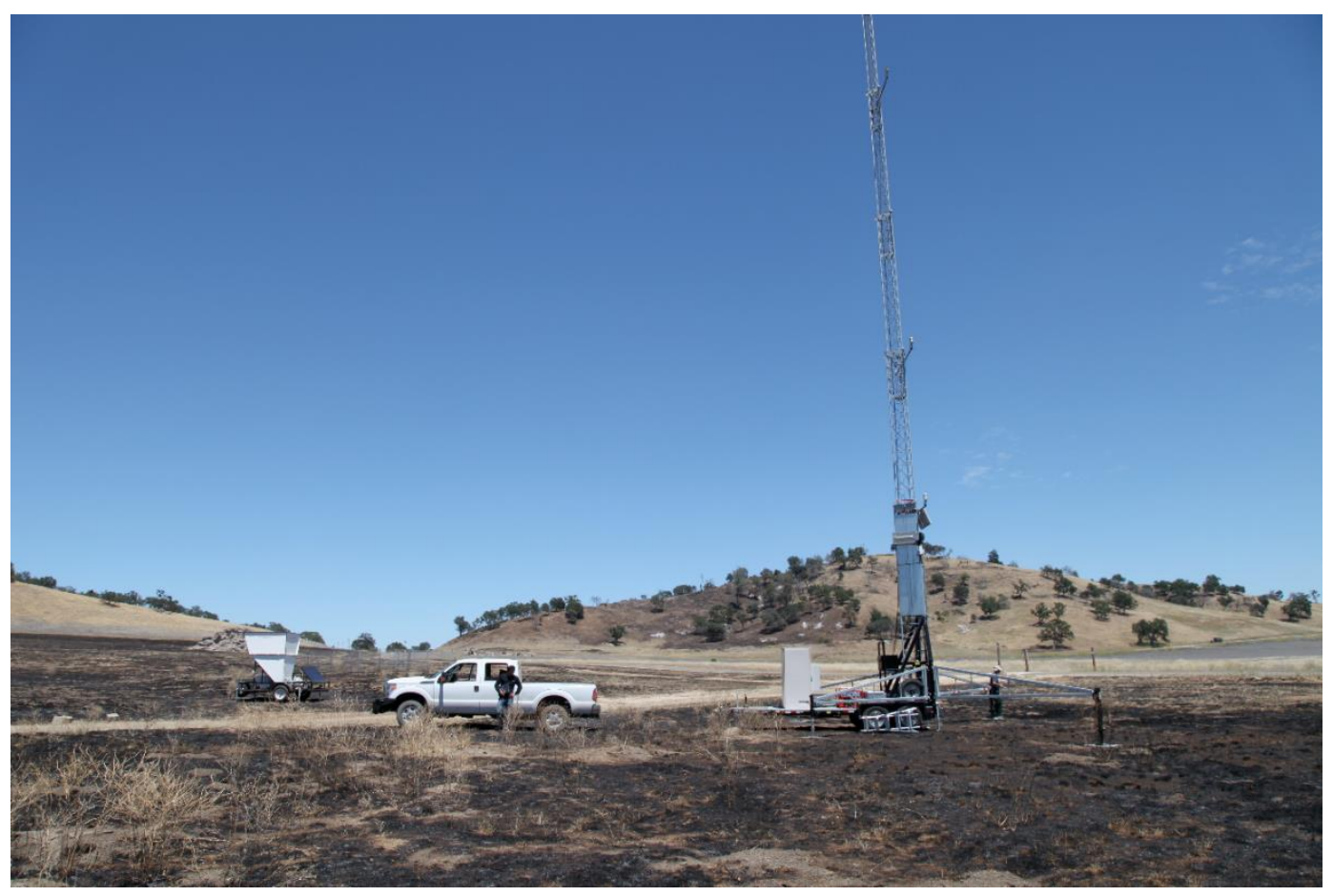

Fig. 9. Photo of Doppler SODAR (left) and CSU-MAPS tower (right).

were averaged to 1 minute. The mobile meteorological tower was described in more detail by Clements and Oliphant (2014).

A Doppler lidar, pictured in Fig. 10, was situated across the valley from the burn plot (Fig. 4), where it performed range-height indicator $(\mathrm{RHI})$ scans during the active burning period of the head fire and then plan-position indicator (PPI) scans were made immediately afterwards. The lidar is capable of full upper hemisphere scanning. The class $1 \mathrm{M}$ laser operates at a $1.5 \mu \mathrm{m}$ wavelength, falling within the near-infrared range, and has a $15 \mathrm{kHz}$ pulse rate. The range of the laser for this experiment was $80 \mathrm{~m}$ to $2000 \mathrm{~m}$ with a range gate size of $18 \mathrm{~m}$. The velocity measurements are accurate to within $0.038 \mathrm{~m} \mathrm{~s}^{-1}$ for range gates with signal-to-noise ratios exceeding $1.015 \mathrm{SNR}+1$. 


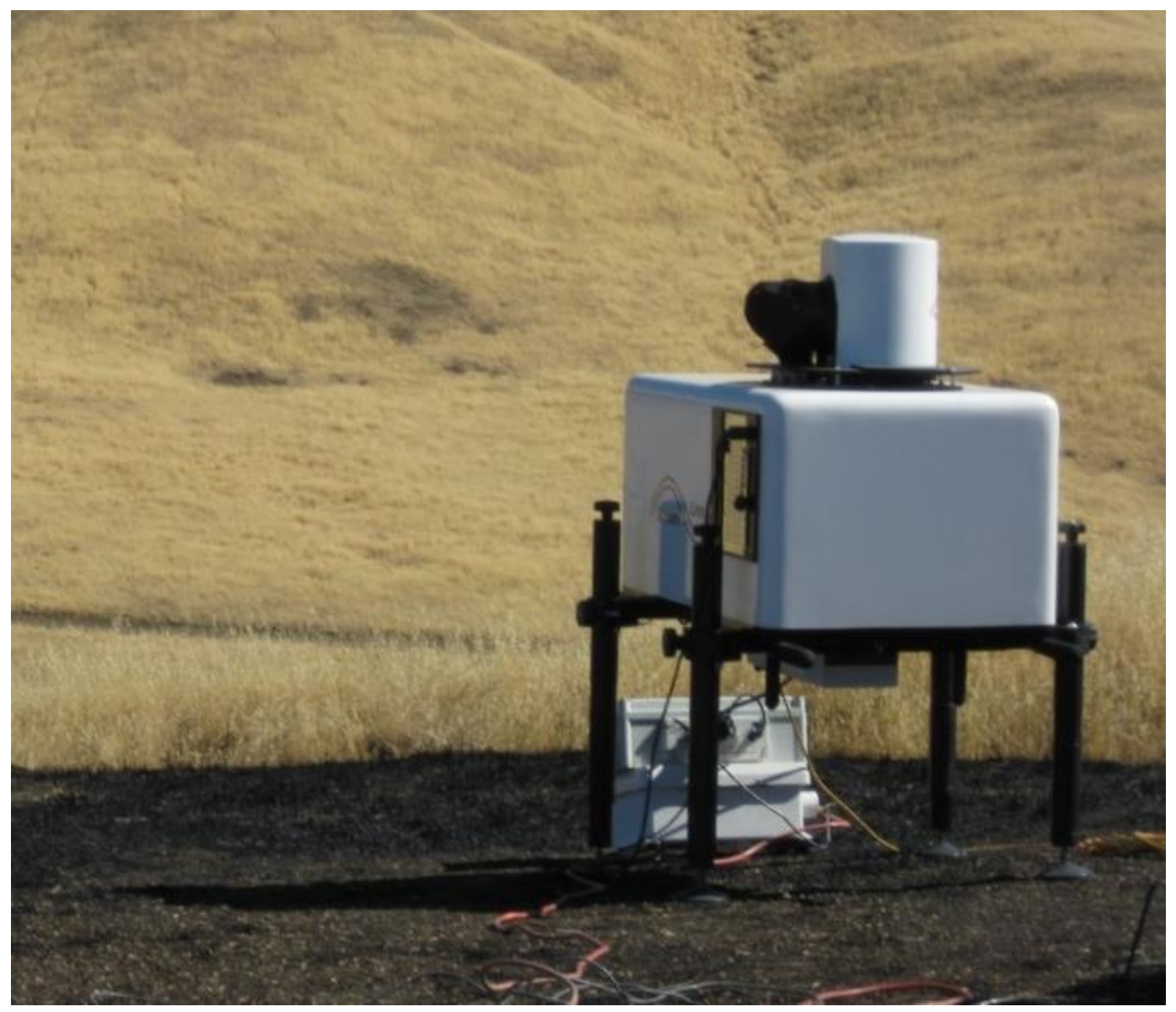

Fig. 10. Photo of Doppler LIDAR.

An upper-air sounding was made prior to ignition at 8:48 PDT near the site of the lidar. A Vaisala Inc. DigiCora III MW31 sounding system and a RS92GPS radiosonde was used. The sounding collected data at $1 \mathrm{~Hz}$ intervals and measured temperature, humidity, barometric pressure, and position obtained from an onboard GPS. Wind speed and direction are calculated from position of the sonde and other variables are calculated in real-time from the sensor measurements. 


\subsection{Synoptic Overview}

The climatological synoptic setup in the western continental United States for the month of June has been described by Davis and Walker (1992) to be in a state of transition. During the month of May, at $500 \mathrm{hPa}$, it is common for the axis of a ridge of high pressure to be located near the west coast of the United States. Through June, this ridge shifted eastward over the Great Basin, and allowed a more monsoonal regime to begin in July. The presence of the ridge on the west coast is usually associated with light winds at all levels of the atmosphere.

The experiment was conducted on 20 June 2012 . On that day at $500 \mathrm{hPa}$, the axis of the ridge was located near the west coast of the United States (Fig. 11). This upper level ridge supported weak winds throughout all levels of the atmosphere over California. Although the $850 \mathrm{hPa}$ map (Fig. 12) shows northerly

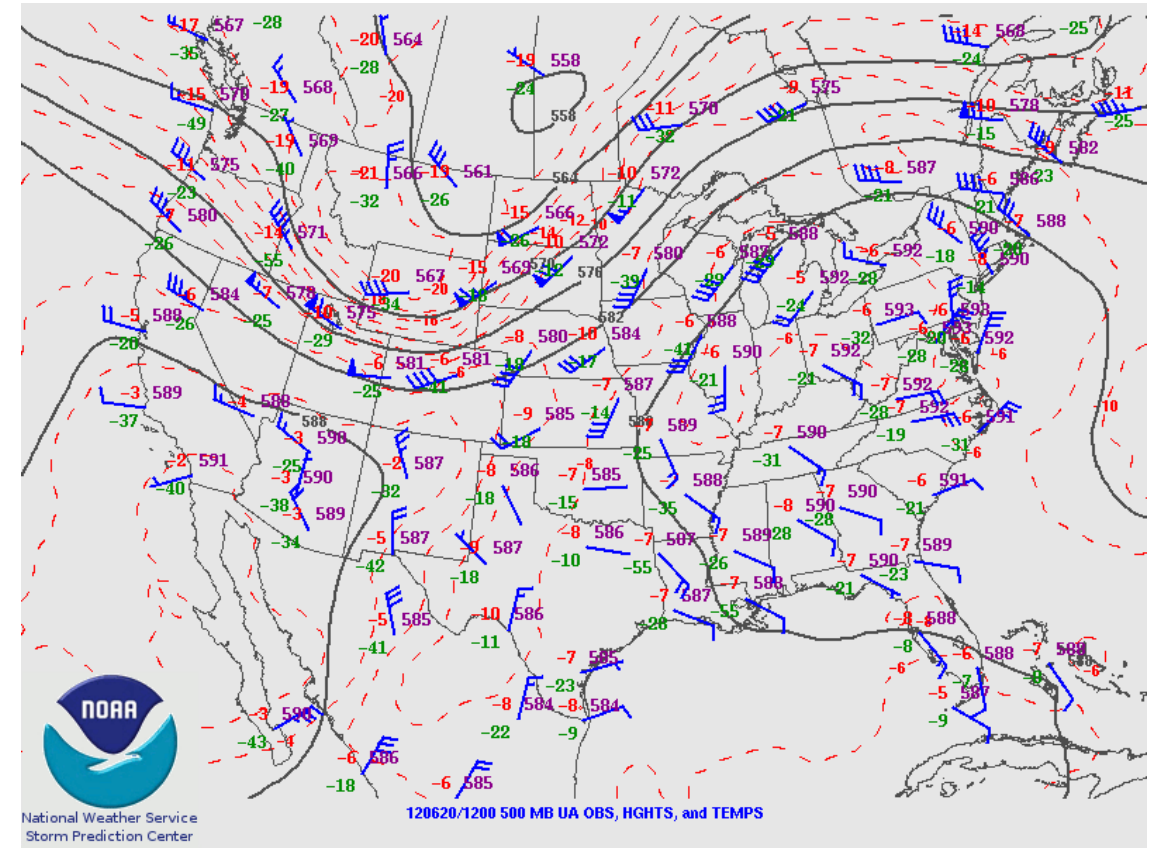

Fig. 11. The $12 Z 500 \mathrm{hPa}$ analysis from 20 June 2012. (Source: NOAA) 


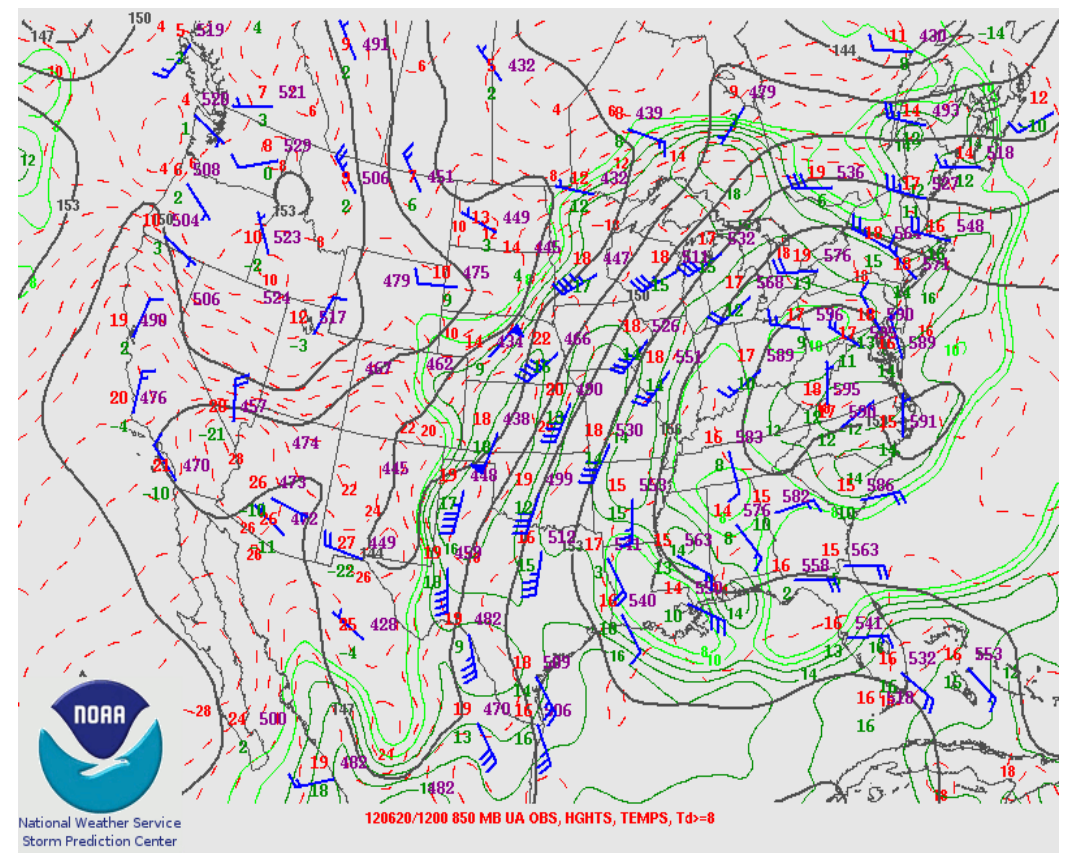

Fig. 12. The $12 \mathrm{Z} 850 \mathrm{hPa}$ analysis from 20 June 2012.

(Source: NOAA)

winds, the velocity of this wind was diminished by a weak pressure gradient. The $12 Z$ surface map (Fig. 13) showed calm winds in central California. For these reasons, terrain driven winds were expected to prevail at the experimentation site.

\section{Chapter 3 - Surface Temperature Pressure Perturbations}

\subsection{Introduction}

\subsubsection{Thermocouple Measurements}

The heat released during the combustion cycle drives many micrometeorological phenomena surrounding wildland fires, including strong buoyancy-driven circulations. Therefore, temperature observations are critical for analysis of fire-atmosphere interactions.

Measuring extreme heat is challenging, but a few methods have been 


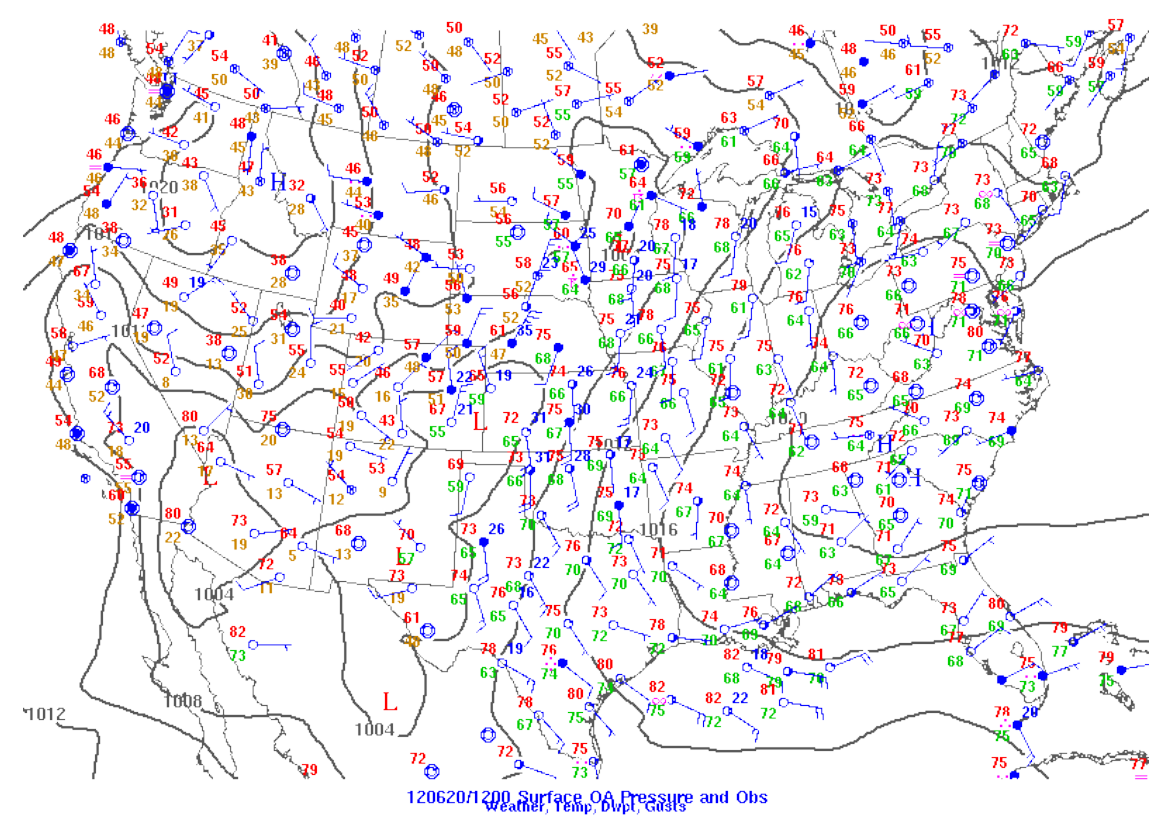

Fig. 13. The $12 Z$ surface analysis from 20 June 2012. (Source: NOAA)

developed. One technique utilized satellites to estimate wildfire temperatures (Dennison et al. 2006). By measuring total spectral radiance of the surface of the earth and applying Planck's equation, temperatures ranging from 225 to $1225^{\circ} \mathrm{C}$ have been observed.

Thermocouples have been the most feasible method of directly measuring the air temperature surrounding a fire. Thermocouples are durable, portable, and relatively inexpensive. Clements (2010) directly observed the thermodynamic structure of a fire plume in a grass fire using fine-wire thermocouples. He observed a maximum temperature of $292.5^{\circ} \mathrm{C}$ at $4.5 \mathrm{~m}$ AGL.

Several issues must be considered when using a thermocouple in the vicinity of fire. Walker and Stalks (1968) showed that errors in the maximum temperature are produced which are dependent on the gauge of the thermocouple. Bova and 
Dickenson (2008) concluded that, if calibrated, data from thermocouples can be useful for estimating fireline characteristics, though comparing thermocouple data between wildfire studies is difficult as device type and deployment style are rarely consistent. In a review of wildfire measurement, Kremens et al. (2010) point out that temperatures observed within the radiation field by thermocouples are dependent on both the characteristics of the measuring device and the fire. Even with these issues, the thermocouple is an inexpensive method of broadly measuring air temperature spatially and temporally in the fire environment.

\subsubsection{Hypothesis}

Due to the negative pressure tendency and the extreme heat at the fire front, a negative covariance between pressure and temperature was expected. It was hypothesized that the strength of a fire-atmosphere interaction could be analyzed from the covariance of temperature and pressure.

\subsection{Methods and Data Processing}

The grid of FSPs was arranged as shown in Fig. 6. The layout was designed to capture the temperature and pressure associated with a spreading fire front by allocating enough points in the lines parallel and perpendicular to the hillside. While a rectangular design would have been preferable, the limited number of FSPs prevented a desirable resolution in both planar directions. The FSPs were placed at a ten-foot grid spacing.

Data were stored on a micro SD card within each FSP. The hard drive was capable of storing up to eight hours of data. The sensors sampled at a 
rate of $1 \mathrm{~Hz}$.

Calibration of the sensors was performed during the post processing of the data. A mean of the ambient conditions was found using data from all of the sensors. The mean temperature and pressure were found to be $32.25^{\circ} \mathrm{C}$ and 959.7 $\mathrm{hPa}$. Means were also calculated for each individual sensor. The difference between the individual and composite means was then added to all data points. Table 2 shows the adjustments that were made to the data from each sensor.

Next, the temperature and pressure data were separated into the mean and deviations from the mean:

$$
\begin{aligned}
& \mathrm{T}=\overline{\mathrm{T}}+\mathrm{T}^{\prime} \\
& \mathrm{P}=\overline{\mathrm{P}}+\mathrm{P}^{\prime}
\end{aligned}
$$

$\overline{\mathrm{T}}$ is the representation of the temperature of the ambient atmosphere, or the mean temperature with no influence from the fire. The mean temperature would Table 2. FSP IDs and offsets made to each dataset

\begin{tabular}{ccc}
\hline Sensor ID Number & $\begin{array}{c}\text { Temperature } \\
\text { Calibration }\left({ }^{\circ} \mathbf{C}\right)\end{array}$ & $\begin{array}{c}\text { Pressure } \\
\text { Calibration }(\mathbf{h P a})\end{array}$ \\
\hline $\mathbf{0 4}$ & -0.3603 & -0.0256 \\
$\mathbf{0 8}$ & 0.2358 & 0.3763 \\
$\mathbf{0 9}$ & 0.2599 & -0.7178 \\
$\mathbf{1 0}$ & 0.2795 & 0.0290 \\
$\mathbf{1 1}$ & 0.2592 & -0.0926 \\
$\mathbf{1 2}$ & -0.1839 & -0.4016 \\
$\mathbf{1 3}$ & 0.3548 & -0.1187 \\
$\mathbf{1 4}$ & 0.3194 & -0.1585 \\
$\mathbf{1 5}$ & -0.4948 & 0.2902 \\
$\mathbf{1 6}$ & -0.0978 & 0.3383 \\
$\mathbf{1 7}$ & 0.2578 & 0.2185 \\
$\mathbf{1 8}$ & -0.0128 & 0.0749 \\
$\mathbf{1 9}$ & -0.8168 & 0.1877 \\
\hline
\end{tabular}


ideally be calculated from a collocated sensor not exposed to the fire. But for this experiment, no such sensor was in place. Therefore, the mean temperature was calculated from a composite of all temperature observations in the grid for the hour prior to the experiment. Next, by subtracting the mean temperature from the observed, the temperature perturbations were found.

Because pressure was sampled at a rate of $1 \mathrm{~Hz}$, and pressure data are affected by changes in voltage input, consecutive samples could change by as much as $0.2 \mathrm{hPa}$. To deal with this issue, the data were processed with a simple averaging scheme, in which data were smoothed by averaging the five data points before and after each point in the time series.

To determine the pressure deviations, a linear de-trending method was utilized following Burba and Anderson (2010). First, a portion of each time series must be selected containing the data associated with the FFP. The FFP lasted no longer than 1 minute at each FSP. Therefore, for each FSP, a data window associated with the FFP was defined as the 30 seconds before and after the maximum temperature in the time series. At the beginning and end of each 1 minute data window, a 1 minute average pressure was computed. A trend line was fit between these two averaged points, and used to define $\overline{\mathrm{P}}$ during the time of FFP. The pressure perturbation, $\mathrm{P}^{\prime}$, was then calculated as the difference between the trend line and actual pressure measured during FFP.

The covariance between temperature and pressure, $\overline{\mathrm{T}^{\prime} \mathrm{P}^{\prime}}$, was found by calculating the product of the deviations and averaging over time. For this 
purpose, a three second Reynold's averaging period was used on the product of the deviations.

Calculating the covariance between temperature and pressure has an additional analytical benefit. Within the pressure data, there are increases and decreases not associated with the fire. To distinguish between the fire induced and non-fire induced changes in pressure, the covariance uses the temperature deviation from the mean, $T^{\prime}$. In ambient conditions, $T^{\prime}$ is approximately zero. This reduces the product of $T^{\prime}$ and $P^{\prime}$ to a negligible value, thus eliminating the nonfire induced changes in pressure.

3.3 Results and Discussion

\subsubsection{Rate of Spread}

The timing of maximum temperature during FFP at each FSP provides an estimate of the fire rate of spread across the grid area. Rate of spread is the amount of time it takes for a fire to propagate across an area. FFP occurred at each of the thirteen grid FSPs during a 6 minute period lasting from 11:22:00 PDT through 11:28:00 PDT, which was determined by the observed temperature maxima.

Fig. 14 shows a time series of temperature from each FSP. It can be seen that as the fire front progressed across the grid, the observed maximum temperatures increased. A peak in maximum temperatures was reached just as the fire front passed the last two FSPs. This suggests that the development of the fire front was completed by this time. Since the direction of fire spread was 


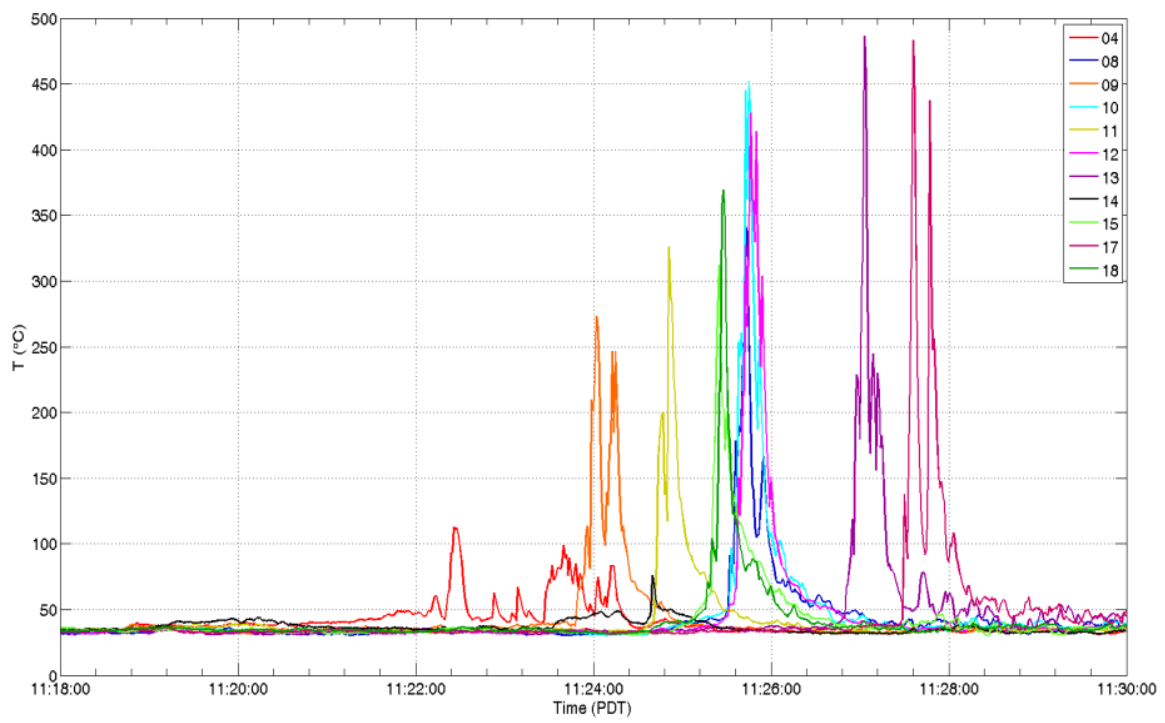

Fig. 14. Temperature time series from each of the FSPs in the grid.

south-southwest to north-northeast across the sensor grid, estimates could only be made from sensors along the same alignment. Fig. 15 shows estimates made from the sensors following this orientation.

These estimates show that the rate of spread increased as the fire front progressed across the west end of the burn plot. From sensor 04, near the ignition line, to sensor 18 , the rate of spread was $0.04 \mathrm{~m} \mathrm{~s}^{-1}$. From sensor 18 to sensor 17 , near the back of the grid, the rate of spread was $0.05 \mathrm{~m} \mathrm{~s}^{-1}$. This was an increase in the spread rate of $0.01 \mathrm{~m} \mathrm{~s}^{-1}$.

It was also observed that the spread rate increases from west to east. The spread was slowest on the western end of the grid where the rate of spread was $0.05 \mathrm{~m} \mathrm{~s}^{-1}$ between sensors 18 and 17 . The rate of spread from sensor 14 to 8 , on the eastern end, was $0.10 \mathrm{~m} \mathrm{~s}^{-1}$. This is a difference of $0.05 \mathrm{~m} \mathrm{~s}^{-1}$ from west to 


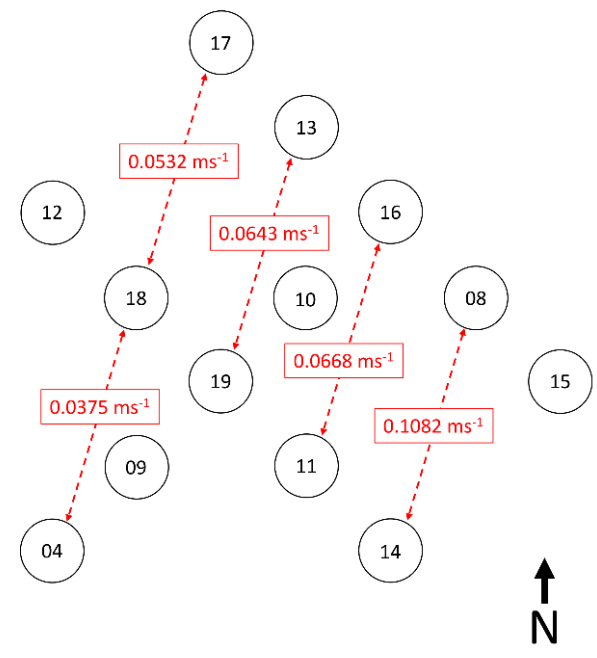

Fig. 15. Estimated rate of spread through sensor grid. Sensor IDs are in black. Rate of spread estimates are in red. Rate of spread is estimated between sensors indicated by red dashed line.

east. This was caused by the head of the fire, where the spread rate is highest, being located further to the east, beyond the sensor grid as seen in Fig. 16.

\subsubsection{Temperature Pressure Covariance}

The 1 minute averaged time series of temperature and pressure are shown next to the respective temperature-pressure covariance in Figs. 17a-v. The maximum temperature of each FSP is contained by a 1 minute period, window AB. The temperature-pressure covariances were calculated between window A-B. The covariance shows how much the temperature and pressure change together through time. As change increases, the measured value becomes more negative.

Before analysis could begin, it was necessary to address a few anomalies in the data. Of the thirteen sensors that were installed, all but four, sensors 4, 14, 16 , and 19 , were able to accurately measure temperatures exceeding $200^{\circ} \mathrm{C}$. 


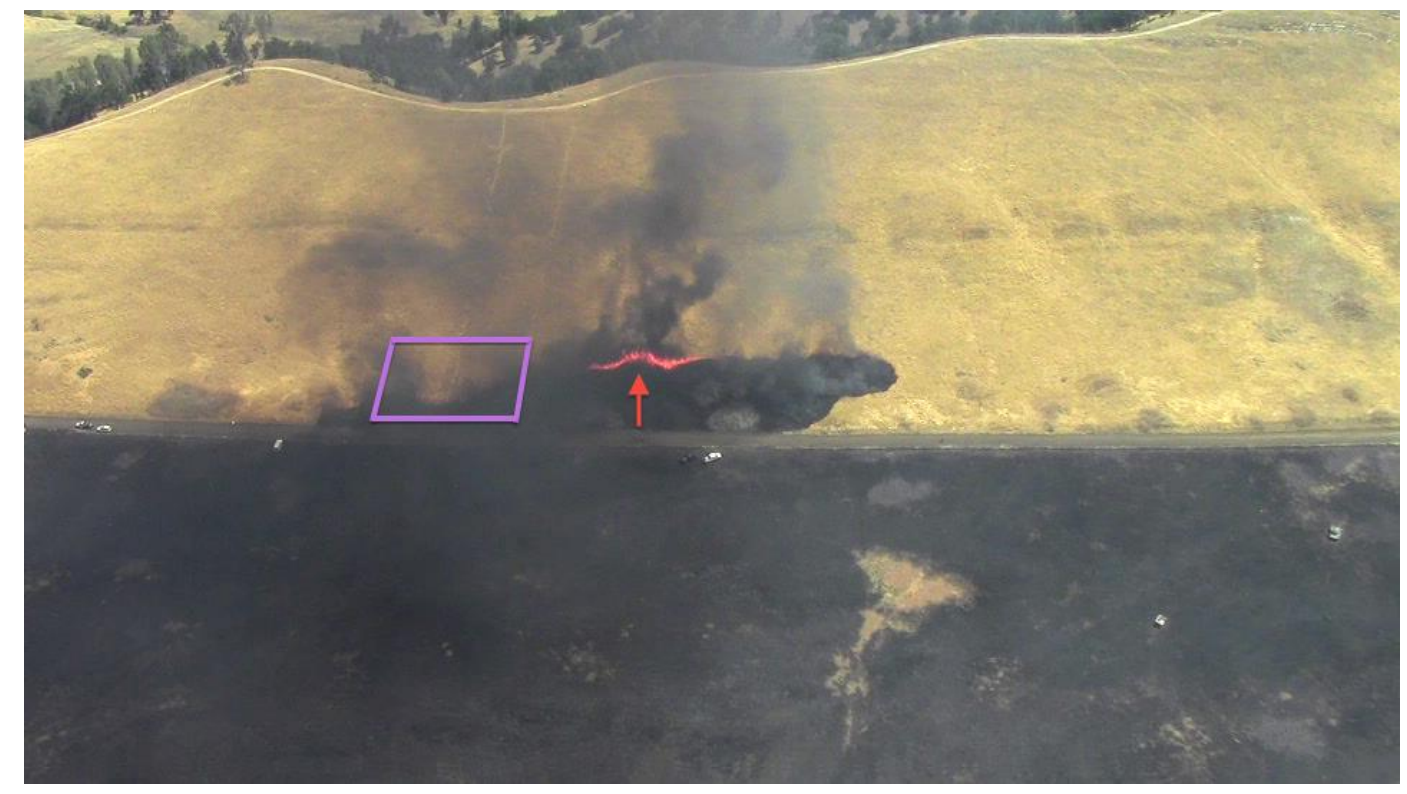

Fig. 16. An aerial photo of the fire. The head of the fire, indicated by the red arrow, began to form east of the area containing the sensor grid, outlined in purple.

The low temperature readings that occurred at sensors 4 and 14 were due to an underdeveloped fire front, as both were located near the ignition line. Data from sensor 16 is an anomaly. Where surrounding sensors observed maximum air temperatures ranging from 350 to $475^{\circ} \mathrm{C}$, sensor 16 recorded a maximum temperature of just $160^{\circ} \mathrm{C}$. While the cause of this is unknown, one reason may be that the fuel bed immediately surrounding sensor 16 was overly compressed during experimental setup. Data from sensor 19 shows that while measuring temperatures exceeding $300^{\circ} \mathrm{C}$, a malfunction occurred during FFP. Subsequent investigation of sensor 19 revealed that the thermocouple junction had been severed due to intense heat. Because of this, sensors 16 and 19 were deemed poor data and were removed from the covariance analysis. 
(a)

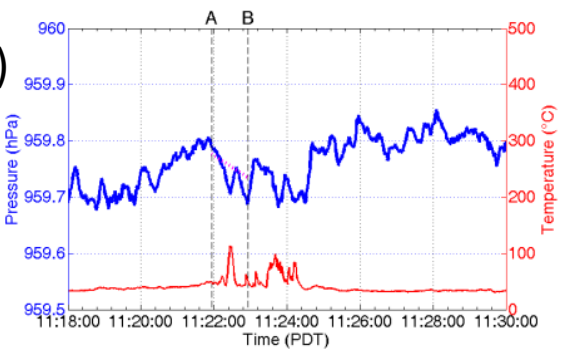

(c)

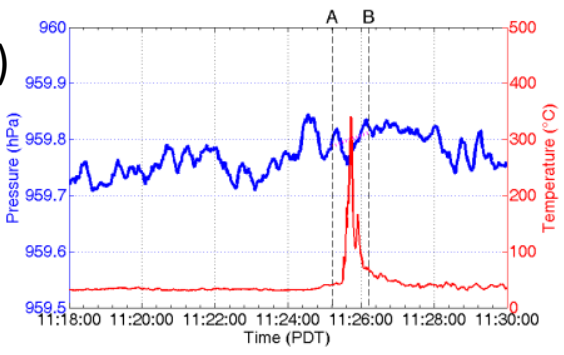

(e)

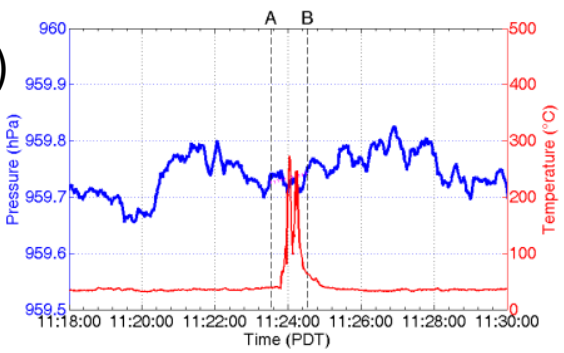

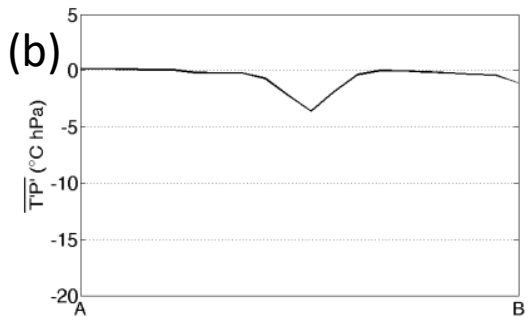
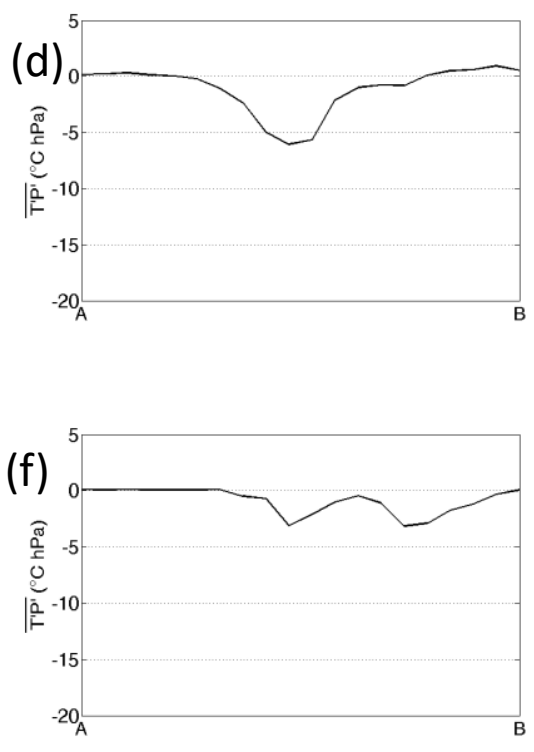

Fig. 17a-f. Temperature and pressure time series with covariance plots for the duration of the fire front passage for sensors 04,08 , and 09 respectively.

The covariance between temperature and pressure was expected to have a negative correlation during FFP. The sign of the covariance is dependent on the pressure deviation. The reason for this is because the temperature deviation will always be positive during FFP.

Sensors nearest the ignition line, 4, 9, and 14, observed the weakest covariance during the FFP, $-3.6,-3.2$, and $-0.1^{\circ} \mathrm{C} h P a$ respectively. At sensor 4 , where the maximum temperature only reached $112.9^{\circ} \mathrm{C}$ (Fig. 17a), the negative covariance was strongly dependent on the negative pressure deviation. Sensor 9 

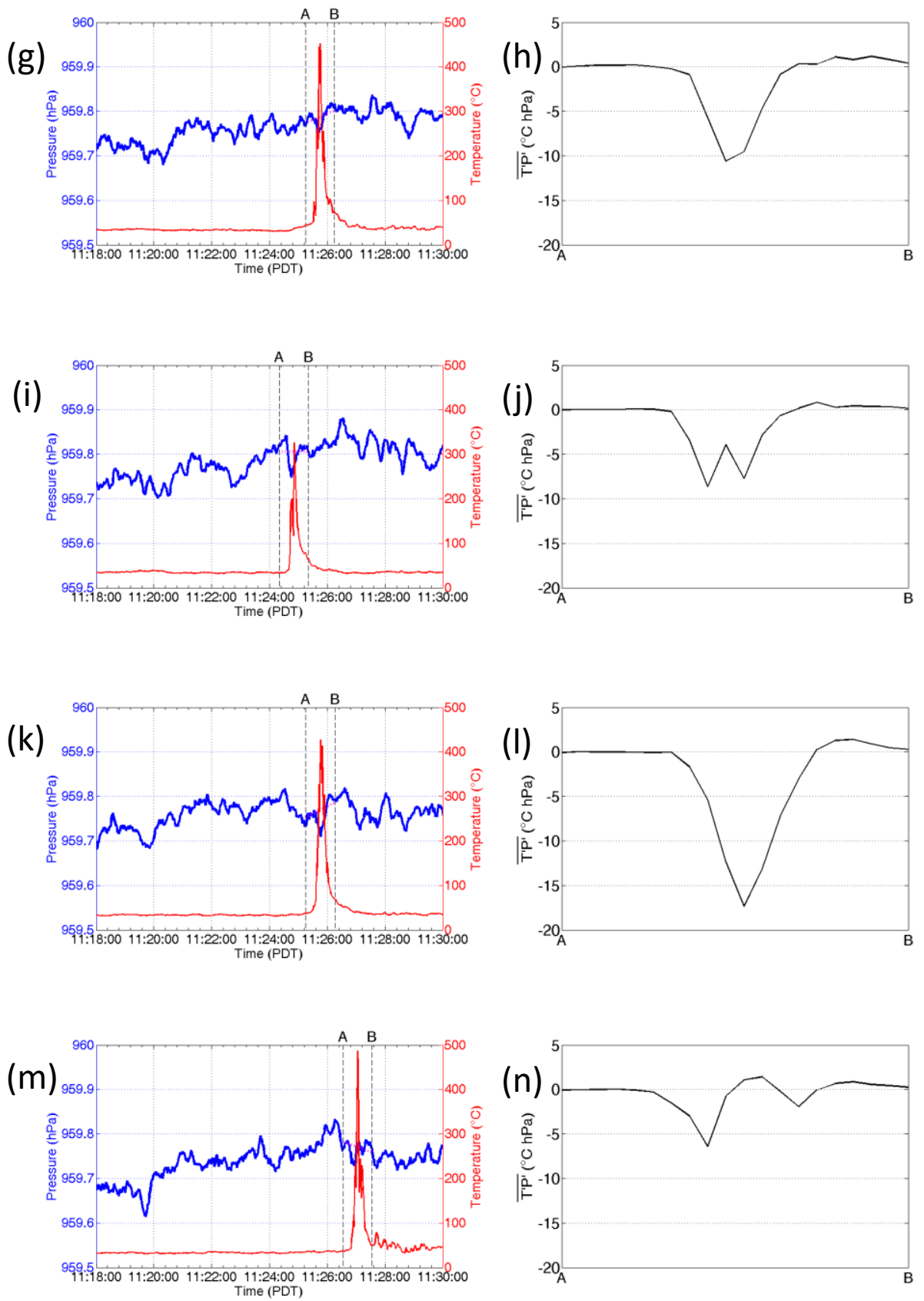

Fig. 17g-n. Temperature and pressure time series with covariance plots for the duration of the fire front passage for sensors $10,11,12$, and 13 respectively. 
(o)
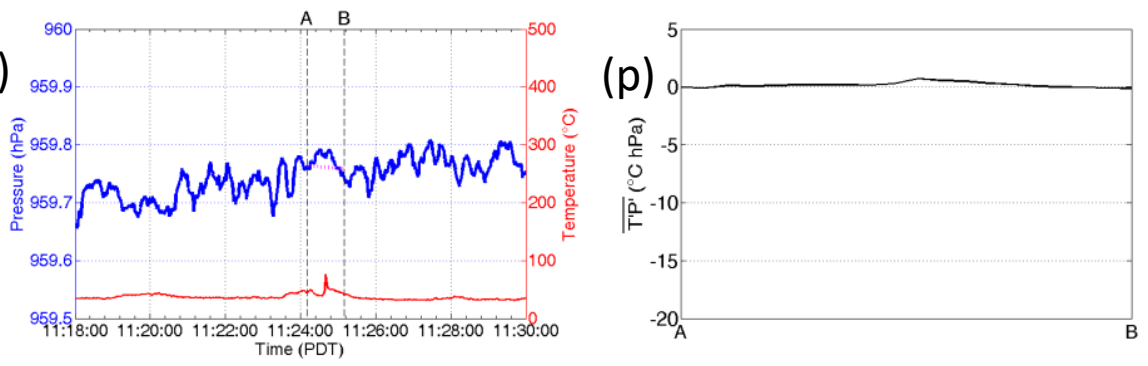

(q)
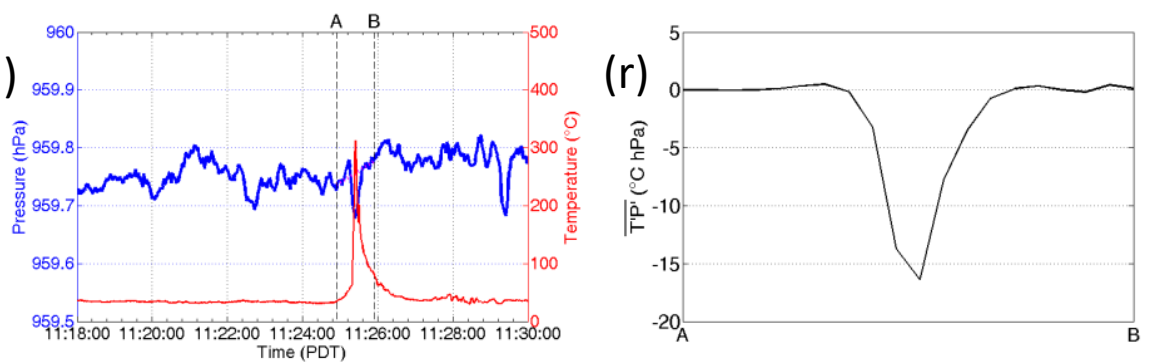

(s)
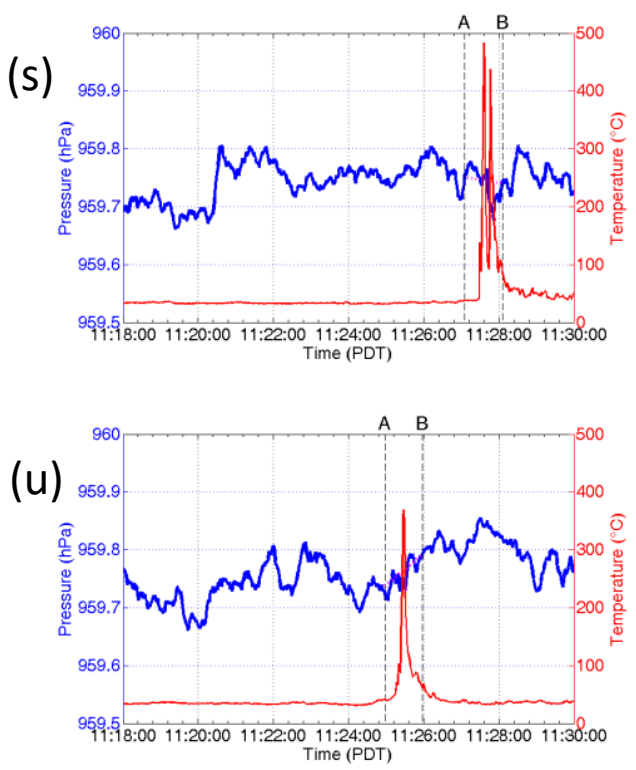
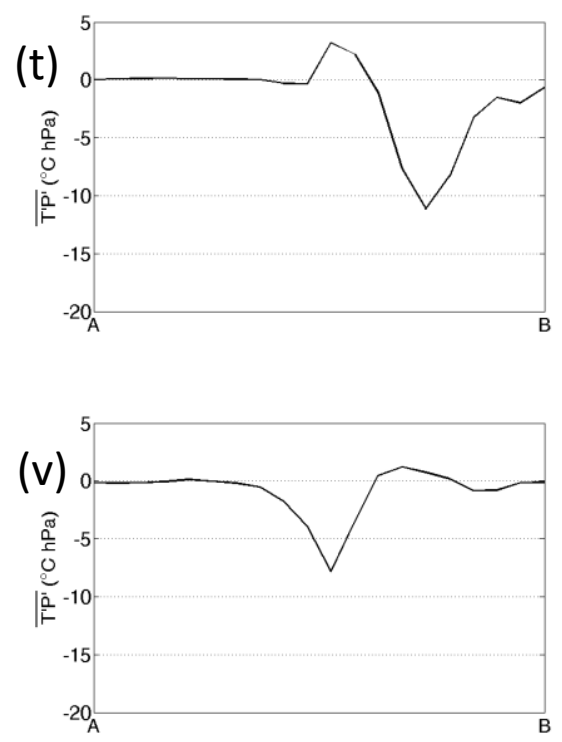

Fig. 17o-v. Temperature and pressure time series with covariance plots for the duration of the fire front passage for sensors $14,15,17$, and 18 respectively. 
had a maximum temperature of $272.3^{\circ} \mathrm{C}$ (Fig. 17e). Although this temperature was well above what was observed at sensor 4 , a weak pressure deviation resulted in similar covariance values. Sensor 14 had the smallest temperature maximum, which was a result of being near the ignition line. The pressure did drop during the FFP, but the mean pressure during the FFP was much lower than the drop in pressure. This resulted in a very weak covariance during FFP at sensor 14 .

The strongest covariance values were observed at sensors 12 (Fig. 17I) and 15 (Fig. 17r), -17.4 and $-16.4{ }^{\circ} \mathrm{C} \mathrm{hPa}$, respectively. Maximum temperatures at these two sensors were 427.6 and $312.0^{\circ} \mathrm{C}$, respectively. The pressure deviations at each of these two stations contrast one another. Sensor 12 shows the greatest pressure deviation, while having a lower temperature measurement. This would suggest that, while there is a link between these two variables during FFP, the intensity of the heat has no correlation with drop in pressure.

The remaining sensors, $08,10,11,13,17$, and 18 , observed covariance strengths ranging from -6.1 to $-11.2^{\circ} \mathrm{C} \mathrm{hPa}$. Maximum temperatures at these sensors varied due to the dynamic fire front. While each sensor shows a strong negative temperature-pressure covariance during FFP, the results of this experiment remain unclear.

The covariances show how much temperature and pressure change with one another. While each sensor observed strong negative covariances, the strength of the covariance during FFP at each sensor varied throughout the grid. This 
indicates, for this data set, that there is no clear relationship between temperature and pressure at the fire front.

There are a few reasons why the results are unclear. First, wind is a primary cause of fire front type. A backing fire and head fire would impinge on the sensors differently. For light winds particularly, without knowing the wind direction at each sensor, it cannot be known how the fire impinged on each sensor. This could be resolved by equipping each FSP with a sonic anemometer.

Second, as seen with sensor 16 , fuel uniformity can greatly affect the measurement. One observation that can be made is that, with the exception of sensor 14, the strongest covariances were observed at the sensors on the edge of the grid. The fuels surrounding these sensors were the least affected by the installation. For future experiments, it would be ideal to install sensing equipment before vegetative growth begins. This would allow for greater fuel uniformity during an experiment.

\subsection{Conclusion}

In summary, a negative covariance between temperature and pressure was expected at the fire front due to intense heating from the fire and a negative pressure tendency caused by rising air at the fire front. Because of the location of the grid in relation to the ignition line, the fire had not fully intensified before reaching the sensors, as observed in Fig. 14. Additionally, the magnitude of the covariances varied greatly across the grid, showing no clear relation between temperature and pressure at the fire front. 
While the data does show that the technique and hypothesis have promise, further testing is needed. Future experiments will need to be well planned and feature additional sensors on the FSPs. Data from FSPs on a consistent and completely developed fire front would be a good comparison for the covariances from this experiment. Another option would be to make observation in a wind tunnel, where wind speed and direction, as well as fuel uniformity, can be controlled.

\section{Chapter 4 - Micrometeorology}

\subsection{Introduction}

The interactions between a fire, the atmosphere, and surrounding topography display a wide range of complexity. Therefore, it can be difficult to provide timely, reliable information to firefighting crews. Computer models operating using the Rothermel fire behavior model (Rothermel 1972), such as Farsite (Finney 1998) and BehavePlus (Andrews 1986), forgo many of the complex physical interactions that occur in the wildfire environment. Instead, they opt for computational efficiency, using only crucial variables to empirically estimate fire behavior. The problem with this technique is that it ignores many meteorological processes affecting fire behavior.

With the introduction of coupled fire-atmosphere models, fully threedimensional fluid dynamical processes have been applied to fire behavior prediction. Kochanski et al. (2013) used WRF-SFIRE to simulate and compare the fire behavior to the observations collected during the FireFlux experiment 
(Clements et al. 2007). The results of the study were encouraging, as comparisons between the model rate of spread, thermodynamic profiles, and three-dimensional winds were close to observed. These studies were conducted on flat terrain, which removed many of the complications that occur with the addition of slope.

There have been many modeling studies that have simulated fire behavior in complex terrain, but few observational datasets currently exist that can evaluate the simulated results. Linn et al. (2007) explored the extent to which the fire and atmosphere were coupled in various complex terrain scenarios. This study used several terrain types with varying ambient wind speeds. Results showed that the effect of the mean wind on the fire spread distance on flat terrain was approximately equal to that of fire spread on a canyon sidewall where the mean wind was obstructed by the opposite canyon sidewall. Simpson et al. (2013) investigated the fire spread on a leeward mountain slope using four different WRF-Fire simulations. The simulations used two fuel types were used and were conducted with both coupling and non-coupling of the fire and atmosphere. Results showed that for each case, the fire spread was initially predominantly upslope, but when the fire reached the ridge top, the fire spread was halted by the cross-ridge winds, and forced to spread laterally across the slope. Simpson et al. (2014) called this fire spread phenomenon vorticity-driven lateral fire spread (VLS) and hypothesized that it was caused as a result of vorticity that formed in the lee of the ridge line. 
In this chapter, the results of the micrometeorological observations will be described. Analysis of in situ sonic anemometer data will be conducted and compared to video imagery and Doppler lidar observations made during the experiment. First, data obtained during the FFP at each of the three towers will be explored followed by other observations of unique events that occurred.

\subsection{Data Processing}

To determine the influence of terrain-induced winds on the fire as it spreads up the hillside, data from each sonic anemometer were rotated into a slope-valley coordinate system (Fig. 18). The valley component of the wind is represented by $u$, where $+u$ is directed up valley and $-u$ is down valley. The v-component is aligned along the slope, where $+v$ is towards the slope and $-v$ is away from the

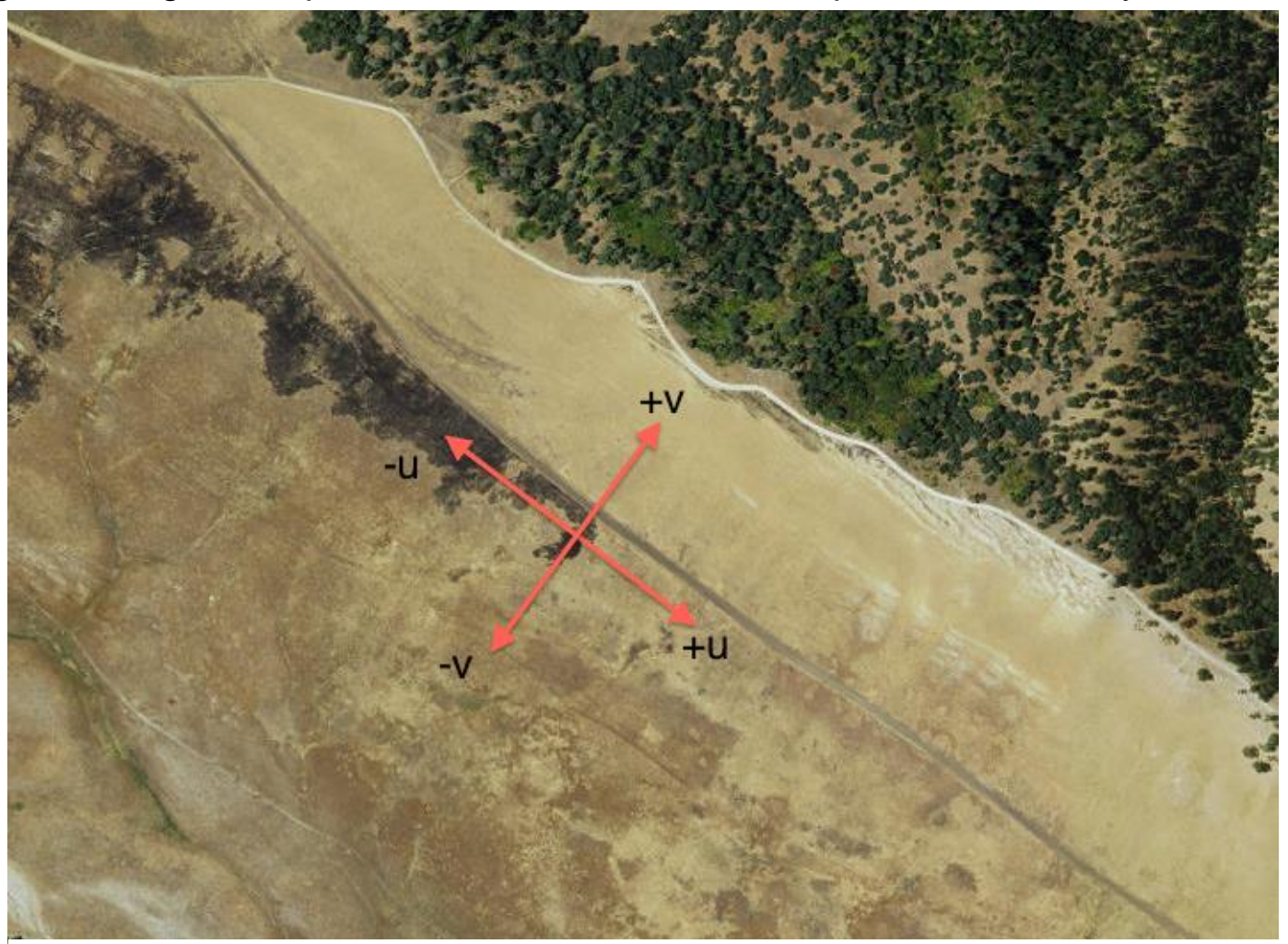

Fig. 18. Slope-valley wind coordinate system 
slope. The vertical velocities are the w-component of the wind. All vertical velocities were tilt-corrected following Wilczak et al. (2001) to eliminate any imprecise leveling of the sonic anemometer. All sonic data were run through a despiking routine to remove any spurious data associated with noise (Lee et al 2004.). Despiking removed data points that exceeded four standard deviations from the mean within a 2-minute moving data window. Any data points that were removed were replaced with linearly interpolated values. Unrealistic spikes during FFP were visually inspected as the turbulent nature of the atmosphere during FFP often causes rapid fluctuations and spikes in wind velocities.

From the despiked and tilt-corrected $10 \mathrm{~Hz}$ data, each variable was then separated into mean and perturbation parts as follows:

$$
\begin{array}{ll}
\mathrm{u}=\overline{\mathrm{u}}+\mathrm{u}^{\prime} & \mathrm{v}=\overline{\mathrm{v}}+\mathrm{v}^{\prime} \\
\mathrm{w}=\overline{\mathrm{w}}+\mathrm{w}^{\prime} & \mathrm{T}=\overline{\mathrm{T}}+\mathrm{T}^{\prime}
\end{array}
$$

where the overbar denotes the mean and the prime denotes the perturbation. The mean was calculated from a 10 minute moving window and subtracted from the instantaneous values to obtain the perturbations.

For temperature perturbations, values collected during the FFP at each tower were removed from the time series. Had temperature data collected during FFP been left in, the temperature mean would have increased by approximately $3^{\circ} \mathrm{C}$. This would have lowered values of temperature perturbations and flux estimates.

Sensible heat flux and turbulent kinetic energy (TKE) were calculated from each time series data set. Sensible heat flux $\left(\mathrm{H}_{\mathrm{s}}\right)$ can be represented by 


$$
\mathrm{H}_{\mathrm{s}}=\rho \mathrm{C}_{\mathrm{p}} \overline{\mathrm{w}^{\prime} \mathrm{T}^{\prime}}
$$

where $\rho$ is air density, $C_{p}$ is heat capacity of dry air at constant pressure, and $\overline{\mathrm{w}^{\prime} \mathrm{T}^{\prime}}$ is the covariance between the vertical velocity and sonic temperature perturbations.

TKE is a measure of the total kinetic energy per unit mass contained within turbulent eddies in the atmosphere. It is equal to one half the sum of the three velocity variances.

$$
\frac{\mathrm{TKE}}{\mathrm{m}}=\frac{1}{2}\left[\overline{\mathrm{u}^{\prime 2}}+\overline{\mathrm{v}^{\prime 2}}+\overline{\mathrm{w}^{\prime 2}}\right]
$$

An analysis of turbulence spectra was also performed on the wind velocities for each of the three towers before, during, and after FFP. The analysis used a Morlet wavelet function to determine the spectral density of the turbulence across frequencies (Torrence and Compo 1998).

\subsection{Fire Front Passage}

\subsubsection{D Wind and Sonic Temperature}

Individual components of the wind velocity were plotted (Fig. 19) to show the magnitude of each over the hour that the experiment was conducted. Before ignition, between 11:00:00 to 11:18:00 PDT, both $u$ and $v$ values can be seen trending between -3 and $4 \mathrm{~m} \mathrm{~s}^{-1}$ at the middle and top towers. The bottom tower observed a sharp reversal of the $u$ and $v$ values at 11:16:00 PDT, and then calmed to near $1 \mathrm{~m} \mathrm{~s}^{-1}$. The vertical velocity values at each tower were near 
(a)

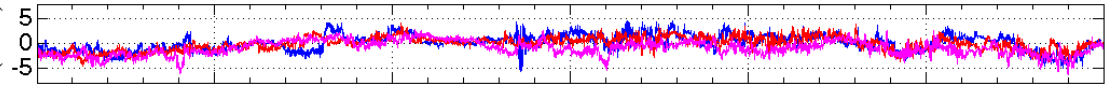

(b)
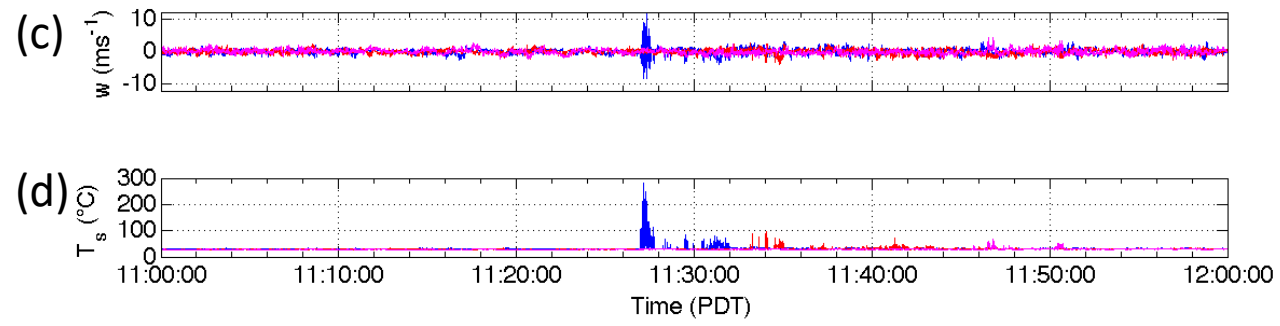

Fig. 19a-d. Time series of $u, v$, and $w$ velocities, as well as sonic temperature for the bottom tower (blue), middle tower (red), and top tower (magenta).

$0 \mathrm{~m} \mathrm{~s}^{-1}$ and showed no trend. The average ambient temperature for this time period was $30^{\circ} \mathrm{C}$.

Fire-induced winds began with the arrival of the fire front at the bottom tower at 11:27:00 PDT. The maximum sonic temperature during this FFP was $287^{\circ} \mathrm{C}$. The temperature then decreased to ambient levels as the fire passed the bottom tower. Four minutes after the fire had passed, periods of high temperature were again observed, which will be discussed later. Within the plume, vertical velocity reached a maximum of $11.1 \mathrm{~m} \mathrm{~s}^{-1}$ at the bottom tower during the FFP.

Wind velocities during FFP at the middle tower were substantially weaker in magnitude than those that occurred at the bottom tower. The FFP at the middle tower occurred at 11:34:00 PDT. The maximum sonic temperature at this tower was $95.2^{\circ} \mathrm{C}$. Negative vertical velocity values during FFP indicate that strong downdrafts occurred at a time when rising motion was expected. 
The FFP at the top tower occurred at 11:46:00 PDT, and at this time the fire had become a weak backing fire. The temperature of this FFP was the lowest of the three towers, reaching only $58.2^{\circ} \mathrm{C}$. The maximum vertical velocity during FFP at the top tower was $4.17 \mathrm{~m} \mathrm{~s}^{-1}$.

The ambient winds from two RAWS, set up on the perimeter of the burn plot, were analyzed to understand FFP variability at each tower. One RAWS was placed on the ridge above the burn plot and the other in the valley near the ignition line. The mean wind was light and variable during the course of the experiment as shown by the wind speed and direction (Fig. 20). From 11:15:00 PDT to 12:00:00 PDT, the wind speeds at both RAWS did not exceed $3 \mathrm{~m} \mathrm{~s}^{-1}$. The wind directions, while mostly easterly, tended to oscillate between north and south from 11:00:00 PDT through 11:30:00 PDT at both sites. These winds were the cause of the irregular fire behavior that occurred during the first half of the

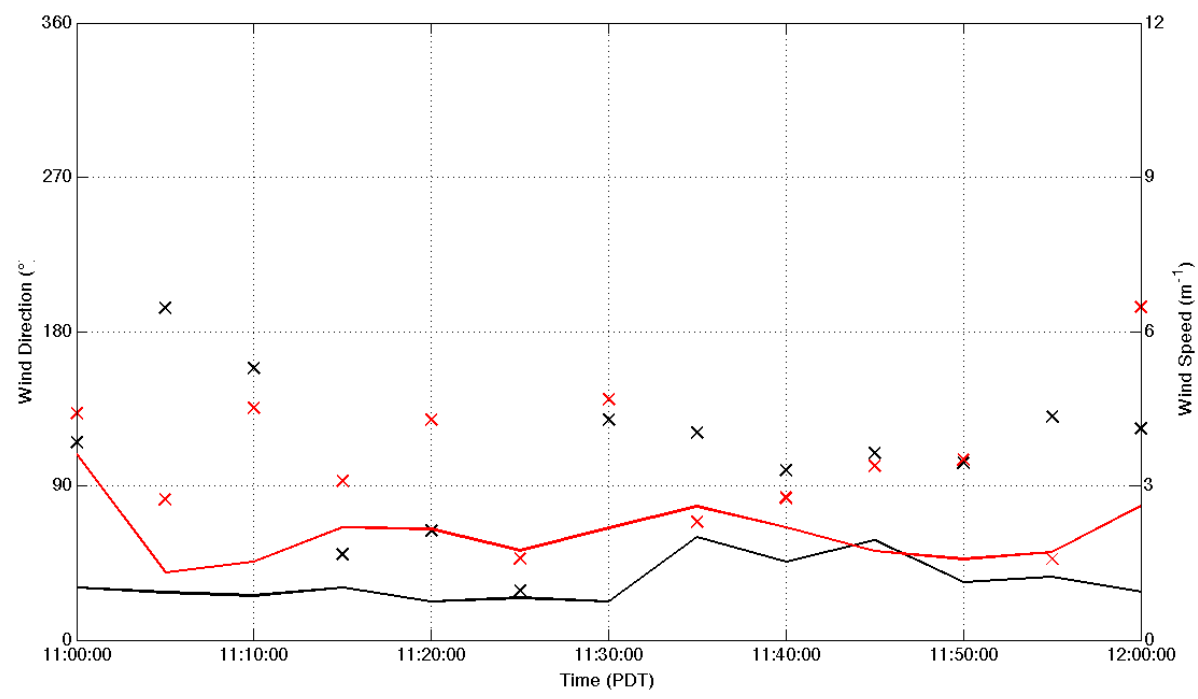

Fig. 20. Five minute averaged two meter wind speed at RAWS located in the valley (red) and ridge (black). 
experiment. From 11:30:00 PDT onward, the wind direction became more easterly at both RAWS, indicating that wind was coming over the ridge. This caused the backing fire behavior that was observed during the second half of the burn.

\subsubsection{Turbulence and Sensible Heat Flux}

Using the radiative heat flux plotted in Fig. 21, the period of FFP can be determined for the bottom and middle towers. For the bottom tower, FFP began at 11:27:00 PDT. The residence time of the fire was approximately 1 minute and the FFP ended at 11:28:00 PDT. Elevated values of radiative heat flux continued until 11:32:00 PDT.

The ambient micrometeorological conditions were vastly different than those during FFP. For example, ambient levels of TKE ranged from 1 to $3 \mathrm{~m}^{2} \mathrm{~s}^{-2}$, but during the FFP, when the fire passed the tower, TKE reached a maximum value

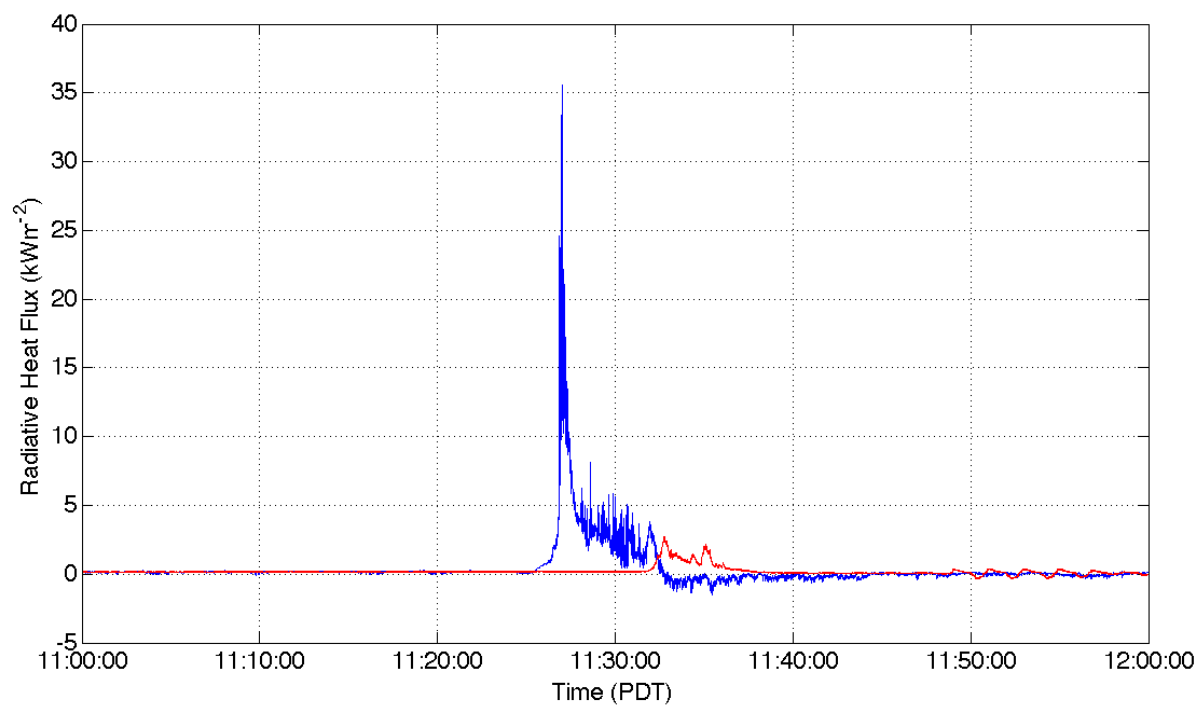

Fig. 21. Radiative heat flux measured at the bottom (blue) and middle (red) towers. 
of $23 \mathrm{~m}^{2} \mathrm{~s}^{-2}$ (Fig. 22a). This increase was the result of fire-induced winds being driven by the convective buoyancy above the fire front. Similarly, $\mathrm{H}_{\mathrm{s}}$ reached a maximum of $330 \mathrm{~kW} \mathrm{~m}{ }^{-2}$ as the fire front passed, whereas ambient $\mathrm{H}_{\mathrm{s}}$ before the FFP was observed to be between -3 and $3 \mathrm{~kW} \mathrm{~m}^{-2}$.

To better understand which variance component dominated the TKE, a time series of variance for each velocity component, Fig. $22 \mathrm{~b}$, is presented. From this figure, it can be seen that the magnitude of vertical velocity variance during the FFP was roughly 1.5 times greater than either $u$ or $v$ components. It can also be seen that during the initial 20 seconds of FFP, the $v$ and $w$ velocities increased much sooner than the $u$ velocities. This was most likely the result of horizontal

(a)

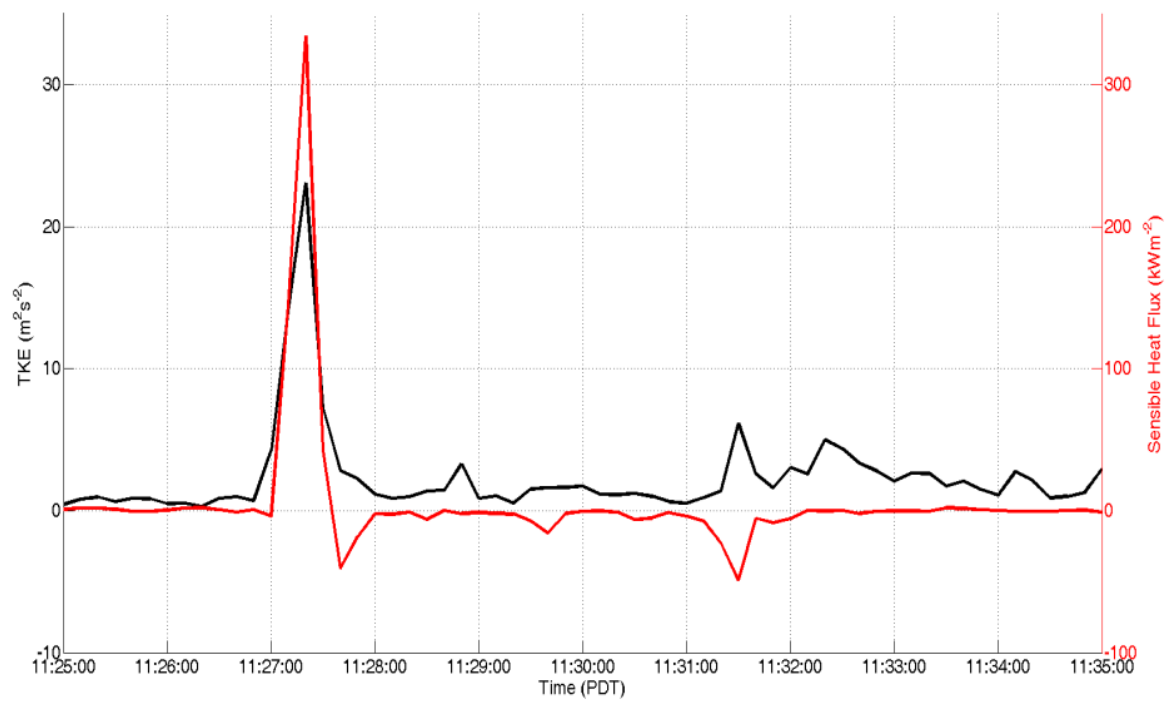

(b)

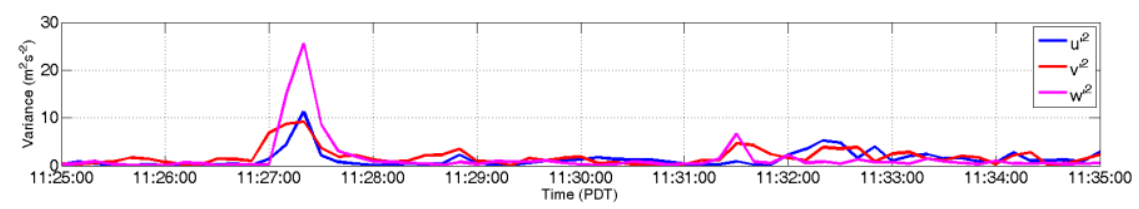

Fig. 22. (a) shows the TKE and $\mathrm{H}_{\mathrm{s}}$ observed at the bottom tower during FFP. (b) shows the velocity variances at the bottom tower during the same time frame. 
shear generated near the boundary of the convectively buoyant plume. Because the fire front was nearly parallel to the ridge top during the FFP at the bottom tower, the $\mathrm{u}$-component of the wind remained weaker as the fire approached. The u-component of the wind increased only as the fire passed the tower, which was the result of turbulence within the plume and fire-induced circulations that resulted from instabilities in the plume.

Lidar measurements of backscatter and radial velocity during the FFP at the first tower are shown in Fig. 23a. The data were processed following the techniques outlined by Charland and Clements (2012). Black contour lines of backscatter show the boundaries of the smoke column. These agree well with the aerial video imagery captured at the same time (Fig. 23b). Figure 23b indicates that the the smoke column became more vertical as the fire passed the bottom tower. The radial velocities measured by the lidar may help explain the cause of the upright plume. Southwesterly winds, areas colored yellow through red, were observed on the valley side of the plume, whereas northeasterly winds were observed on the ridge side. These two winds converged and the winds near the plume weakened causing the plume to become more upright, rather than being tilted over in the wind.

After the FFP had occurred at the bottom tower, several instances of negative $\mathrm{H}_{\mathrm{s}}$ were observed. The first negative value, approximately $-45 \mathrm{~kW} \mathrm{~m}^{-2}$, occurred directly after the maximum $\mathrm{H}_{\mathrm{s}}$ was reached during FFP. The interpretation of the negative heat flux is that warmer air was transported downward to the surface 
(a)

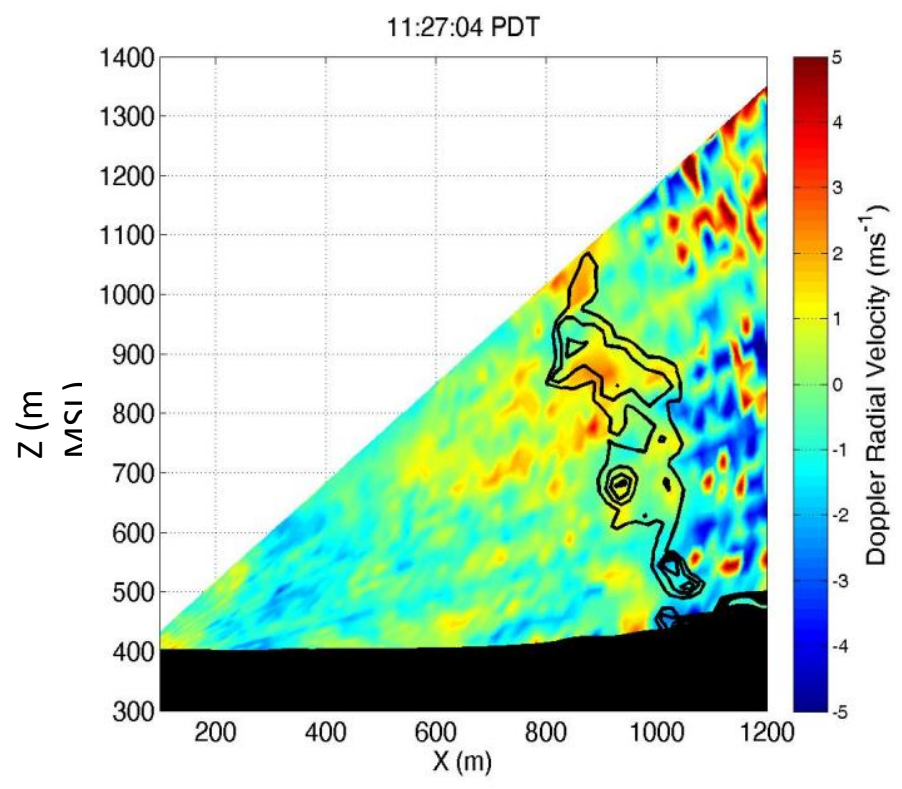

(b)

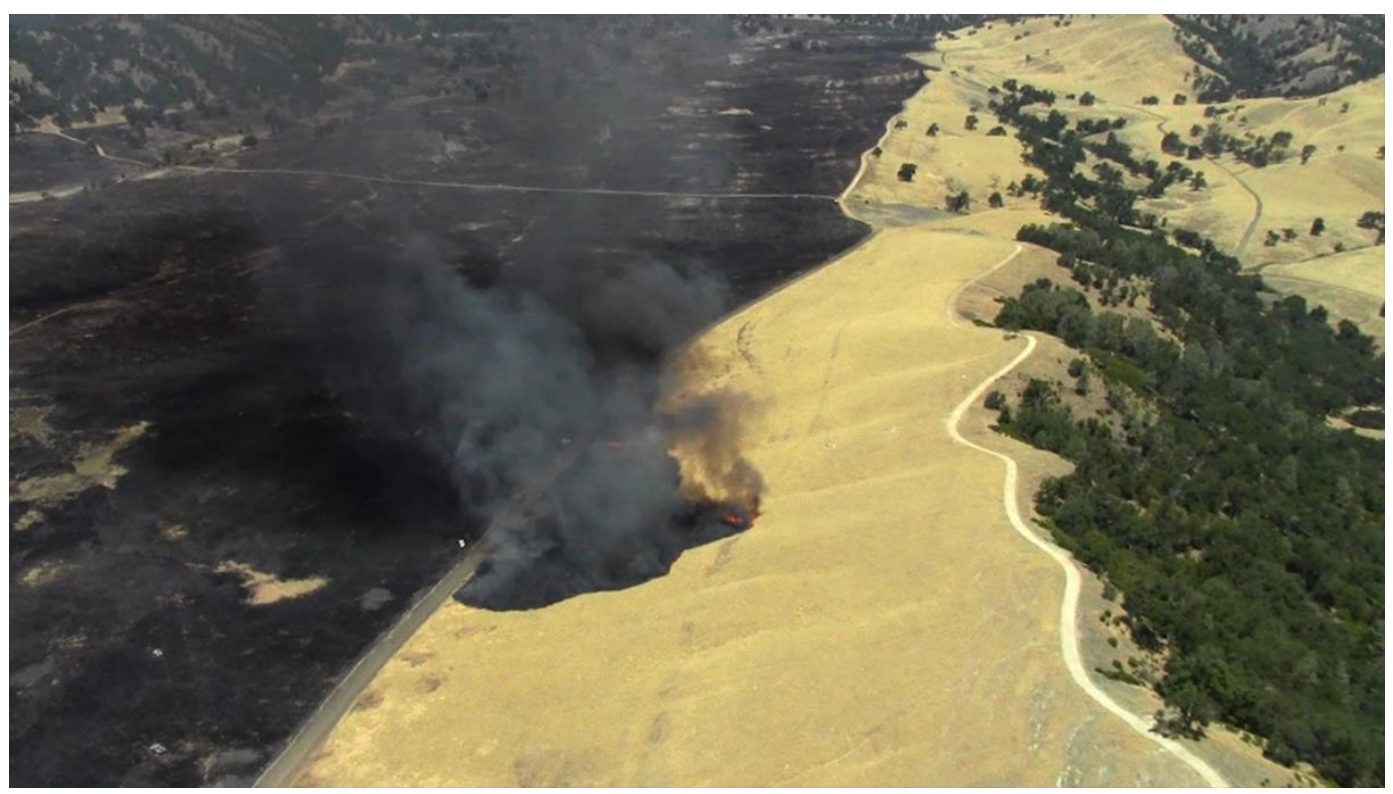

Fig. 23. (a) RHI scan performed by the Doppler lidar during the FFP at the bottom tower. Warmer colors represent southwesterly wind, cooler colors are northeasterly. (b) corresponding aerial photograph.

from aloft. Following the FFP, three weaker instances of negative $\mathrm{H}_{\mathrm{s}}$ occurred, ranging from -10 to $-20 \mathrm{~kW} \mathrm{~m}^{-2}$. Then at 11:31:30 PDT a second period of negative $\mathrm{H}_{\mathrm{s}}$ occurred which had a value of $-50 \mathrm{~kW} \mathrm{~m} \mathrm{~m}^{-2}$. The negative value of $\mathrm{H}_{\mathrm{s}}$ 
indicates that heated air was sinking at this time. An associated increase in TKE at this time was composed of elevated values in the $v$ and $w$ velocity variances. Since FFP had already occurred at the bottom tower, these observations would suggest a downslope wind was present and was transferring heat downslope through the array of instruments on the bottom tower.

At the middle tower, the FFP began at 11:34:00 PDT and lasted for approximately 1.33 minutes (Fig. 24). At this time in the experiment, downslope winds had caused the fire to become a low intensity backing fire. As a result, the spread rate decreased, leading to an extended period of FFP at the middle tower.

(a)

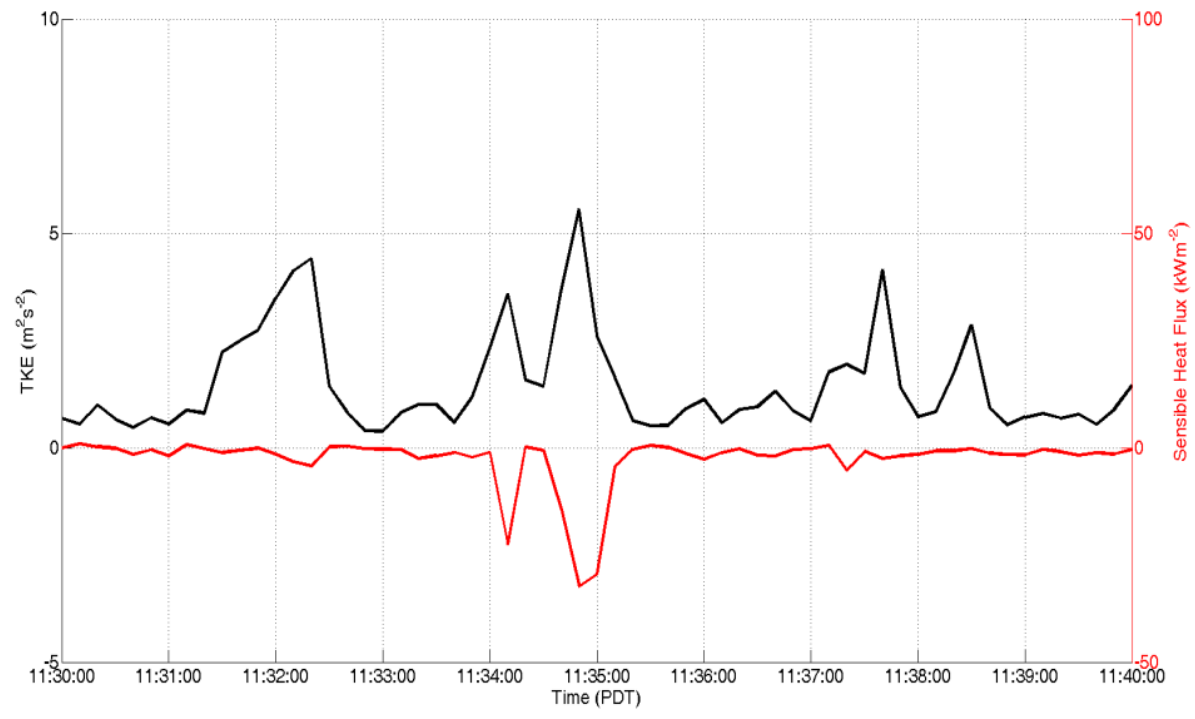

(b)

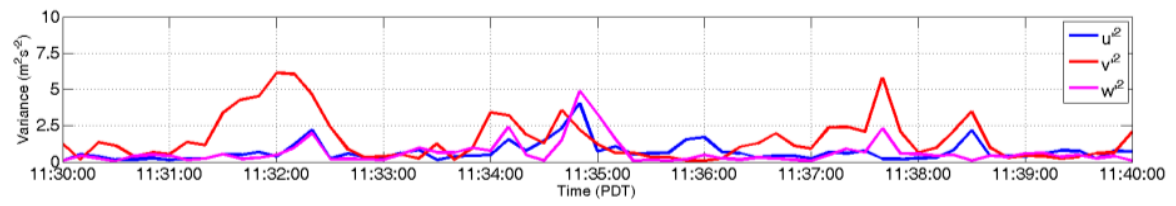

Fig. 24. (a) shows the TKE and $\mathrm{H}_{\mathrm{s}}$ observed at the middle tower during FFP. (b) shows the velocity variances at the middle tower during the same time frame. 
No increase in $\mathrm{H}_{\mathrm{s}}$ was observed during the FFP at the middle tower, rather a value of $-35 \mathrm{kWs}^{-2}$ was observed. This would suggest that heat was being transported downslope.

The magnitude of the TKE and $\mathrm{H}_{\mathrm{s}}$ at the middle tower was substantially less than that of the bottom tower. During FFP, the maximum TKE was measured to be $5.7 \mathrm{~m}^{2} \mathrm{~s}^{-2}$, a value of $17.3 \mathrm{~m}^{2} \mathrm{~s}^{-2}$ less compared to the bottom tower. The velocity variances during the FFP show roughly equal values, indicating that the TKE was not driven by any specific component of the wind.

Lidar and aerial imagery during the FFP at the middle tower, Figs. 25a and $25 \mathrm{~b}$, provide better detail to the changes in the wind that occurred on the slope. It can be seen in the lidar velocities that the wind over the plot had changed to a northeasterly wind, replacing the southwesterly winds that existed during FFP at the bottom tower. This caused dramatic decrease in the fire behavior, marked by the significant decrease in $\mathrm{H}_{\mathrm{s}}$ from the bottom tower to the middle tower. These strong northeasterly winds forced air down the slope and tilted the smoke column over the valley, as shown in both lidar data and aerial imagery.

In Fig. 24, several additional peaks in TKE were observed where no increase in $\mathrm{H}_{\mathrm{s}}$ was found. These TKE peaks occured during changes in the wind direction on the hillside. The elevated values of TKE, beginning at 11:31:30 PDT, were associated with a change in v-component velocities, as can be seen in the high level of v'. Two higher TKE values were observed post FFP at 11:37:40 and 11:38:30 PDT. At each of these times, v' contributed a large portion to the TKE. 
(a)

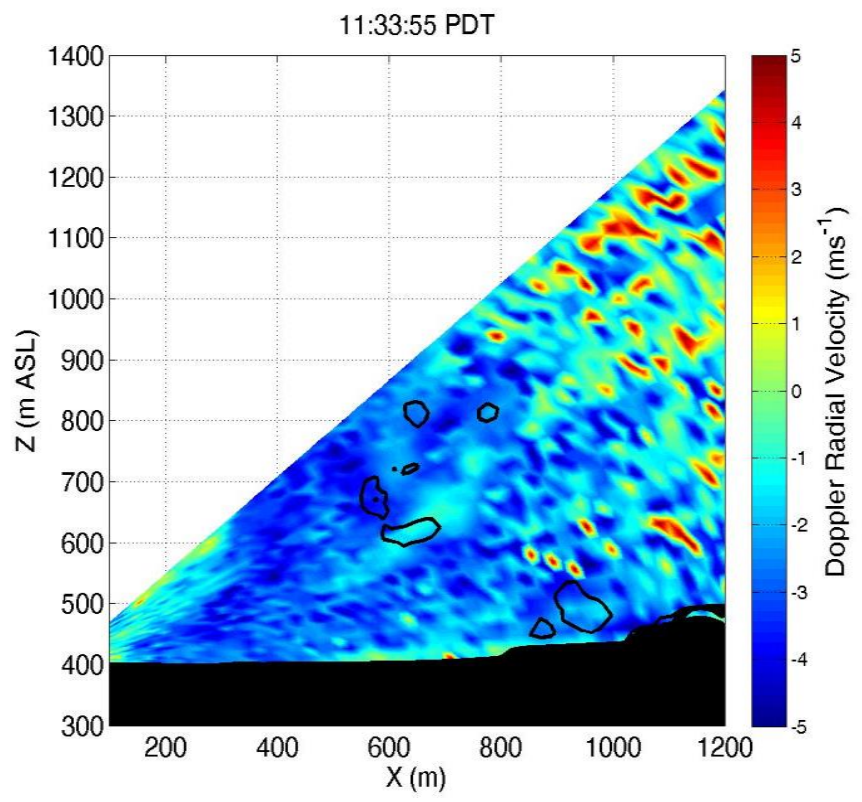

(b)

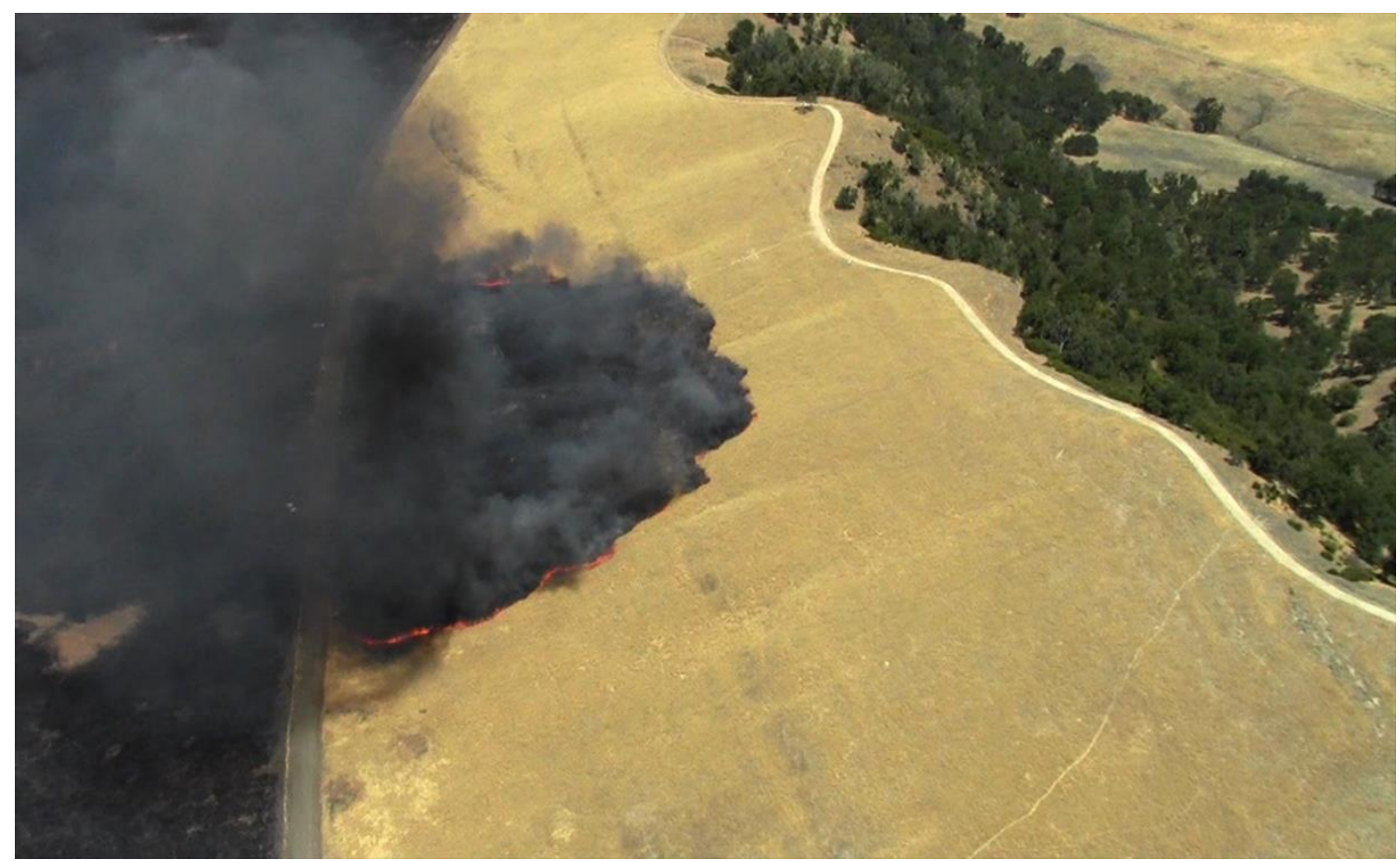

Fig. 25. (a) RHI scan from the Doppler lidar taken during FFP at the middle tower. Warmer colors represent southwesterly wind, cooler colors are northeasterly. (b) corresponding aerial photograph.

The TKE at 11:37:40 PDT also contained a large portion of w', which indicates that the wind was following the terrain. The TKE at 11:38:40 PDT had higher 
values of u', signaling a cross-slope wind, not necessarilly following the terrain.

At the tower nearest the top of the hillside, the low intensity backing fire continued. FFP at the top tower began at 11:46:30 PDT. The maximum $\mathrm{H}_{\mathrm{s}}$ observed during the FFP was $24.9 \mathrm{~kW} \mathrm{~m}^{-2}$ (Fig. 26a). The TKE observed during the same time was not substantial enough to be distinguishable from ambient conditions without comparing it with Hs.

During the FFP, maximum observed TKE was $3.9 \mathrm{~m}^{2} \mathrm{~s}^{-2}$. The velocity variances at the top tower (Fig. 26b) show that, at the time of FFP, the primary wind components contributing to TKE were the $u$ and $w$ wind velocities.

(a)

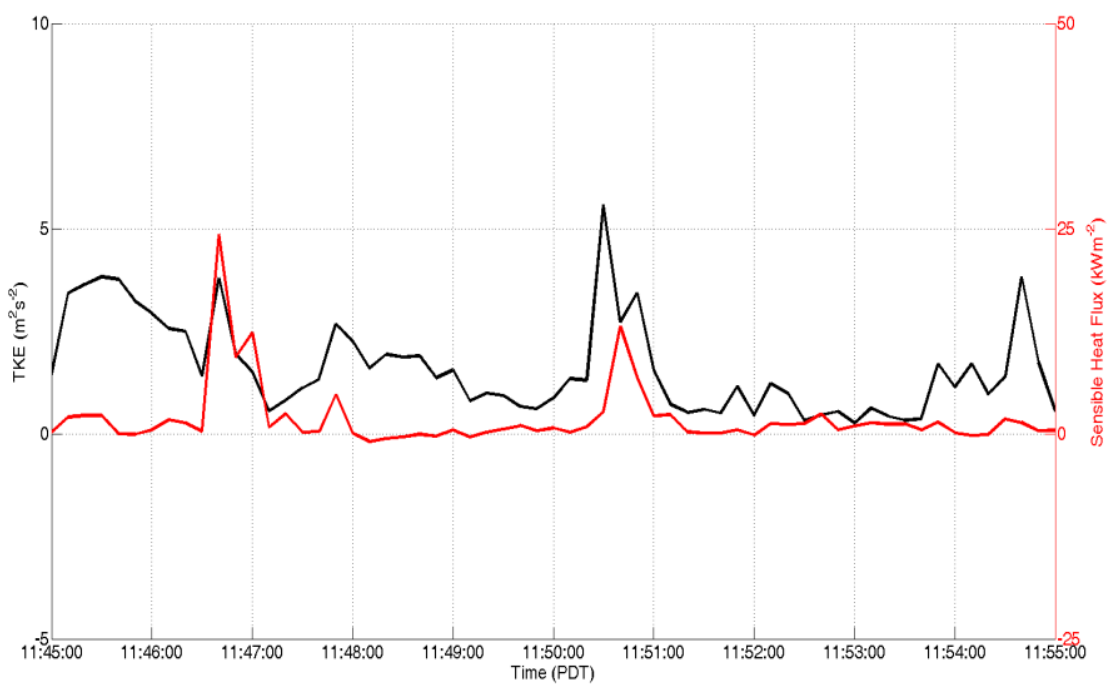

(b)

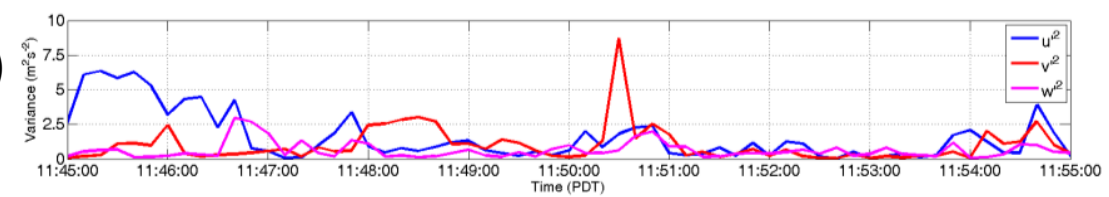

Fig. 26. (a) shows the TKE and $\mathrm{H}_{\mathrm{s}}$ observed at the top tower during FFP. (b) shows the velocity variances at the top tower during the same time frame. 
Several additional peaks in TKE are also seen in Fig. 26a. At 11:50:30 PDT, TKE measured $5.7 \mathrm{~m}^{2} \mathrm{~s}^{-2}$ and $\mathrm{H}_{\mathrm{s}}$ measured $13.6 \mathrm{~kW} \mathrm{~m}^{-2}$. By this time, the fire had passed the tower and was located at a slightly higher position on the slope. The cause of these elevated values of TKE and $\mathrm{H}_{\mathrm{s}}$ can be seen in Fig. 19b. During the time period from 11:50:00 to 11:51:00 PDT, a sharp decrease in the $v$ wind component was observed, indicating that a strong northeasterly gust had occurred. This corresponds with the maximum in the v velocity variance, seen in Fig. 26b.

Video imagery from the 11:49:00 to 11:52:00 PDT time period, shown in Fig. 27, indicates that smoke was being advected downslope at 11:51:00 PDT. Since air is shown to be sinking downslope, and the sensible heat flux during the period shows positive values, cool air sinking downslope was also considered a possibility. This combination would also yield a positive heat flux. For this reason,

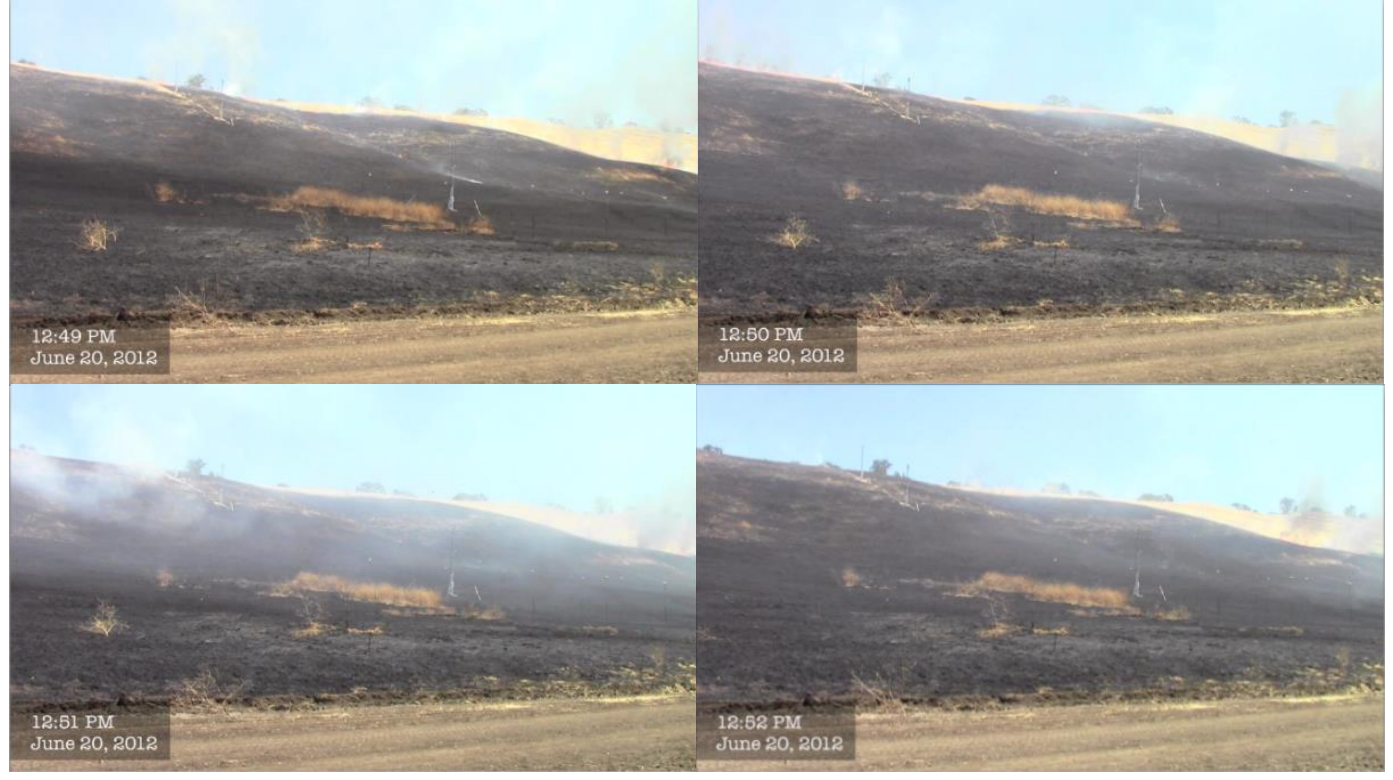

Fig 27. Four photos taken in 1 minute intervals depicting the downslope wind dispersing the smoke down the slope. 
time series plots of T' and w' are shown in Fig. 28. From these figures, it can be seen that elevated values of T' correspond to positive values of $w^{\prime}$ in the period just prior to the downslope wind at 11:51:00 PDT. This agrees with the positive values of sensible heat flux seen in Fig. 26a during the same period.

Momentum fluxes (Fig. 29) during the downslope wind period show how momentum shifted through the three wind velocity components. One issue with momentum fluxes presented in time series is that positive values can occur when both momentum diviations are positive or both negative. Negative momentum fluxes can occur when one variable is positive and the other negative, or vice versa. For this reason, vertical velocity deviations seen in Fig. $28 \mathrm{~b}$ can be used to interpret the positive and negative values of the momentum fluxes. It can be seen that until 11:50:00 PDT, no significant momentum fluxes occur (Fig. 29). Just after 11:50:00 PDT, a slight transfer of momentum occurred between the
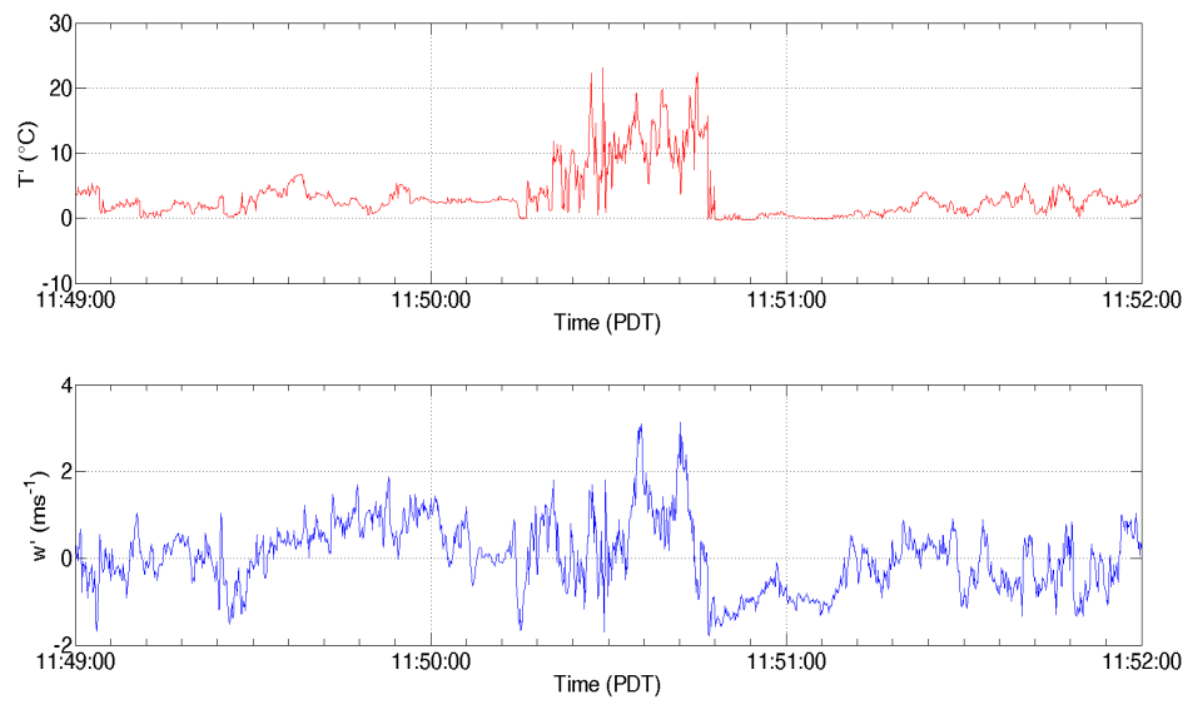

Fig. 28. Perturbation time series of sonic temperature (a) and vertical velocity (b) from the top tower during a downslope wind. 

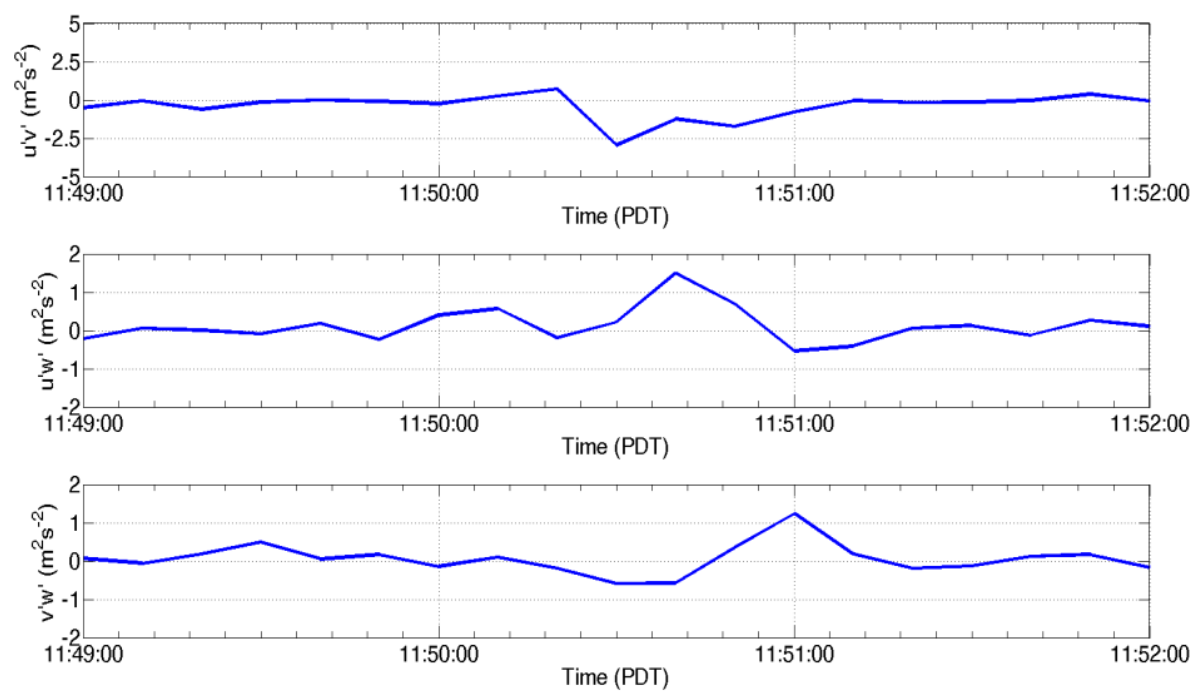

Fig. 29. Time series of momentum flux for (a) horizontal winds, (b) slope winds, and (c) cross-slope winds.

positive $u$ and $w$ velocities. At 11:50:30 PDT, the $u^{\prime} v$ ' momentum flux reaches a maximum value, as momentum was shifted from a positive valley flow to a negative slope flow. Also at this time, the $v$ velocity variance reaches a maximum. This was the mechanism for the smoke column being driven back down the slope, causing the temperature perturbations to increase (Fig. 28a). As this occurred, convective pulses caused positive deviations in the vertical velocities (Fig. 28b).

The most signifiant part of this event was the reversal of the vertical velocities occuring at 11:50:45 PDT. This also caused a change of sign in the v' $w^{\prime}$ momentum flux from negative to positive. This suggests that the $v$ velocites remained negative for the duration of the event. While w' can be seen decreasing at 11:51:00 PDT, v'w' reaches a maximum value, indicating the $v$ values must 
have become more negative. This result indicates that the downslope wind transported smoke from the top of the ridge down into the valley (Fig. 27c).

\subsubsection{Turbulence Spectra}

Energy contained within turbulence is transported from larger eddies to smaller eddies where it is dissipated (Šavli 2012). Šavli went on to show that large eddies tend to be more intense than smaller eddies. And because the larger eddies are more intense, they are capable of generating shear, thus creating smaller eddies. An in depth analysis of turbulence spectra associated with fire was performed on datasets from four field campaigns by Seto et al. (2013). Their analysis of the horizontal velocity spectra showed that increases at mid to high frequencies was most likely attributable to eddies shedding off of the fire rather than ambient wind shear. The vertical velocity spectra increased across all frequencies during FFP and the observed temperature spectra was described as "white noise", as it failed to follow the $-2 / 3$ inertial subrange slope (Kolmogorov, 1941) in the higher frequencies.

The turbulence spectra for this campaign was separated into $\mathrm{u}, \mathrm{v}$, and $\mathrm{w}$ wind velocities, as well as temperature (Figs. 30a-d). The velocity spectra were normalized using friction velocity. The spectra are compiled from data encompassing 9 minutes prior to and after the time of maximum temperature, which represents the time of FFP. The 9 minute period was used because of the extended duration of the FFP at the middle and top towers where the rate of spread had decreased. 
(a)

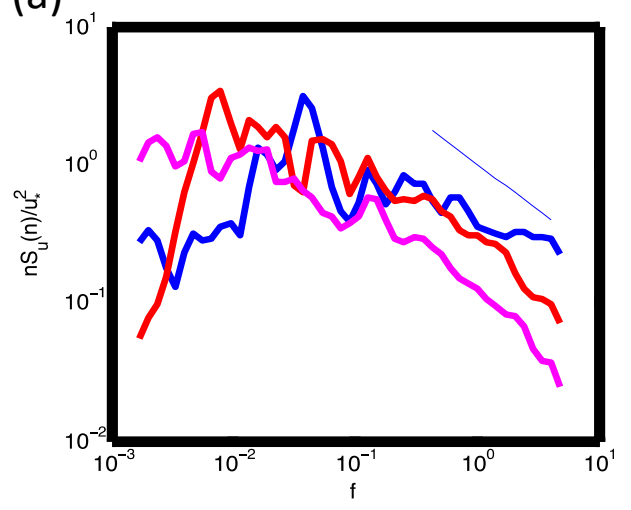

(c)

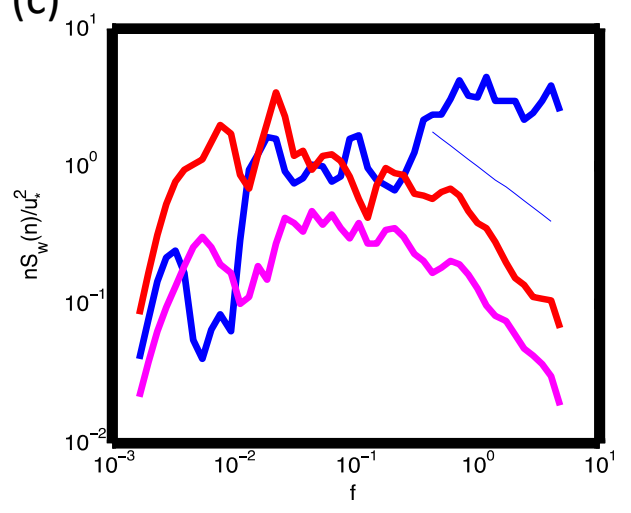

(b)

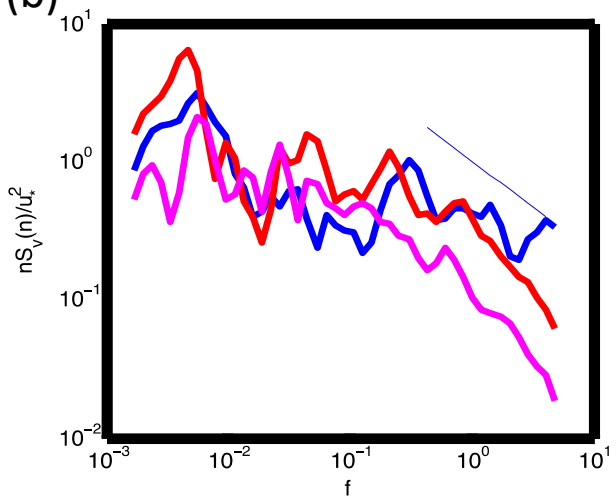

(d)

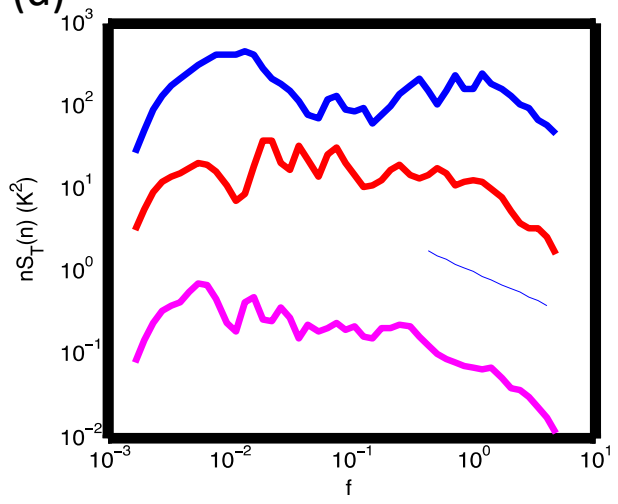

Fig. 30. Normalized power spectra during fire front passage at each tower for (a) u, (b) v, and (c) w wind velocities, as well as (d) sonic temperature. The bottom tower is in blue, middle in red, top in magenta.

The u spectra are shown in Fig. 30a. The most notable features of these spectra are the low frequencies, where the spectra at the bottom tower is significantly lower than the other towers. Because the two upper towers were exposed to the northeasterly wind above the ridge, they experienced a higher level of wind shear, which elevated the lower frequency spectra.

The $v$ spectra is shown in Fig. 30b. The v spectra of each tower at FFP were fairly uniform with one another. Like the u spectra, much higher values were obtained in the lower frequencies, indicating that larger eddies and wind shear 
were more dominant than the smaller eddies associated with the fire. A significant increase in v velocity spectra was observed near $0.3 \mathrm{~Hz}$ at the bottom tower during FFP, which was also found in the u spectra (Fig. 30a).

The vertical velocity spectra (Fig. 30c) displays the best example of the difference between high and low intensity fire induced turbulence generation. Higher intensity fire was observed at the bottom tower, while lower intensity was observed at the middle and top towers. The turbulence spectra at the bottom tower reached the highest values in the frequencies greater than $0.3 \mathrm{~Hz}$. For frequencies greater than $1 \mathrm{~Hz}$, the energy associated with turbulence generated by the fire front was a whole order of magnitude larger than that observed during the lower intensity FFP.

\subsection{Summary}

The evolution of the fire spread can be better understood from the analysis of the micrometeorological observations made at different location along the slope. The maximum observed intensity occurred as the fire passed the bottom tower where the slope was nearly flat with little inclination. Lidar data at this time showed light southwesterly upslope winds and a nearly vertical smoke plume. As the fire progressed upslope and passed the middle tower, lidar observations revealed a strong reversal of the wind to a northeasterly downslope wind. This slowed the forward spread of the fire and substantially weakened its intensity. At this time, negative values of sensible heat flux were observed. This indicates that heat and plume air were being transported downslope by the northeasterly winds 
above the ridge. The low intensity backing fire continued slowly spreading up the slope as it passed the top tower where the lowest heat fluxes and minimal fireatmosphere coupling were observed.

\section{Chapter 5 - Vorticity Estimation and Fire Whirls}

\subsection{Introduction}

Vorticity is described as the spin of air in the atmosphere about some axis, vertically or horizontally. It is typically generated baroclinically, by shear stress, or by body forces. Each of these three types of vorticity generation can be observed in the atmosphere surrounding a wildfire (Forthofer and Goodrick, 2011). Baroclinic vorticity is generated when the extreme temperature gradient between the plume of the fire and the ambient air creates an imbalance with the vertical static pressure gradient. The vorticity that is generated by this imbalance acts to mix cool and warm air in an attempt to return the atmosphere to a static state. Shear vorticity is generated by varying wind speeds. At the surface, this occurs primarily due to frictional drag.

Vorticity can be modified via transport, axial tilt, or stretching. Fire whirls provide the best example for each of these modifications. For a whirl to form, either vertical vorticity needs to be stretched or horizontal vorticity needs to be tilted vertically and stretched. Stretching occurs as a result of vorticity advection across the fireline. The intense vertical momentum provided by the buoyant air stretches the vorticity and increases the rotational momentum. 
Unique fireline geometry has also been found to be beneficial to fire whirl development. Numerical modeling has revealed that an L-shaped pattern in the fireline can be associated with fire whirls and rapid fire spread (Forthofer et al. 2007). The results from the model run corresponded well with the observations made when this L-shaped pattern was recreated in a wind tunnel (Kuwana et al. 2013). Kuwana et al. showed that fire whirls forming in the bend of the L-shape require a critical wind velocity that is dependent on the heat release rate and dimensions of the fire.

A vorticity budget for fire-atmosphere interactions could prove useful in understanding vorticity dynamics in and around the fireline. With this study, vorticity was estimated from two sonic anemometers to examine a period in which fire spread rapidly intensified.

\subsection{Data Processing}

Vorticity was estimated from the sonic anemometers located on each of the towers. Vorticity measurements utilizing sonic anemometers have been performed previously by Ohtou et al. (1983), who studied vertical transport of vorticity at the surface. Traditionally, calculating horizontal vorticity requires four points in space. But with only two sonic anemometers, an estimation could be made using the equation

$$
\omega=\frac{\Delta \mathrm{w}}{\Delta \mathrm{y}}-\frac{\Delta \mathrm{v}}{\Delta \mathrm{z}}
$$

where $\Delta \mathrm{w}$ is the change in vertical velocity, $\Delta \mathrm{y}$ is the horizontal distance between the two towers, $\Delta \mathrm{v}$ is the change in the v-component of the wind, and $\Delta \mathrm{z}$ is the 
change in height between the two towers. Since the towers were georeferenced, the difference in their elevation and the distance between them was known. By differencing the change in vertical velocity over the change in distance and the change in slope velocity over the change in elevation, the horizontal vorticity parallel to the slope was estimated.

\subsection{Description of event}

10 minute averaged data from a sodar (Fig. 31) shows that weak southerly winds were present below $50 \mathrm{~m}$ for at least an hour, leading up to the formation of the L-shape in the fireline. The L-shape began to materialize at approximately 11:27 PDT.

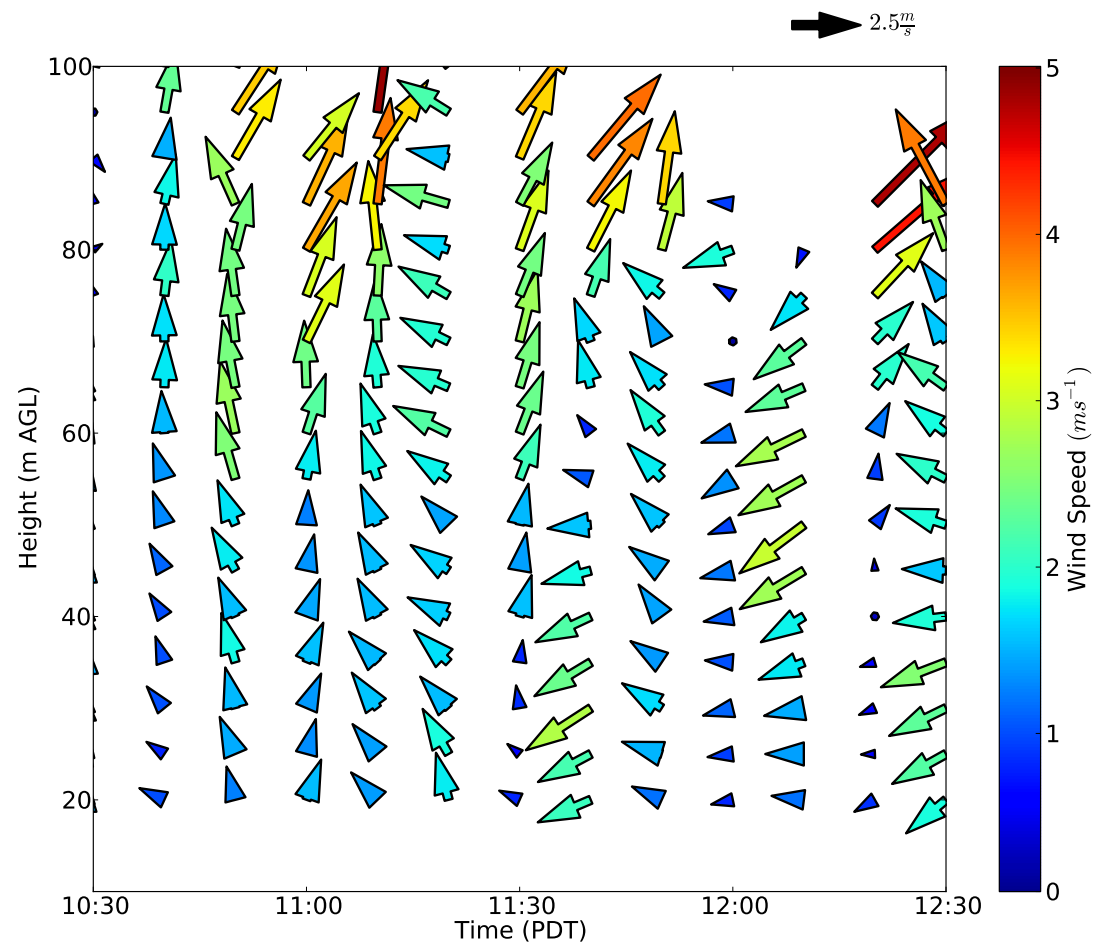

Fig. 31. 10 minute averaged sodar wind profile observed near the valley center. 
The L-shaped fireline formed as a result of opposing winds near the surface on the hillside. A northeast flow caused winds to blow downslope over the western portion of the burn plot and caused a backing fire. In the eastern region of the burn plot, an upslope wind formed the head of the fire. Fig. 32a is a photo of the L-shape in the fireline that resulted from the two wind patterns over the burn plot. The photo was taken just prior to the formation of the fire whirl seen in Fig. 32b.

At 11:31:30 PDT, the wind suddenly shifted to a northeasterly direction. This shift was observed in the 10 minute averaged sodar data at 11:40 PDT in Fig. 31. The interaction between the northeasterly wind and the fire front caused a fire whirl to develop in the bend of the L-shape. This dramatically increased the spread rate of the fire towards the northwest.

Fig. 33 shows 1 minute contours of fireline locations. The L-shape is clearly
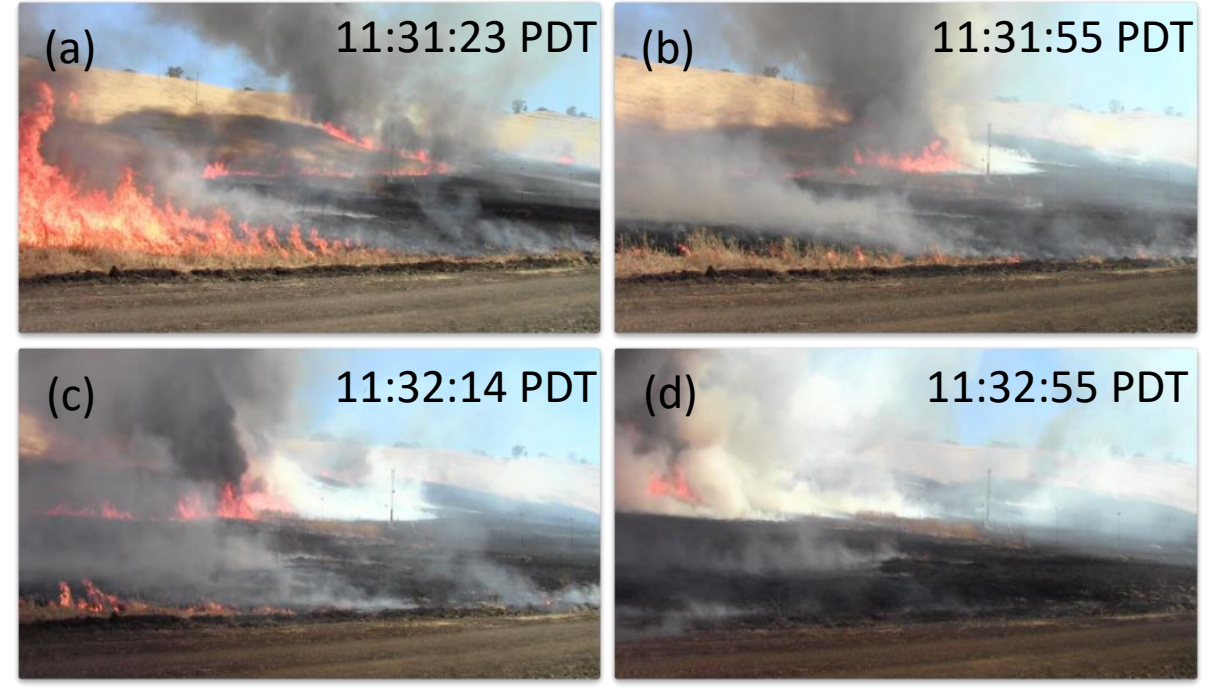

Fig. 32a-d. A series of photos depicting an L-shaped fireline, a fire whirl, and the resulting rapid increase in the rate of spread. 


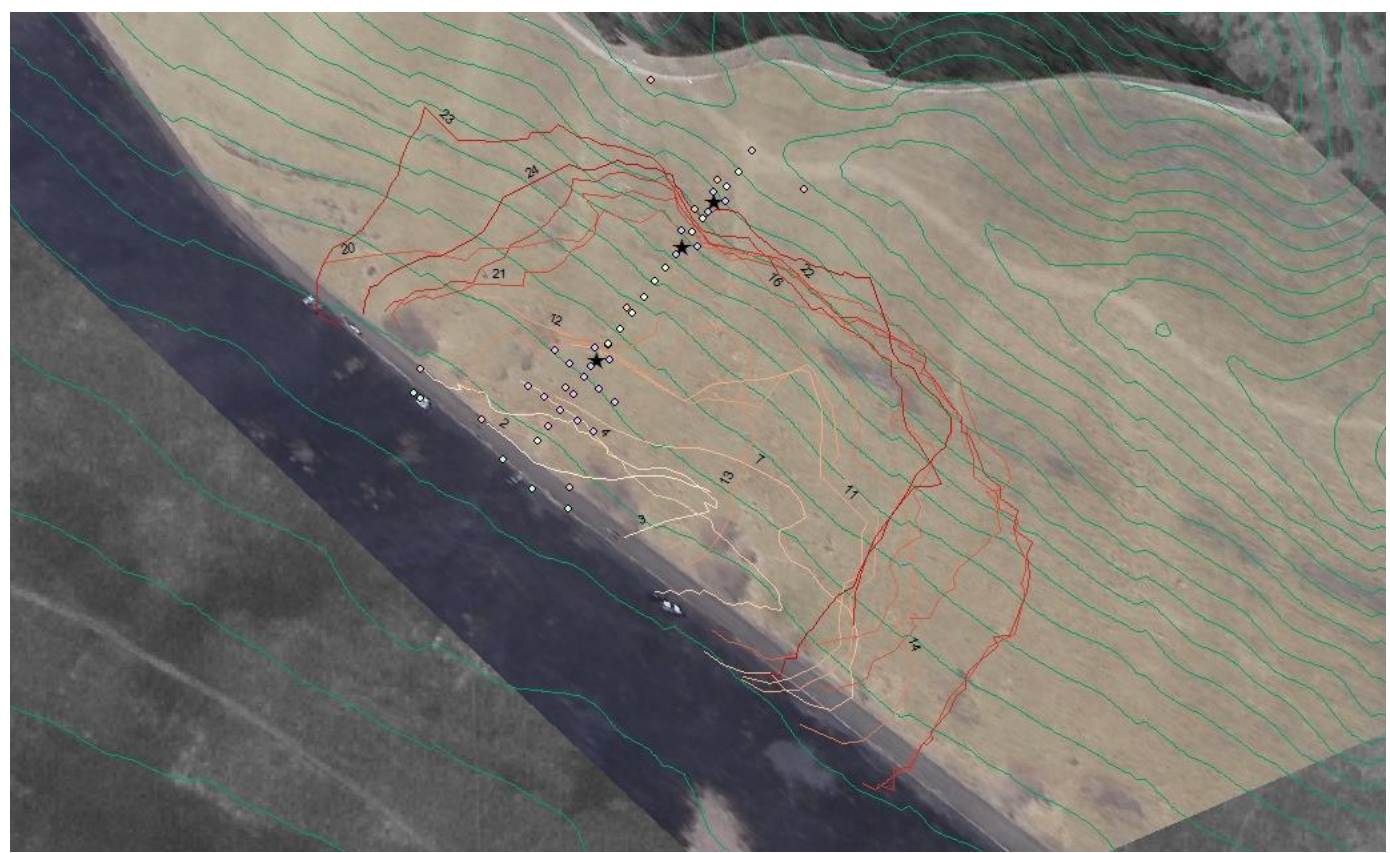

Fig. 33. A map of 1 minute interval fireline locations georeferenced from aerial photography. Figure produced by Dianne Hall and used with permission.

defined in the 14 minute contour. This was followed by a large gap between the contours indicating the increased spread of the fire.

A diagnosis of this event was made difficult because of sparse data points.

But two hypotheses were developed from the data available based on horizontal and vertical vorticity.

\subsection{Results}

\subsubsection{Horizontal Vorticity}

Between 11:30 and 11:40 PDT, sodar data indicated the development of a strong northeasterly wind. As this northeasterly wind aloft moved over the southerly wind within the valley, shear vorticity was generated over the fireline. A lidar $\mathrm{RHI}$ scan from this time (Fig. 34) shows the inbound northeasterly wind 


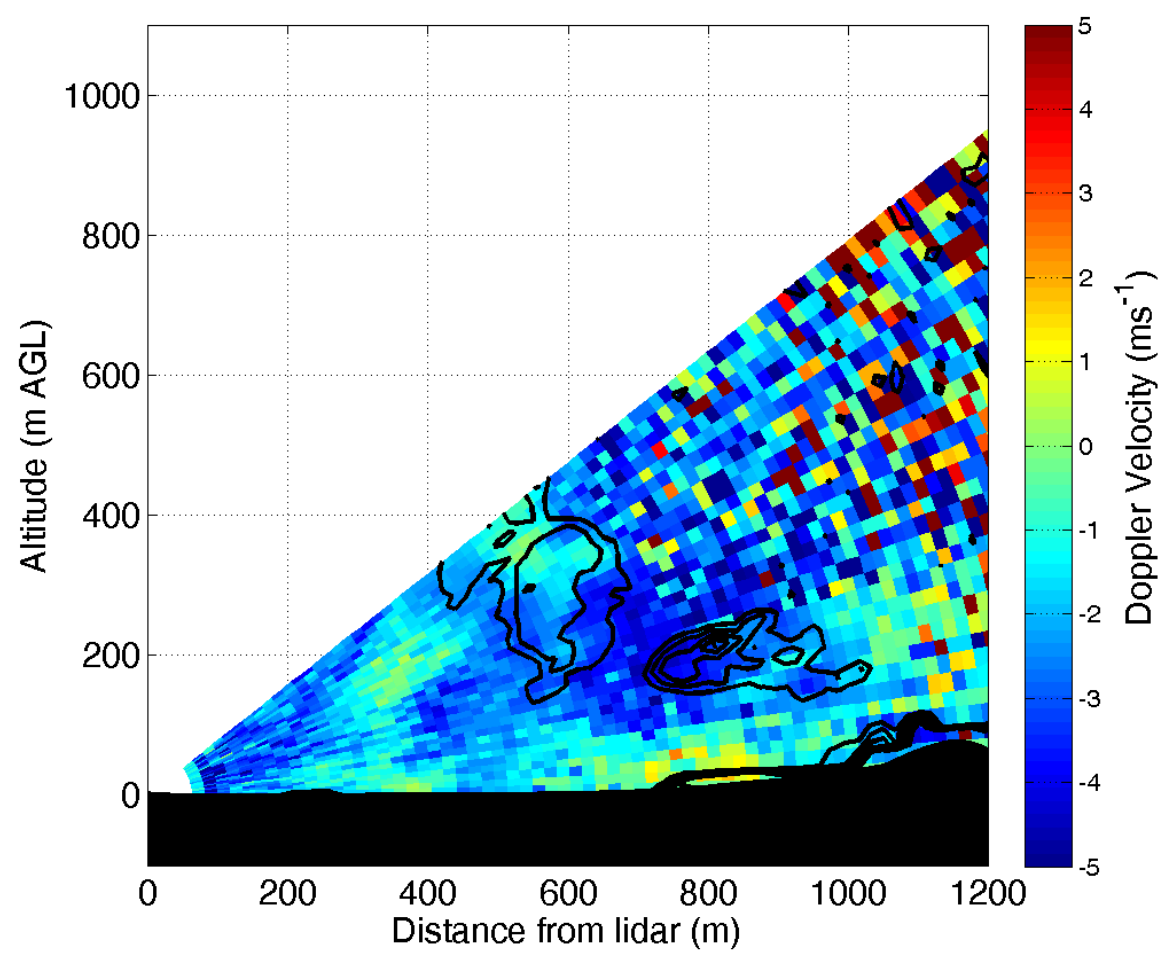

Fig. 34 Lidar $\mathrm{RHI}$ scan taken during the northeasterly wind. Outbound winds in warmer colors near the surface show the valley winds. The cooler colors aloft represent the northeasterly wind.

above the outbound southeasterly surface wind. This event corresponded well with the observed timing of the fire whirl and rapid intensification of the fire spread captured in Figs. 32a-d.

Fig. 35 shows a time series of the estimated horizontal vorticity from the bottom two towers during the time frame of the event. The maximum estimated horizontal vorticity of $-0.2 \mathrm{~s}^{-1}$ occurred at approximately $11: 31: 35$ PDT. The heated buoyant air tilted the vorticity vertically over the fireline and the rotation intensified as the whirl was stretched within the bend of the L-shaped fire front. 


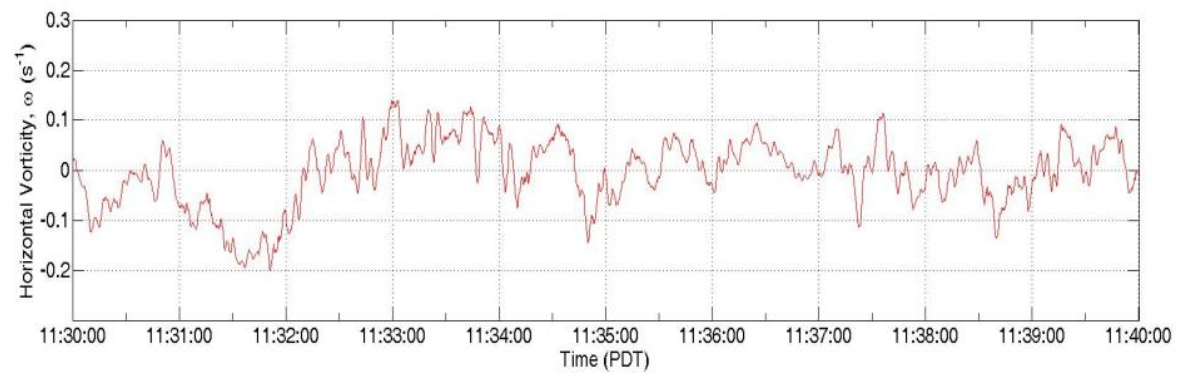

Fig. 35. Time series of estimated horizontal vorticity during the time of increased fire spread.

\subsubsection{Vertical Vorticity and Lidar Observed Dust Devils}

The second hypothesis is that vertical vorticity was responsible for the fire whirl. It is likely that a high level of ambient vertical vorticity was present on the hillside. This was generated in the shear between the southerly valley winds and northeasterly winds aloft. It can be suggested from the images, Figs. 32a-d, that the interaction between these two winds resulted in the L-shape of the fireline.

The lidar conducted PPI scans of the post-fire atmosphere within the valley. It can be seen (Fig. 36) that the southerly and northeasterly winds were both present over the slope of the hill. From this, a vertically oriented vorticity can be assumed between winds. But because these scans occurred after the experiment had been conducted, it was difficult to ascertain whether the same conditions were present during the experiment.

Although the experiment was over, lidar PPI scans continued to observe whirls shedding from near the ridge, propagating downhill, and crossing the valley. Figs. 37a-f displays the formation and propagation of one whirl in between the two opposing horizontal winds. The whirl lifted a large amount of ash into the 


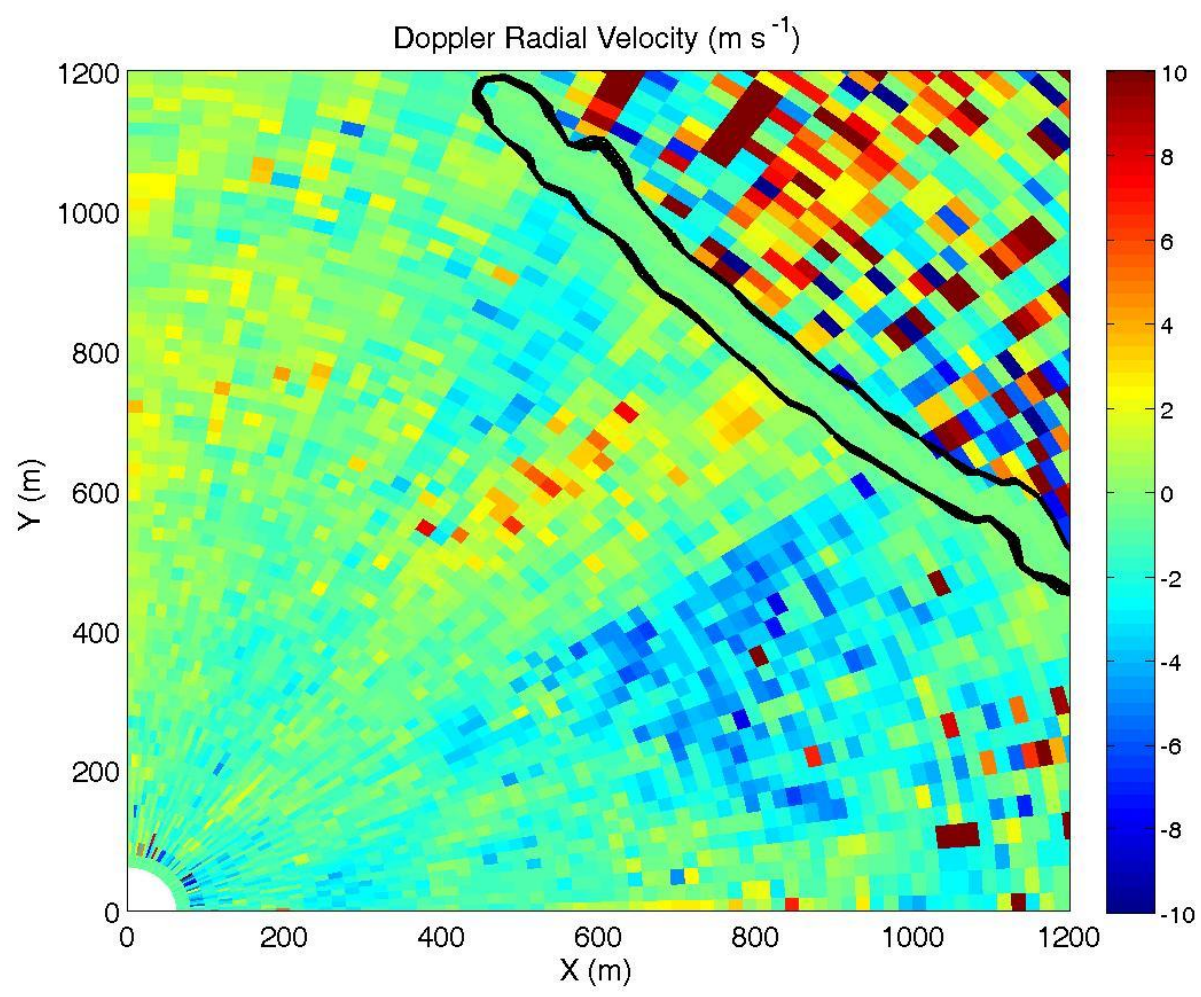

Fig. 36. A lidar PPI scan of alternating inbound and outbound winds over the valley. Cooler colors represent inbound winds; warmer colors are outbound winds. The laser collided with the hillside at $\sim 1 \mathrm{~km}$, resulting in the elevated backscatter and a high level of noise in the leeward section.

air, allowing elevated levels of backscatter to be measured in the vicinity of the whirl. Several photos were also captured of the whirls (Fig. 38).

\subsubsection{Discussion}

Some numerical modeling has been performed in the area of lee side fire spread on a slope. Simpson et al. (2013) used the WRF-Fire model to perform 2D and 3D simulations of lee side fire spread in varying atmospheric stabilities. It was found that strong positive vorticity is typically generated near the top of the leeward slope and extended roughly $1 \mathrm{~km}$ downwind of the ridge. Additionally, 
(a)

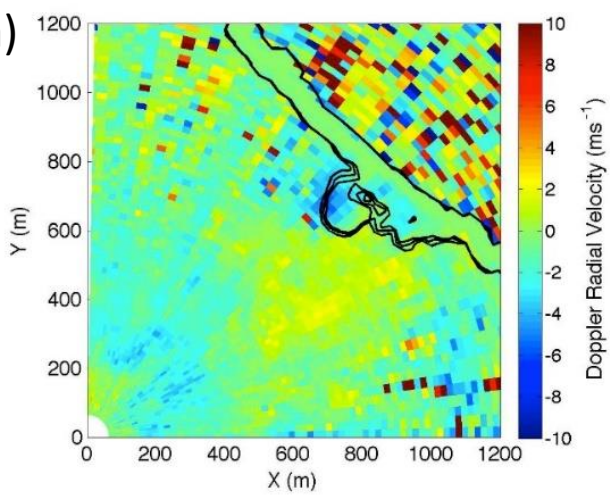

(c)

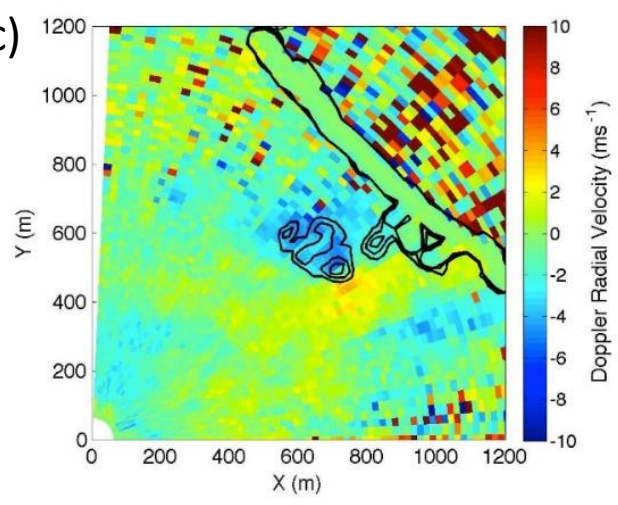

(e)

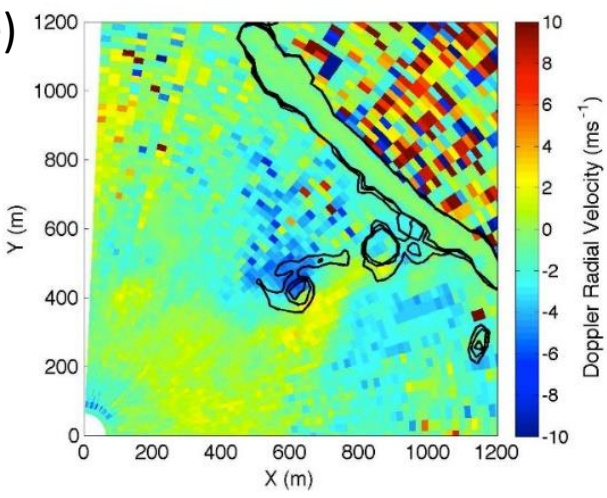

(b)

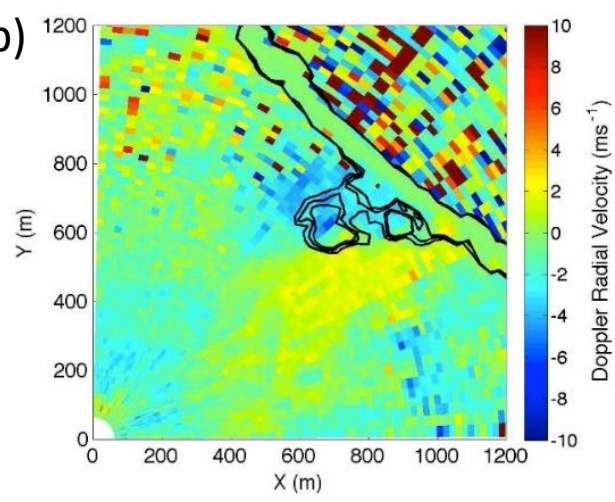

(d)

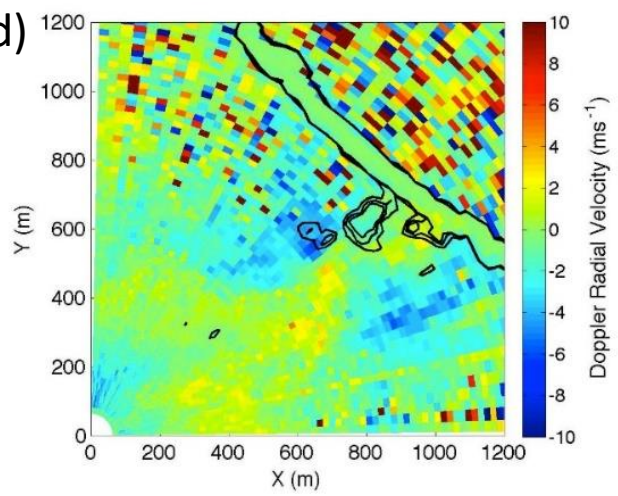

(f)

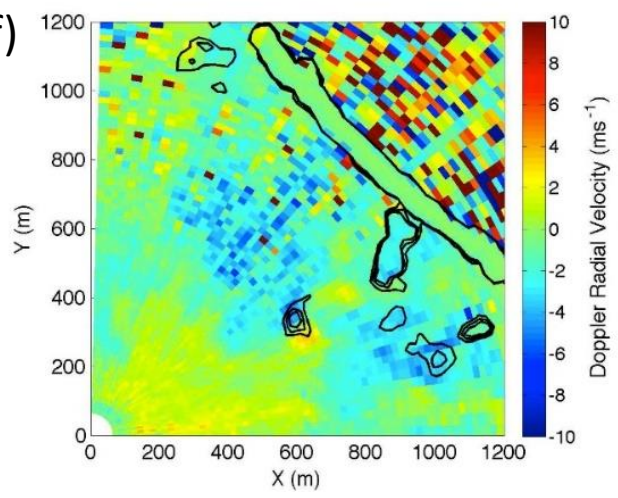

Fig. 37a-f. A series of lidar PPI scans depicting a velocity couplet forming near the ridge and propagating downslope and across the valley. Warmer colors represent outbound wind, cooler colors inbound. The laser collided with the hillside at $\sim 1 \mathrm{~km}$ and is shown by the linear high backscatter. Smoke was lifted into the air by the whirl resulting in elevated backscatter surrounding the velocity couplets. 


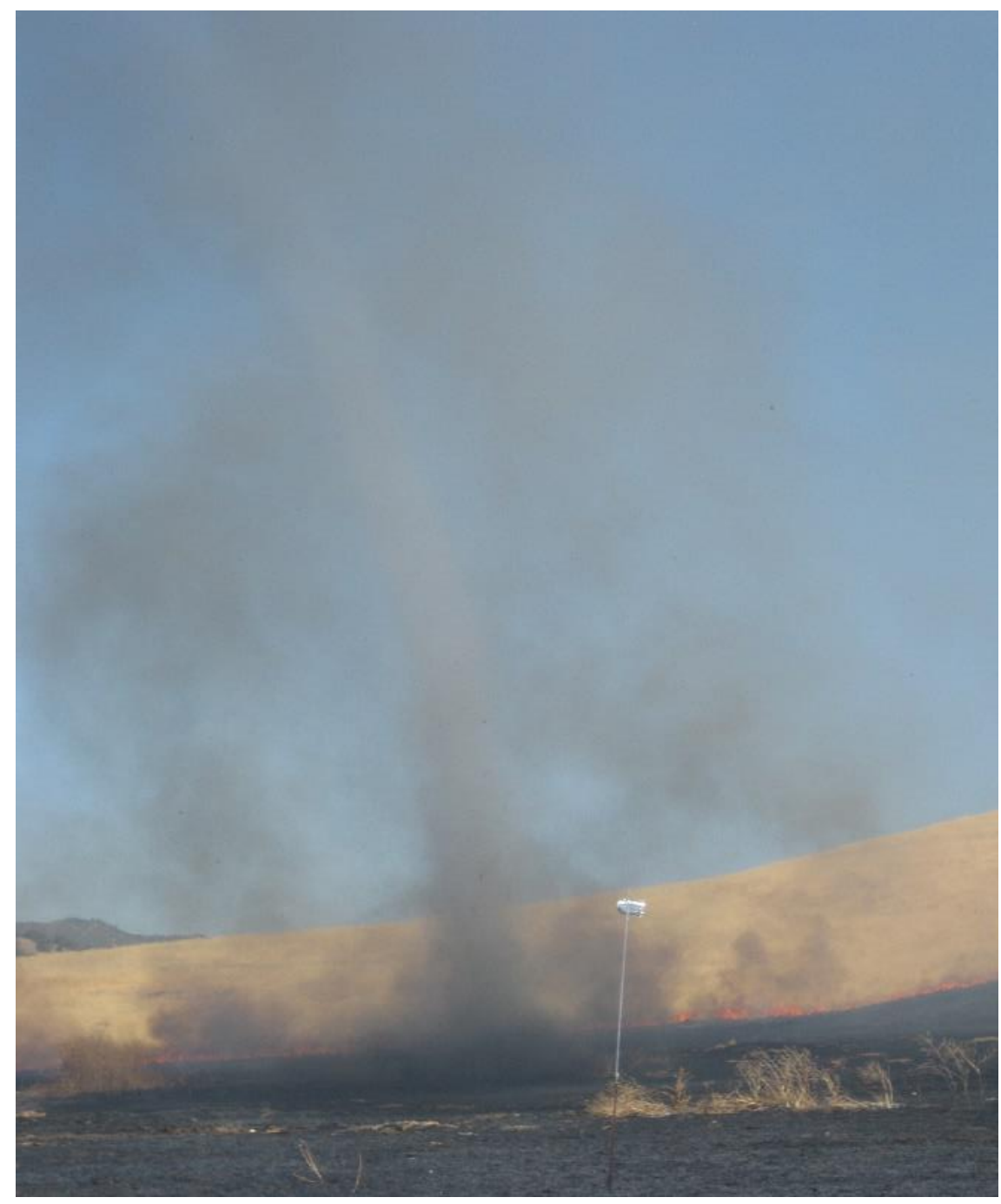

Fig. 38. A photo of a whirl lifting ash into the air in the wake of the fire.

it was shown that leeside winds were dominated by small-scale turbulence rather than a leeside rotor. A high degree of spatial variability was also found in the average horizontal winds for the 3D model runs, which agrees well with the Doppler lidar PPI scans. These model simulations fit well with the vertical vorticity hypothesis. The propagating vorticity, generated near the ridge between the 
southerly wind within the valley and the northeasterly wind above, was tilted vertically over the fire.

Simpson et al. went on to discuss the vertical velocity over the slope after the fire. He showed that areas of updraft and downdraft occurred on opposing sides of the fireline. This caused an area of counterclockwise rotating flow. This fits exceptionally well with the "L-shaped" fireline and what was observed. They also found that the updraft-downdraft interfaced led to a doubling of the lateral fire spread, which agrees exceptionally well with our observations.

In a separate paper, Simpson et al. (2014) explored vorticity driven lateral fire spread using the WRF-fire model. They identified three distinct stages of spread. First, fire spreads upslope towards the ridge. Second, the fire spreads laterally at a higher rate than the base spread. Third, lateral spread becomes intermittent and at a high rate near the ridge. Using a fire-atmosphere coupled WRF-FIRE model, Simpson et al. linked fire whirls occurring near the fireline to rapid lateral fire spread on a slope. The simulations were repeated with a non-coupled fireatmosphere. It was shown that fire whirls did not occur near the fireline and the fire spread very little laterally as a result. This indicated that vorticity generated fire whirls were the result of interactions between the fire, atmosphere, and terrain.

The observations from our experiment support the coupled models results. An elevated level of vorticity was observed during the development of the fire whirl within the L-shape bend in an asymmetrical fireline. This caused a rapid increase 
in the lateral fire spread on the slope as seen in the photos and map of fireline contours.

\subsection{Summary and Conclusion}

During an experiment in complex terrain, a unique event occurred in which a fire whirl caused a sudden and rapid increase in fire spread. Based on previous literature, it was postulated that the cause of this event was related to fireline geometry and either horizontal or vertical vorticity. The opposing southeasterly and northeasterly winds made determining the axis of the vorticity difficult. A strengthening northeasterly wind was observed by Doppler lidar just prior to the event causing strong horizontal vorticity to develop. The lidar also observed the two winds on a horizontal plane during a period after the fire. It was suggested that areas of vertical vorticity could be present above the burn area between the two winds. As a result, fire whirls were a common occurrence at this time.

\section{Chapter 6 - Summary and Conclusion}

An experiment was conducted on a hillside in which a prescribed head fire was ignited. The purpose was to collect data and observe the atmosphere surrounding a fire on a hillside under ideal conditions. The data set could then be used to compare numerical simulations.

An array of meteorological instrumentation was deployed within a valley in central California. Sensors measuring temperature, pressure, three-dimensional winds, and radiation were attached to three towers that spanned the burn plot. Among them were thermocouples, barometers, sonic anemometers, and 
radiometers. Remote sensing measurements were made using a Doppler lidar, a microwave profiler, and a Doppler sodar.

Data from the experiments were presented in three chapters. Among the data presented were pressure-temperature perturbations, micrometeorology, and vorticity observations. Negative covariances were observed between pressure and temperature. It was found that the magnitude of each covariance was determined by the intensity of the fire. The negative values were primarily caused by negative pressure tendencies resulting from surface convergence into the plume. The increased amplitude of the covariances was a result of the extreme temperature perturbations. Due to an underdeveloped fire front at the time of FFP, several of the covariances were substantially weaker. Further experimentation should be conducted on a more idealized fire to determine the utility of pressure-temperature covariances for fire behavior analysis.

Observations of TKE and sensible heat flux were made as the fire propagated upslope. Measurements at the bottom tower showed the highest values. This FFP occurred during a time period in which the fire was mostly a head fire. The FFP at the second tower showed a much lower value of TKE. Here the fire had become a backing fire. Downslope winds at this time resulted in a negative heat flux. At the top tower, the low intensity backing fire continued. The stronger northerly winds near the ridge top pushed the plume through the sonic anemometer several times, resulting in sporadic increases of TKE. 
The turbulence spectra during FFP at each tower were also compared. The most significant observation was the elevated values in the mid to high frequencies of vertical velocity at the bottom tower. This was the result of the elevated fire intensity during FFP at the bottom tower. The middle and top towers did not observe an increase in vertical velocity spectra. This was caused by a transition in fire behavior from a heading fire to a backing fire, resulting in much lower intensity during the two FFPs.

A case can be made for the presence of both horizontal and vertical vorticity presence on the slope during the experiment. It was determined from previous numerical modeling studies that horizontal vorticity was most likely the driver of the rapid lateral spread. $\mathrm{RHI}$ scans performed by the Doppler lidar revealed an area of strong shear where horizontal vorticity could occur. Estimates from the sonic anemometers showed increased horizontal vorticity during a fire whirl and subsequent rapid fire spread.

Vertical vorticity was supported by PPI scans from the lidar taken during the post experiment. Areas of outbound and inbound winds were observed on a horizontal plane over the slope. Additionally, rotational couplets were observed occurring between these areas of opposing winds. Dust devils were photographed occurring at these times and could be a catalyst for the fire whirl that occurred. 


\section{REFERENCES}

Albini, F. A., R. G. Baughman, 1979: Estimating windspeeds for predicting wildland fire behavior. USDA Forest Service Research Paper INT (USA), .

Andrews, P. L., 1986: BEHAVE: fire behavior prediction and fuel modeling system-BURN subsystem, Part 1.

Beals, E. A., 1914: value of weather forecasts in the problem of protecting forests from fire.

Bowman, D. M., J. K. Balch, P. Artaxo, W. J. Bond, J. M. Carlson, M. A. Cochrane, C. M. D'Antonio, R. S. Defries, J. C. Doyle, S. P. Harrison, F. H. Johnston, J. E. Keeley, M. A. Krawchuk, C. A. Kull, J. B. Marston, M. A. Moritz, I. C. Prentice, C. I. Roos, A. C. Scott, T. W. Swetnam, G. R. van der Werf, and S. J. Pyne, 2009: Fire in the Earth system. Science, 324, 481-484, doi:10.1126/science.1163886 [doi].

Clements, C. B., 2010: Thermodynamic structure of a grass fire plume. Int.J.Wildland Fire, 19, 895-902.

Clements, C. B., R. Perna, M. Jang, D. Lee, M. Patel, S. Street, S. Zhong, S. Goodrick, J. Li, and B. E. Potter, 2007: Observing the dynamics of wildland grass fires: FireFlux-a field validation experiment. Bull.Am.Meteorol.Soc., 88, 1369-1382.

Clements, C. B., S. Zhong, X. Bian, W. E. Heilman, and D. W. Byun, 2008: First observations of turbulence generated by grass fires. Journal of Geophysical Research: Atmospheres (1984-2012), 113.

Clements, C. B. and A. J. Oliphant, 2014: The California State University Mobile Atmospheric Profiling System: A Facility for Research and Education in Boundary Layer Meteorology. Bull. Amer. Meteor. Soc., 95, 1713-1724.

Cunningham, P., R. R. Linn, 2007: Numerical simulations of grass fires using a coupled atmosphere-fire model: Dynamics of fire spread. Journal of Geophysical Research: Atmospheres (1984-2012), 112.

Dennison, P. E., K. Charoensiri, D. A. Roberts, S. H. Peterson, and R. O. Green, 2006: Wildfire temperature and land cover modeling using hyperspectral data. Remote Sens.Environ., 100, 212-222. 
Filippi, J., X. Pialat, and C. B. Clements, 2013: Assessment of ForeFire/Meso-NH for wildland fire/atmosphere coupled simulation of the FireFlux experiment. Proceedings of the Combustion Institute, 34, 2633-2640.

Finney, M. A., 1998: FARSITE users guide and technical documentation. USDA Forest Service Research Paper RMRS-RP-4, .

Huang, C., Y. Lin, M. Kaplan, and J. Charney, 2009: Synoptic-scale and mesoscale environments conducive to forest fires during the October 2003 extreme fire event in southern California. Journal of Applied Meteorology and Climatology, 48, 553-579.

Kitzberger, T., P. M. Brown, E. K. Heyerdahl, T. W. Swetnam, and T. T. Veblen, 2007: Contingent Pacific-Atlantic Ocean influence on multicentury wildfire synchrony over western North America. Proc.Natl.Acad.Sci.U.S.A., 104, 543548, doi:0606078104 [pii].

Kochanski, A. K., M. A. Jenkins, J. Mandel, J. Beezley, and S. Krueger, 2013: Real time simulation of 2007 Santa Ana fires. For.Ecol.Manage., 294, 136149.

Linn, R. R., J. L. Winterkamp, D. R. Weise, and C. Edminster, 2010: A numerical study of slope and fuel structure effects on coupled wildfire behaviour. Int.J.Wildland Fire, 19, 179-201.

Linn, R., J. Winterkamp, C. Edminster, J. J. Colman, and W. S. Smith, 2007: Coupled influences of topography and wind on wildland fire behaviour. Int.J.Wildland Fire, 16, 183-195.

Mell, W. E., K. B. McGrattan, and H. R. Baum, 1996: Numerical simulation of combustion in fire plumes. Proc. Symposium (International) on Combustion, Elsevier, 1523-1530.

Rehm, R. G., H. R. Baum, 1978: The Equations of Motion for Thermally Driven, Buoyant Flows. Journal of Research of the National Bureau of Standards, 83, 297-308.

Rothermel, R. C., 1972: A mathematical model for predicting fire spread in wildland fuels.

Rothermel, R. C., 1983: How to predict the spread and intensity of forest and range fires. 
Šavli, M., 2012: Turbulence kinetic energy-TKE. Proc. University of Ljubljana, Faculty of Mathematics and Physics, Department of Meteorology. Seminar: 4th Class. May, .

Schroeder, M. J., M. Glovinsky, V. F. Henricks, F. C. Hood, and M. K. Hull, 1964: Synoptic weather types associated with critical fire weather, .

Simpson, C. C., J. J. Sharples, J. P. Evans, and M. F. McCabe, 2013: Large eddy simulation of atypical wildland fire spread on leeward slopes. Int.J.Wildland Fire, 22, 599-614.

Simpson, C. C., J.J. Sharples, and J.P. Evans, 2014: Resolving vorticity-driven lateral fire spread using the WRF-Fire coupled atmosphere-fire numerical model, Nat. Hazards Earth Syst. Sci., 14, 2359-2371.

Viegas, D. X., 2004: Slope and wind effects on fire propagation. Int.J.Wildland Fire, 13, 143-156.

Walker, J., B. Stocks, 1968: Thermocouple errors in forest fire research. Fire Technol., 4, 59-62.

Westerling, A. L., H. G. Hidalgo, D. R. Cayan, and T. W. Swetnam, 2006:

Warming and earlier spring increase western U.S. forest wildfire activity. Science, 313, 940-943, doi:1128834 [pii]. 